OAK RIDGE NATIONAL LABORATORY

MARTIN MARUETRA
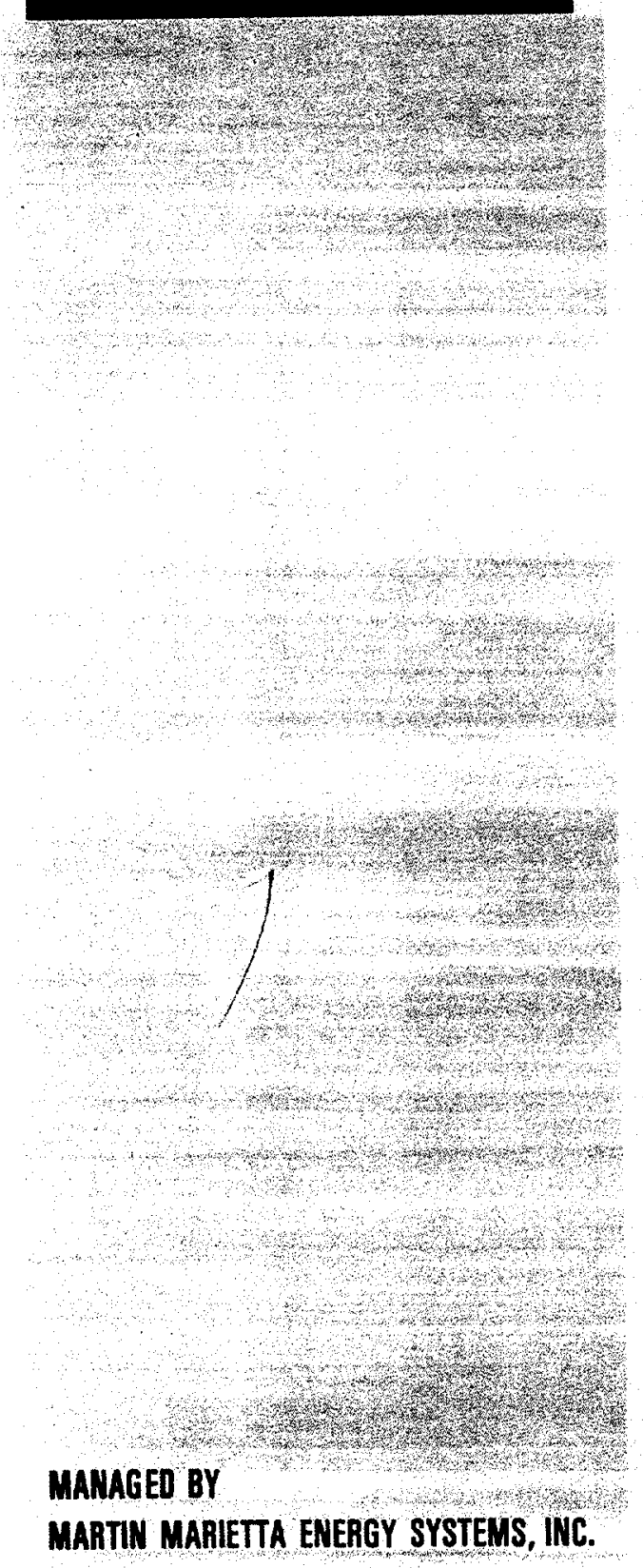

FOR THE UNITED STATES

DEPARTMENT OF ENERGY
THE INTEGRATION OF RENEWABLE ENERGY SOURCES INTO ELECTRIC POWER DISTRIBUTION SYSTEMS
H. W. Zaininger

P. R. Ellis

J. C. Schaefer

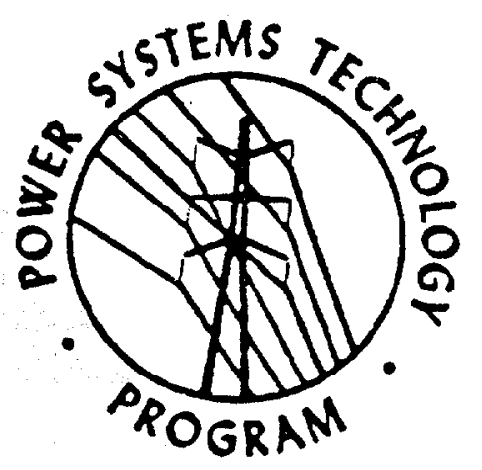




\title{
THE INTEGRATION OF RENEWABLE ENERGY SOURCES INTO ELECTRIC POWER DISTRIBUTION SYSTEMS
}

\author{
Volume II: UTILITY CASE ASSESSMENTS
}

\author{
H. W. Zaininger \\ P. R. Ellis \\ J. C. Schaefer \\ Zaininger Engineering Company
}

June 1994

Prepared by Zaininger Engineering Company, Inc.

1590 Oakland Road, Suite B211

San Jose, CA 95131

under

Subcontract 15X-SK724V

for the

Power Systems Technology Program

Energy Division

Oak Ridge National Laboratory

Oak Ridge, Tennessee 37831

managed by

Martin Marietta Energy Systems, Inc.

for the

U.S. Department of Energy

under Contract DE-AC05-84OR21400 
$=$ 
LIST OF FIGURES $\ldots \ldots \ldots \ldots \ldots \ldots \ldots \ldots \ldots \ldots \ldots \ldots \ldots$

LIST OF TABLES $\ldots \ldots \ldots \ldots \ldots \ldots \ldots \ldots \ldots \ldots \ldots \ldots \ldots \ldots$ ix

ACRONYMS AND ABBREVIATIONS $\ldots \ldots \ldots \ldots \ldots \ldots \ldots \ldots \ldots$

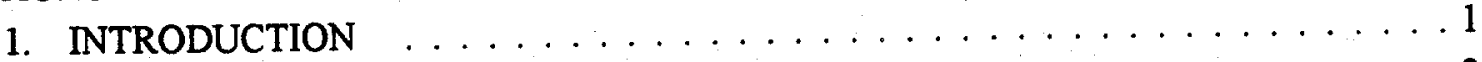

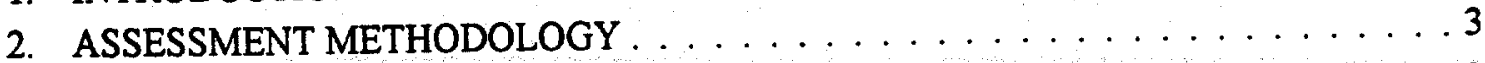

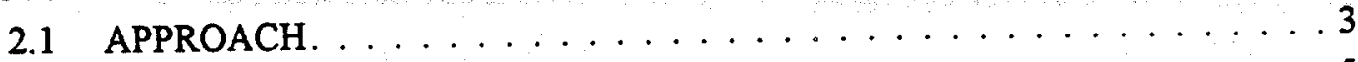

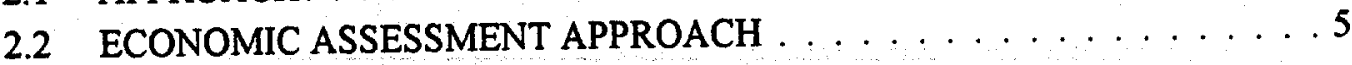

2.3 FUNCTIONAL ELECTRIC POWER DISTRIBUTION SYSTEM

2.5 DISTRIBUTION SYSTEM BENEFITS $\ldots \ldots \ldots \ldots \ldots \ldots \ldots \ldots$

2.5.1 Distribution Facility Deferral . . . . . . . . . . . . . . . . 10

2.5.2 Loss Reduction Benefits . . . . . . . . . . . . . . . 11

2.5.3 Distribution Voltage and Power Factor Correction Benefits . . . . . . 11

2.5.4 Potential Distribution System Harmonics Impacts . . . . . . . . . 12

2.5.5 Relaying, Switching, or Sectionalizing Impacts . . . . . . . . 12

2.5.6 Enhanced Distribution Reliability . . . . . . . . . . . . . 13

2.6 ENERGY DISPLACEMENT AND CAPACITY VALUE BENEFITS $\ldots \ldots 14$

2.6.1 Energy Displacement Benefits . . . . . . . . . . . . . . . . . 14

2.6 .2 Capacity Value Benefits . . . . . . . . . . . . 15

2.7 TRANSMISSION SYSTEM BENEFITS $\ldots \ldots \ldots \ldots \ldots \ldots \ldots$

2.7.1 Transmission Facility Deferral . . . . . . . . . . . . . . . . 15

2.7.2 Transmission Loss Reduction Benefits. . . . . . . . . . . . . . . 16

2.8 ENVIRONMENTAL AND OTHER APPLICABLE BENEFITS $\ldots \ldots \ldots 16$

2.8.1 Energy Policy Act and Clean Air Act Amendments . . . . . . . . . . 16

2.8.2 Externality Costs . . . . . . . . . . . . . . . . . 17

2.8.3 Other Potential PV and WT Benefits. . . . . . . . . . 17

3. RENEWABLE ENERGY SOURCE COST AND PERFORMANCE $\ldots \ldots \ldots \ldots 18$

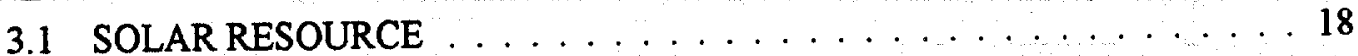

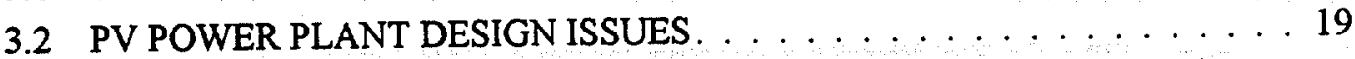

3.3 PV COST AND PERFORMANCE ASSUMPTIONS $\ldots \ldots \ldots \ldots 20$

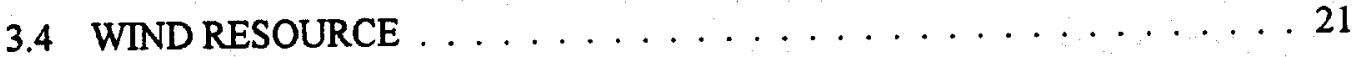

3.5 WT PLANT DESIGN ISSUES $\ldots \ldots \ldots \ldots \ldots \ldots \ldots \ldots \ldots \ldots \ldots$

3.6 WT COST AND PERFORMANCE ASSUMPTIONS . . . . . . . 22

3.7 BATTERY STORAGE COST AND PERFORMANCE

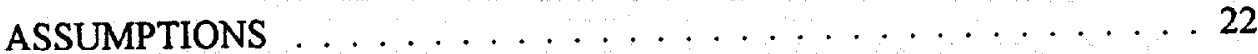

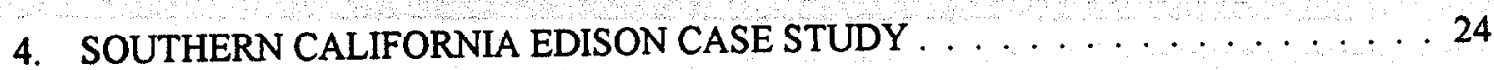


4.1 DISTRIBUTION SYSTEM DESCRIPTION AND DESIGN PRACTICES . . . 24

4.2 PV AND WT PERFORMANCE CHARACTERISTICS . . . . . . . . . . . . 25

4.3 ASSUMPTIONS AND BENEFITS QUANTIFIED . . . . . . . . . . . . 29

4.4 BENEFIT-COST RESULTS . . . . . . . . . . . . . . . . 32

4.4.1 Suburban Distribution System . . . . . . . . . . . . . 32

4.4 .2 Rural Distribution Systems . . . . . . . . . . . . . . . . . . 40 40

4.5 CASE STUDY CONCLUSIONS AND OBSERVATIONS . . . . . . . . . . 44

5. GREEN MOUNTAIN POWER. . . . . . . . . . . . . . . . . . 46

5.1 DISTRIBUTION SYSTEM DESCRIPTION AND DESIGN PRACTICES . . . 46

5.2 PV AND WT PERFORMANCE CHARACTERISTICS . . . . . . . . . . . . 48

5.3 ASSUMPTIONS AND BENEFITS QUANTIFIED . . . . . . . . . . . . 51

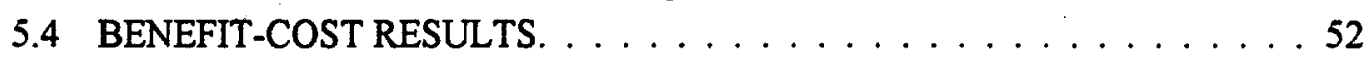

5.4 .1 Valley Distribution Systems . . . . . . . . . . . . . . 52

5.4 .2 Mountain Distribution Feeders . . . . . . . . . . . . . . 55

5.5 CASE STUDY CONCLUSIONS AND OBSERVATIONS . . . . . . . . 56

6. PUBLIC SERVICE COMPANY OF NEW MEXICO . . . . . . . . . . . . . . . . 58

6.1 DISTRIBUTION SYSTEM DESCRIPTION AND DESIGN PRACTICES . . . 58

6.2 PV PERFORMANCE CHARACTERISTICS. . . . . . . . . . . . . . . 59

6.3 ASSUMPTIONS AND BENEFITS QUANTIFIED . . . . . . . . . . . . . 62

6.4 BENEFIT-COST RESULTS. . . . . . . . . . . . . . . . . . 64

6.6 CASE STUDY CONCLUSIONS AND OBSERVATIONS . . . . . . . . . . 69

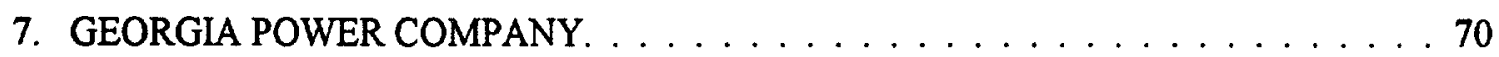

7.1 DISTRIBUTION SYSTEM DESCRIPTION AND DESIGN PRACTICES . . . 70

7.2 PV PERFORMANCE CHARACTERISTICS. . . . . . . . . . . . . 72

7.3 ASSUMPTIONS AND BENEFITS QUANTIFIED . . . . . . . . . . . . . 74

7.4 BENEFIT-COST RESULTS. . . . . . . . . . . . . . . 75

7.5 CASE STUDY CONCLUSIONS AND OBSERVATIONS . . . . . . . . 77

8. FLORIDA POWER AND LIGHT . . . . . . . . . . . . . . . . . . 79

8.1 DISTRIBUTION SYSTEM DESCRIPTION AND DESIGN PRACTICES . . . 79

8.2 PV PERFORMANCE CHARACTERISTICS . . . . . . . . . . . . . . 81

8.3 ASSUMPTIONS AND BENEFITS QUANTIFIED . . . . . . . . . . . . 83

8.4 BENEFIT-COST RESULTS . . . . . . . . . . . . . . . . . . . . . 84

8.5 CASE STUDY CONCLUSIONS AND OBSERVATIONS. . . . . . . . . 85

9. LENOIR CITY UTILITIES BOARD . . . . . . . . . . . . . . . . . 87

9.1 DISTRIBUTION SYSTEM DESCRIPTION AND DESIGN PRACTICES . . 87

9.2 PV PERFORMANCE CHARACTERISTICS . . . . . . . . . . . . . . . . . 87

9.3 ASSUMPTIONS AND BENEFITS QUANTIFIED . . . . . . . . . . . . 88

9.4 BENEFIT-COST RESULTS . . . . . . . . . . . . . . . . . . . . . 89

9.5 CASE STUDY CONCLUSIONS AND OBSERVATIONS . . . . . . . . . . 89

10. ORCAS POWER AND LIGHT COMPANY . . . . . . . . . . . . . . . . . . 91 
10.1 DISTRIBUTION CIRCUIT EXPANSION PLAN DESCRIPTION . . . . . . . 91

10.2 PV AND WT PERFORMANCE CHARACTERISTICS . . . . . . . . . . . . 91

10.3 ASSUMPTIONS AND BENEFITS QUANTIFIED . . . . . . . . . . . . . . . . . . . . . . . 93

10.4 BENEFIT-COST RESULTS. . . . . . . . . . . . . . . . . . . . . . . .

10.5 PRELIMINARY STUDY OBSERVATIONS. . . . . . . . 100

11. REFERENCES 101

APPENDIX A. COMPARISON WITH PG\&E AND APS BENEFITS . . . . . . . . . 103 



\section{LIST OF FIGURES}

Page

2.1. Overview of assessment methodology . . . . . . . . . . . . 4

2.2. Electric power systems schematic . . . . . . . . . . . . . . . 7

3.1. Representative $50-\mathrm{kW}$ WT power curve . . . . . . . . . . . 22

4.1. PV system monthly performance per kilowatt . . . . . . . . . . . 27

4.2. Fixed-oientation $\mathrm{PV}$ daily output per $\mathrm{kW} \ldots \ldots \ldots \ldots \ldots \ldots \ldots$

4.3. Two-axis tracking PV daily output per $\mathrm{kW} \ldots \ldots \ldots \ldots \ldots$

4.4. WT system monthly performance per $\mathrm{kW} \ldots \ldots \ldots \ldots$

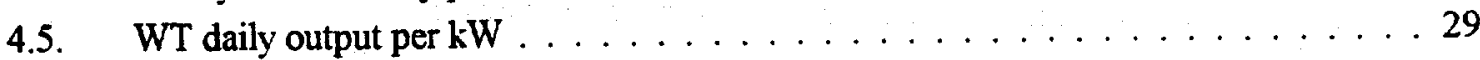

4.6. SCE 1990 summer and winter peak day loadshape . . . . . . . . . . . . . 31

4.7. Representative underground $120 / 40 \mathrm{~V}$ residential secondary system . . . . . . . . 33

4.8. Representative residential loadshape during summer peak day . . . . . . . . . 33

4.9. Representative suburban distribution primary system . . . . . . . . . . . 35

4.10. Example of commercial loads which correlate nicely with PV output . . . . . . . . 36

4.11. PV impact on summer peak for commercial loads . . . . . . . . . . . . 36

4.12. PV impact on summer peak for mixed commercial and residential loads . . . . . . . 37

4.13. PV impact on summer peak for residential loads . . . . . . . . . . . . . 37

4.14. Magnitude of summer peak reduction for various load shapes . . . . . . . . 38

4.15. Representative rural distribution system . . . . . . . . . . . . . . 41

4.16. Rural agricultural and water pumping load shape . . . . . . . . . . . . . 41

5.1. PV system monthly performance per $\mathrm{kW} \ldots \ldots \ldots \ldots$

5.2. Fixed-orientation $\mathrm{PV}$ daily output per $\mathrm{kW} \ldots \ldots \ldots \ldots . \ldots . \ldots . \ldots$

5.3. Two-axis tracking PV daily output per $\mathrm{kW} \ldots \ldots \ldots \ldots$

5.4. WT system monthly performance per $\mathrm{kW} \ldots \ldots \ldots \ldots$

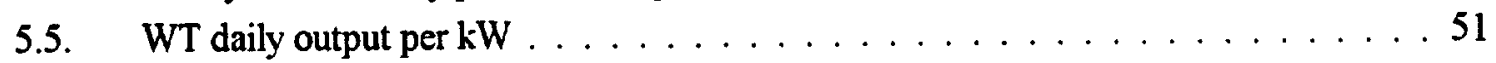

5.6. Representative valley feeder load shape for winter peak day . . . . . . . . . 53

5.7. Representative mountain feeder load shape . . . . . . . . . . . . . . 55

6.1. PV system monthly performance per $k W \ldots \ldots \ldots 1$

6.2. Fixed-orientation PV daily output per $k W \ldots \ldots \ldots \ldots \ldots$

6.3. Two-axis tracking PV daily output per $\mathrm{kW} \ldots \ldots \ldots \ldots$

6.4. PNM summer peak day load shape. . . . . . . . . . . . . . . . 64

6.5. Representative commercial load shapes . . . . . . . . . . . . . . 65

6.6. Representative mixed commercial and residential load shapes . . . . . . . . . 66

6.7. Representative residential load shapes . . . . . . . . . . . . . . 66

7.1. PV system monthly performance per $\mathrm{kW} \ldots \ldots \ldots \ldots \ldots$

7.2. Fixed-orientation PV daily output per $\mathrm{kW} \ldots \ldots \ldots \ldots \ldots$

7.3. Two-axis tracking PV daily output per $k W \ldots \ldots \ldots$ 
7.4. GPC summer daily load shapes . . . . . . . . . . . . . . 75

8.1. PV system monthly performance per $\mathrm{kW} \ldots \ldots \ldots 1 \ldots \ldots$

8.2. Fixed-orientation PV daily output per $\mathrm{kW} \ldots \ldots \ldots \ldots 2$

8.3. Two-Axis tracking PV daily output per $\mathrm{kW} \ldots \ldots \ldots \ldots 2$

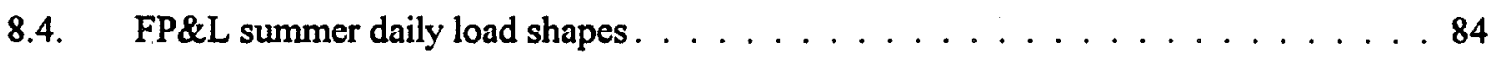

9.1. PV system monthly performance per $\mathrm{kW} \ldots \ldots \ldots$. . . . . . . . . 87

9.2. Representative winter fixed-orientation $\mathrm{PV}$ daily output per $\mathrm{kW} \ldots \ldots$. . . . . . 88

9.3. Representative LCUB winter peak day load shape with and without PV . . . . . . 89

10.1. PV system monthly performance per $\mathrm{kW} \ldots \ldots \ldots \ldots$. . . . . . . . . 91

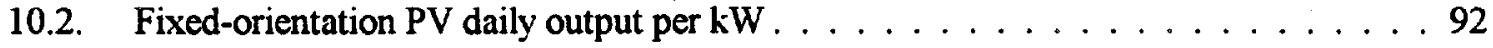

10.3. Orcas Power \& Light Company February peak daily loadshape . . . . . . . . . . . 92

10.4. Projected 1997/1998 winter peak load days for January, February and March . . . . 97

10.5. Use of a 1-MW, 3-hour battery plant to reduce February 1997-1998 peak load . . . 99

10.6. Use of a 1-MW, 3-hour battery plant to reduce August 1998 peak load . . . . . . . 99

A.1. Comparison of SCE, APS and PG\&E benefits . . . . . . . . . . . . . . . 105

A.2. Breakdown in values by benefit classification . . . . . . . . . . . 106 


\section{LIST OF TABLES}

Page

2.1. Typical MVA and $k V A$ ratings for distribution system facilities . . . . . . . 8

3.1. Comparison global radiation annual average daily radiation $\left(\mathrm{kwh} / \mathrm{m}^{2}\right) \ldots \ldots \ldots$

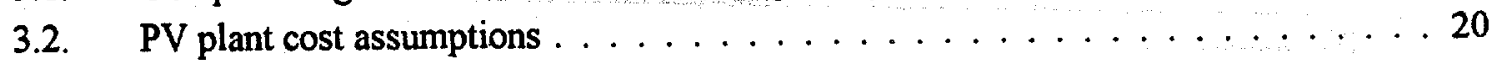

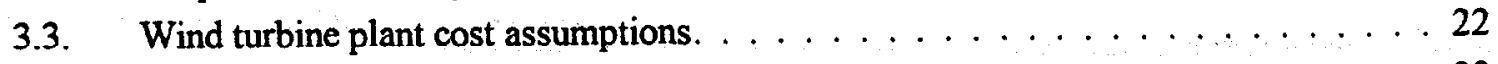

3.4. Battery storage cost and performance assumptions $\ldots \ldots \ldots \ldots \ldots \ldots \ldots$

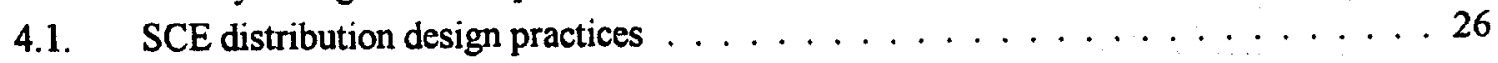

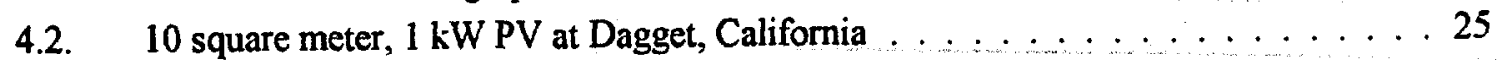

4.3. SCE financial assumptions . . . . . . . . . . . . . . . . . . . 29

4.4. Distribution facility cost assumptions . . . . . . . . . . . . . 30

4.5. Benefit and cost results-residential secondary system $24 \mathrm{~kW}$ fixed-orientation PV . . . . . . . . . . . . . . 34

4.6. Benefit and cost results-10\% PV penetration in heavily loaded SCE suburban distribution system, distributed fixed-orientation PV ........... 39

4.7. Benefit and cost results-10\% PV penetration heavily loaded suburban distribution system large two-axis tracking $\mathrm{PV} \ldots \ldots \ldots \ldots \ldots \ldots$. . . . . . . 40

4.8. Benefits and costs-MW PV at end of rural feeder, fixed orientation PV . . . . . . 42

4.9. Benefits and costs -2 MW PV at end of rural feeder two-axis tracking PV . . . . 44 43

4.10. Benefits and costs $-2 \mathrm{MW}$ windfarm at the end of nural feeder. . . . . . . . 43

5.1. GMP distribution design practices . . . . . . . . . . . . . . . 47

5.2. Ten square meter, 1-kW PV at Burlington, Vermont . . . . . . . . . . . 48

5.3. GMP financial assumptions . . . . . . . . . . . . . . 51

5.4. Benefit and cost results-valley system, $2 \mathrm{MW}$ of distributed fixed-orientation PV . . . . . . . . . . . . . . . . 54

5.5. Benefit and cost results-valley system, two 1 MW PV plants with two-axis tracking end of feeders . . . . . . . . . . . . . . 54

5.6. Benefit and cost results - mountain feeder, $1 \mathrm{MW}$ windfarm at end of feeder. . . . . 56

6.1. PNM distribution design practices . . . . . . . . . . . . 60

6.2. Ten square meter, $1-\mathrm{kW}$ PV at Albuquerque, N.M. . . . . . . . . . . . . . 59

6.3. PNM financial assumptions . . . . . . . . . . . . . . 62

6.4. Distribution facility cost assumptions . . . . . . . . . . . . 63

6.5. Benefit and cost results-commercial load shape, $3 \mathrm{MW}$ of distributed fixed-orientation PV . . . . . . . . . . . . . . 65

6.6. Benefit and cost results-mixed commercial and residential load shape, $3 \mathrm{MW}$ of distributed fixed-orientation PV . . . . . . . . . . . . . . 67

6.7. Benefit and cost results-residential loadshape $3 \mathrm{MW}$ of distributed fixed-orientation PV . . . . . . . . . . . . . . . 68

6.8. Benefit and cost results-commercial load shape, modular PV additions . . . . . . . 68

6.9. Benefit and cost results-commercial load shape, modular PV additions-slow $1 \%$ growth. . . . . . . . . . . . . . . . . . 69 
7.1. GPC distribution practices . . . . . . . . . . . . . 71

7.2. Ten square meter, $1 \mathrm{~kW}$ PV at Atlanta, Georgia. . . . . . . . . . . . . 72

7.3. GPC financial assumptions. . . . . . . . . . . . . . . 74

7.4. Benefit and cost results-suburban distribution system, $10 \%$ fixed-orientation PV penetration . . . . . . . . . . . . . . . 76

7.5. Benefit and cost results-rural feeder $1 \mathrm{MW}$ fixed-orientation PV plant . . . . . . 77

8.1. FP\&L distribution design practices $\ldots \ldots \ldots \ldots \ldots$

8.2. Ten square meter, $1 . \mathrm{kW}$ PV at Miami . . . . . . . . . . . . 81

8.3 Florida Power \& Light financial assumptions . . . . . . . . . . . . 83

8.4. Benefit and cost results-suburban distribution system, 5.2-MW distributed fixed-orientation PV . . . . . . . . . . . . . . 85

9.1. PV annual benefit cost summary-Lenoir City Utilities Board . . . . . . . . . . . . 89

10.1. OPALCO financial assumptions . . . . . . . . . . . . . . 93

10.2. Planned Lopez-Eastsound circuit upgrade costs . . . . . . . . . . . . . . . . . 94

10.3. OPALCO 1994-1995 demand and energy cost . . . . . . . . . . . . . . . 94

10.4. Projected annual peak load at Eastsound . . . . . . . . . . . . . . . . 95

10.5. Benefit and cost results-1-MW PV fixed-orientation. . . . . . . . . . . . . . 95

10.6. Benefit and cost results-1-MW windfarm . . . . . . . . . . . . . 96

10.7. Benefit and cost results-modular addition of 1-MW windfarm . . . . . . . . . 97

10.8. Benefit and cost results-1-MW windfarm plus transportable battery for

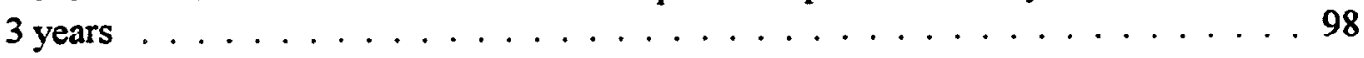




\section{ACRONYMS AND ABBREVIATIONS}

\begin{tabular}{|c|c|}
\hline AAC & all aluminum conductor \\
\hline ACSR & aluminum conductor steel reinforced \\
\hline APS & Arizona Public Service Company \\
\hline CAAA & Clean Air Act amendments of 1990 \\
\hline clp & cross-linked polyethylene \\
\hline CI & capital investment \\
\hline CRF & capital recovery factor \\
\hline $\mathrm{CO}_{2}$ & carbon dioxide \\
\hline DSM & demand-side management \\
\hline EPACT & Energy Policy Act of 1992 \\
\hline EPRI & Electric Power Research Institute \\
\hline FA & forced air \\
\hline FCR & levelized annual fixed charge rate \\
\hline FP\&L & Florida Power Company \\
\hline GMP & Green Mountain Power Company \\
\hline GPC & Georgia Power Company \\
\hline IEEE & Institute of Electrical and Electronics Engineers \\
\hline IRP & integrated resource planning \\
\hline LTC & load tap changer \\
\hline LCUB & Lenoir City Utilities Board \\
\hline NESC & National Electric Safety Code \\
\hline N.P. & nameplate \\
\hline NREL & National Renewable Encrgy Laboratory \\
\hline NSRDB & National Solar Radiation Data Base \\
\hline $0-\mathrm{h}$ & overhead \\
\hline O\&M & operation and maintenance \\
\hline OPALCO & Orcas Power \& Light \\
\hline ORNL & Oak Ridge National Laboratory \\
\hline P.F. & power factor \\
\hline PG\&E & Pacific Gas \& Electric \\
\hline PNM & Public Service Company of New Mexico \\
\hline & per unit; ie $80 \%=0.8$ per unit \\
\hline
\end{tabular}




$\begin{array}{ll}\text { PUC } & \text { Public Utility Commission } \\ \text { PV } & \text { photovoltaics } \\ \text { PVUSA } & \text { photovoltaics for utility scale applications } \\ \text { PWF } & \text { present worth factor } \\ \text { PWRR } & \text { present worth of revenue requirements } \\ \text { RW } & \text { right-of-way } \\ \text { SCC } & \text { short circuit current } \\ \text { SCE } & \text { Southern California Edison } \\ \text { SMUD } & \text { Sacramento Municipal Utility District } \\ \text { SO } & \text { Sulphur dioxide } \\ \text { T\&D } & \text { transmission and distribution } \\ \text { TMY } & \text { typical meteorological year } \\ \text { TVA } & \text { Tennessee Valley Authority } \\ \text { u-g } & \text { underground } \\ \text { WT } & \text { wind turbines } \\ \text { ZECO } & \text { Zaininger Engineering Company, Inc. }\end{array}$




\section{INTRODUCTION}

Electric utility distribution system impacts associated with the integration of renewable energy sources such as photovoltaics (PV) and wind turbines (WT) are considered in this project. The impacts are expected to vary from site to site according to the following characteristics:

- the local solar insolation and/or wind characteristics,

- renewable energy source penetration level,

- whether battery or other energy storage systems are applied, and

- local utility distribution design standards and planning practices.

Small, distributed renewable energy sources are connected to the utility distribution system like other, similar kW- and MW-scale equipment and loads. Residential applications are expected to be connected to single-phase $120 / 240-\mathrm{V}$ secondaries. Larger $\mathrm{kW}$-scale applications may be connected to three-phase secondaries, and larger hundred-kW and MW-scale applications, such as MW-scale windfarms or PV plants, may be connected to electric utility primary systems via customer-owned primary and secondary collection systems. In any case, the installation of small, distributed renewable energy sources is expected to have a significant impact on local utility distribution primary and secondary system economics.

Small, distributed renewable energy sources installed on utility distribution systems will also produce nonsite-specific utility generation system benefits such as energy and capacity displacement benefits, in addition to the local site-specific distribution system benefits. Although generation system benefits are not site-specific, they are utility-specific, and they vary significantly among utilities in different regions. In addition, transmission system benefits, environmental benefits and other benefits may apply. These benefits also vary significantly among utilities and regions.

Seven utility case studies considering PV, WT, and battery storage were conducted to identify a range of potential renewable energy source distribution system applications. The following utility-and site-specific conditions that may affect the economic viability of distributed renewable energy sources were considered:

- distribution system characteristics, and design standards, and voltage levels; load density, reliability, and power quality;

- solar insolation and wind resource levels;

- utility generation characteristics and load profiles;

- investor-owned and publicly owned utilities, size, and financial assumptions. 
Case studies were performed for seven utility systems:

UTHITY

Southern California Edison

Public Service Company of New Mexico

Green Mountain Power Company

Georgia Power Company

Florida Power \& Light Company

Lenoir City Utilities Board

Orcas Power \& Light Company
STATE

California

New Mexico

Vermont

Georgia

Florida

Tennessee

Washington

\section{RENEWABLES STUDIED}

PV \& WT

PV

PV \& WT

PV

PV

PV

PV \& WT

Section 2 describes the assessment methodology used to perform the utility case studies and discusses potential economic benefits and costs associated with applying renewable energy sources and storage to electric utility distribution systems. Section 3 presents PV and WT cost and performance assumptions. Sections 4 through 10 present the results of the case studies for each of the seven utility systems. 


\section{ASSESSMENT METHODOLOGY}

\subsection{APPROACH}

One major objective of this project was to develop an assessment methodology and produce results that are credible and acceptable to electric utility distribution engineers and system planners. Thus, the methodology was developed to assess renewable energy sources from a utility perspective and is compatible with the technical and economic assessment techniques employed by utility engineers and planners.

Figure 2.1 presents an overview of the methodology developed to assess the technical and economic feasibility of integrating renewable energy sources and storage facilities into electric power distribution systems. The methodology utilizes a spreadsheet program written in EXCEL 4.0 which will perform appropriate technical distribution system modeling, and provide an economic benefit-cost analysis. It uses a bottom-up approach and provides flexibility for considering renewable resourses at different levels of aggregation on a utility system. The resulting site-specific and nonsite-specific utility benefits are then combined and compared with the cost of the renewable energy generation and storage system.

First, the best available data were collected from each utility during a site visit. Appropriate distribution design standards and associated line and transformer per-unit material and labor cost estimates were obtained, along with representative circuit layouts. The members of the project team familiarized themselves with each utility's distribution planning and design philosophy, reliability and power quality criteria. Energy and capacity costs, and economic assessment procedures and assumptions also were obtained. Transmission costs and applicable environmental externalities were obtained from the utility when available. Scenarios for suitable rural, suburban, and urban distribution systems were then defined using appropriate utility distribution planning and design considerations.

A planning study was then performed on the rural, suburban, and urban distribution primary and secondary system scenarios for each utility. The studies assumed installation within a typical 5-year distribution planning horizon; the study period was 30 years. First, a base-case distribution system expansion without solar and wind was performed using the cost and distribution planning and design information collected from each utility. Then a similar expansion of the distribution system scenarios was performed, integrating solar and wind applications for an appropriate range of penetration.

The spreadsheet program is used to calculate real and reactive power flows, voltage regulation, and power factor correction requirements during appropriate on- and off-peak conditions. The calculations are conducted with and without various penetration levels of solar and wind, incorporating individual utility distribution design standards, philosophies, and assumptions. Hourly renewable resource performance is modeled, and distribution losses are then calculated for weekdays and weekend days monthly, and accumulated to determine annual energy savings and distribution loss reduction values. The resulting site-specific distribution system benefits are then combined with other utility benefits including energy displacement value, generation capacity value, bulk transmission capacity and loss benefits, and various environmental and other applicable benefits.

Annual solar, wind, and storage costs are calculated for the schedule of solar and wind additions using economic assumptions compatible with those used to calculate the utility benefits. These costs include fixed charges on renewable energy source capital investment, annual operation and maintenance costs, and, where applicable, any annual utility fuel cost increase associated with charging and discharging storage. 


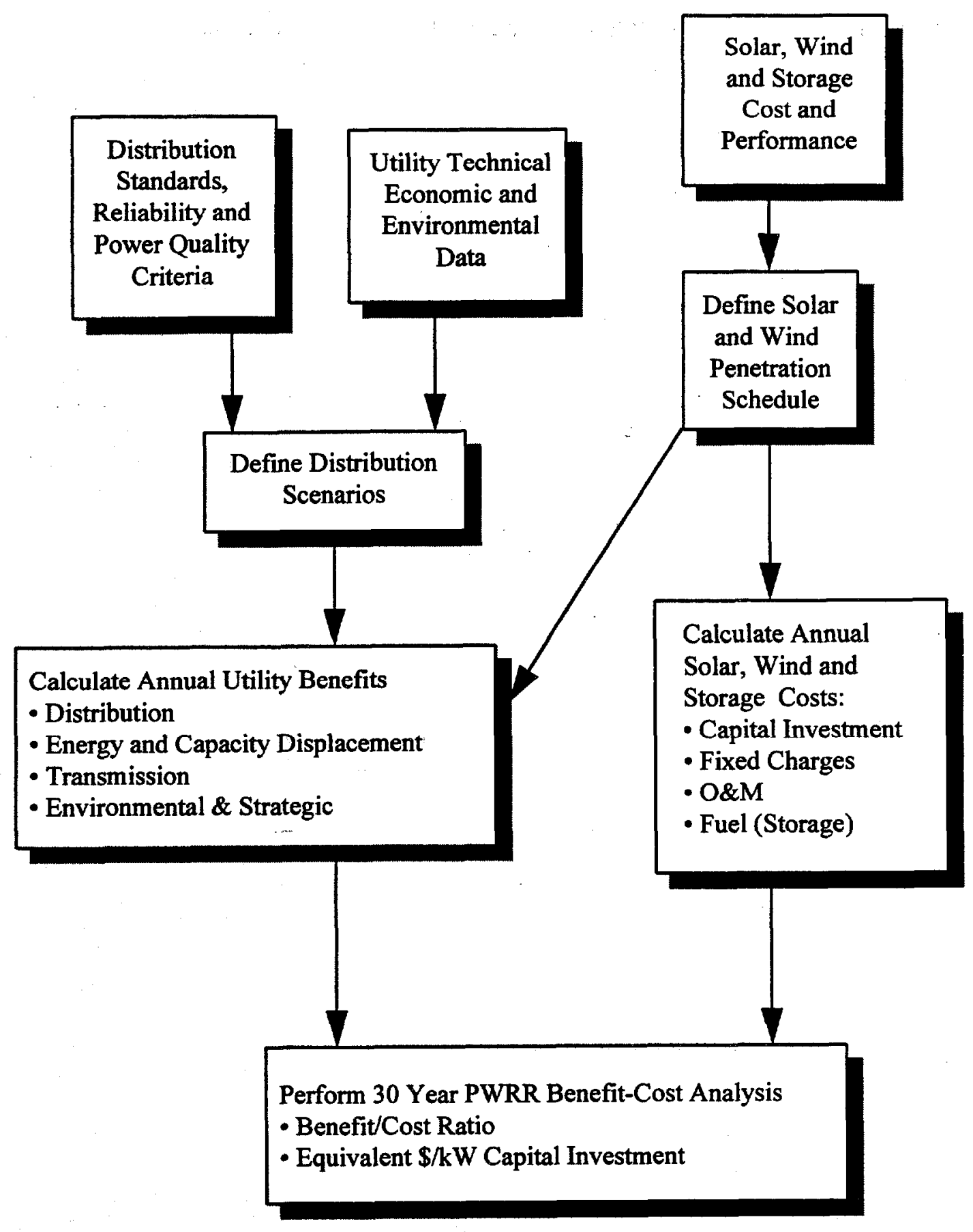

Fig. 2.1. Overview of assessment methodology.

The spreadsheet benefit/cost model employs a 30-year present worth of revenue requirement (PWRR) engineering economic analysis, and converts the resultant combined PWRR benefits to equivalent $\$ / \mathrm{kW}$ renewable resource capital investment credits, using the specified utility financial parameters. 


\subsection{ECONOMIC ASSESSMENT APPROACH}

The primary economic assessment approach used in this project consists of performing a benefit-cost assessment using PWRR engineering economic analysis, providing for suitable economic and financial parameters corresponding to different investor-owned and public utility perspectives and assumptions. ${ }^{1-3}$

The purpose of PWRR analysis is to compare alternative expansion plans. This is an economic rather than a financial assessment. It assumes that the required capital for the alternative expansion plans can be borrowed without financial constraints. Existing capital investments installed before the study period are assumed to be sunk costs, and associated revenue requirements are not included in a PWRR economic analysis.

The benefit-cost calculations for six of the seven utilities were performed using this PWRR economic approach. The calculations for the seventh, Lenoir City Utilities Board, used simplified payback economic methodology, which was compatible with the utility's economic assessment approach. The PWRR approach, which is compatible with the system planning techniques generally employed by both private and public utilities worldwide, consists of calculating the relative annual revenue required to support the alternative utility system expansion plans with and without renewable energy resources throughout the study period. Levelized annual fixed charges (or annual carrying charges) are calculated for the new generation, transmission, and distribution system capital investments. These fixed charges are added to the system operating costs to determine the annual revenue required. The total annual revenues are then discounted to the first year of the study period. All of the individual PWRR benefits and costs are then converted to equivalent $\$ / \mathrm{kW}$ capital investment $(\mathrm{CI})$ values using the PWRR-capital investment relationships in Eqs. (1) and (2) for utility capital investment. Converting the PWRR results to equivalent $\$ / k W$ values provides a clear measure of the relative magnitude of the various benefits compared with the renewable energy source capital investment.

In this study, all generation capital investments (total installed costs), including solar and wind renewable energy source are presented in $\$ / \mathrm{kW}$ because that is the normal way to present utility generation installed costs.

$$
P W R R_{C I}=C I \times F C R \times P W F ;
$$

$$
C I(\$)=\$ / k W_{C I} \times k W_{C I}
$$

where

$$
\begin{aligned}
& \text { PWRR = present worth of revenue requirements, } \\
& \text { CI = capital investment, } \\
& \text { FCR = levelized annual fixed charge rate, } \\
& \text { PWF = present worth factor. }
\end{aligned}
$$

The PWRR economic approach can be used for both current and constant dollar economic evaluations when appropriate discount rates, fixed charge rates, and escalation rates are employed. In this study, all of the utilities supplied current dollar financial data. However, the financial parameters varied among utilities. 
Some utilities convert PWRR to levelized annual revenue requirements. This transformation is performed by multiplying PWRR by the capital recovery factor (CRF). The equations for present worth factor (PWF) and CRF [Eqs. (3) and (4)] are reciprocal. PWF converts a levelized annual value to its equivalent present worth, while CRF converts a present worth value to a levelized annual value.

$$
\begin{aligned}
& P W F=\frac{(1+i)^{n}-1}{\left(i(1+i)^{n}\right.} ; \\
& C R F=\frac{i(1+i)^{n}}{(1+i)^{n}-1},
\end{aligned}
$$

where

$$
\begin{aligned}
& \mathbf{i}=\text { study discount rate } \\
& \mathrm{n}=\text { number of years. }
\end{aligned}
$$

\subsection{FUNCTIONAL ELECTRIC POWER DISTRIBUTION SYSTEM DESCRIPTION}

This section presents a functional description of electric power distribution system characteristics. The purpose is to define distribution system facilities to (1) put distribution system issues in perspective and (2) provide a basis to compare solar and wind generation application scenarios with typical electric utility distribution system characteristics.

An electric power system, illustrated schematically in Fig. 2.2, consists of three general subsystems:

- generating plants to produce electric power,

- a transmission system to deliver the power to the major load centers, and

- numerous distribution systems to distribute the power locally within each load center.

The distribution substation is the link between the transmission (or subtransmission) system and the local distribution system. The purpose of a distribution substation is to step the line voltage down from transmission system voltages $(69$ to $765 \mathrm{kV})$ to 4 to $34.5 \mathrm{kV}$ for distribution of the electric power to loads within a load center, and to provide switching and control for the transmission, subtransmission, and distribution lines connected to the substation. High-side control, circuit breakers, and switching equipment are similar to the equipment at generating and transmission substations. On the low side, distribution class sectionalizing and relaying equipment, and voltage regulation facilities are generally installed.

An electric distribution system consists of both primary and secondary systems. The (utility owned) primary system consists of circuits that may be radial, loop, or parallel feed and that typically range from 2 to more than 10 miles in length. The primary lines are composed of threephase feeders, and three-phase (3Ø) and single-phase (1Ø) (and two-phase) laterals tapped off the feeders. Generally, feeders and laterals provide three-phase service to large industrial and commercial loads of approximately $100 \mathrm{~kW}$ or more. Customer-owned secondary systems are employed. Smaller commercial and residential loads are served at the secondary system level. The 
primary lines ( 4 to $34.5 \mathrm{kV}$ ) are protected by sectionalizing equipment installed at the distribution substation and out on the lines.

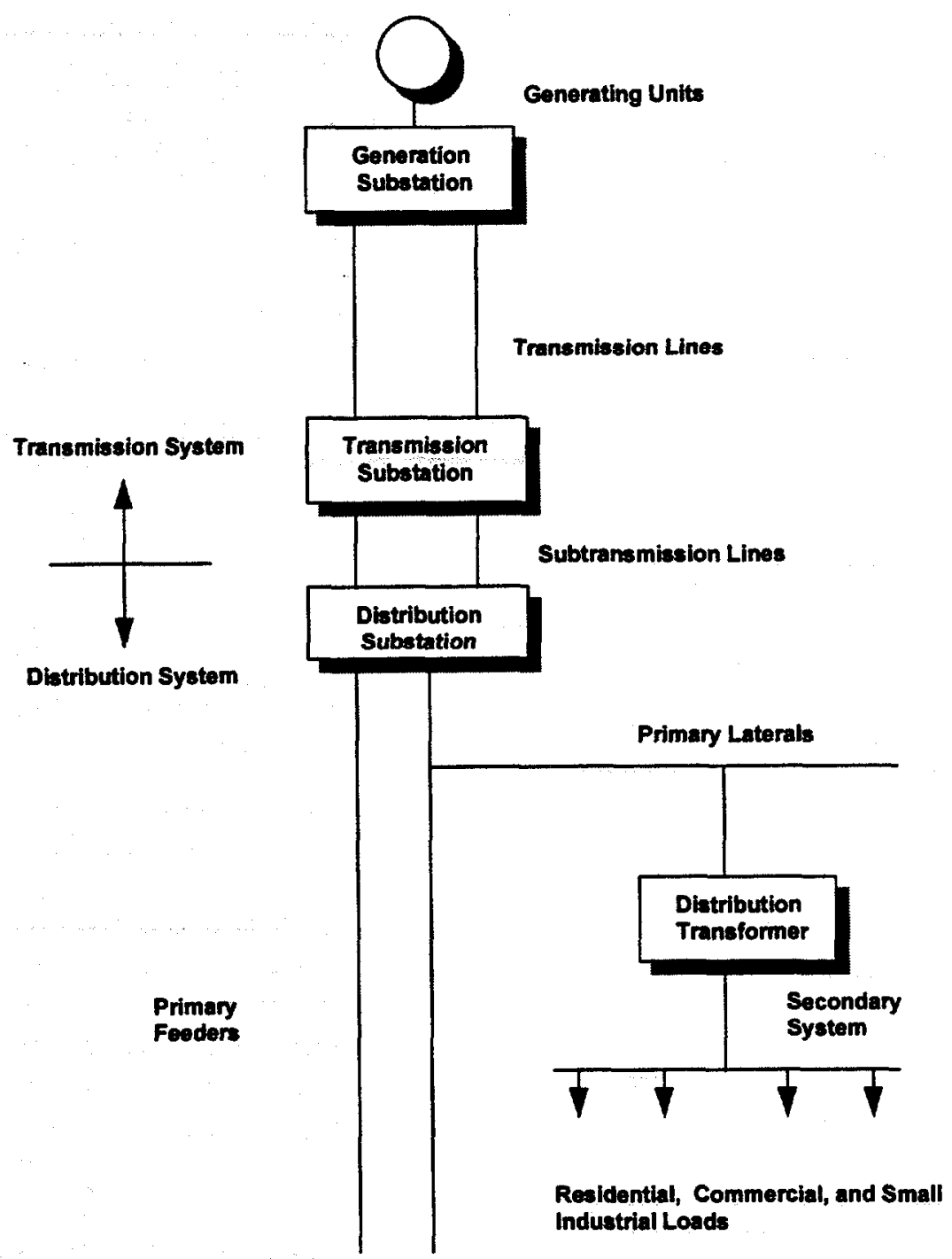

Fig. 2.2. Electric power system schematic.

Distribution transformers convert the voltage from the primary level ( 4 to $34.5 \mathrm{kV}$ ) to the secondary level (less than $600 \mathrm{~V}$ ) for serving residential or small commercial loads. For residential use, the voltage is typically converted to single-phase three-wire $120 / 240 \mathrm{~V}$ using one single-phase transformer connected to a primary system lateral. Areas containing commercial and industrial loads may be served using three-phase four-wire $120 / 208 \mathrm{~V}, 240 / 416 \mathrm{~V}$, or $277 / 480 \mathrm{~V}$ service; or three-phase $240 \mathrm{~V}$ or $480 \mathrm{~V}$ service. In major metropolitan areas, three-phase secondary networks such as four-wire $120 / 208 \mathrm{~V}$ may be used. 
A (utility-owned) secondary system (less than $600 \mathrm{~V}$ ) serves the individual residential and/or small commercial loads. In rural areas or residential areas with large (several-acre) lot sizes, the secondary may consist of one 120/240 V service drop served by a single-phase distribution transformer. In suburban residential areas, the secondary system may consist of several houses (service drops) served from a single-phase secondary feeder. A metropolitan three-phase secondary network may serve numerous loads. The length of individual distribution secondary systems is typically measured in tens or hundreds of feet rather than miles. Typically, single-phase distribution secondary system peak loads range from 3 to $100 \mathrm{~kW}$, and three-phase distribution secondary system peak loads range from 50 to $2500 \mathrm{~kW}$.

Typical MVA and kVA ratings for various distribution system facilities are summarized in Table 2.1.

Table 2.1. Typical MVA and kVA ratings for distribution system facilities

\begin{tabular}{lc}
\hline Item & Rating \\
\hline Distribution substation & 10 MVA-200 MVA \\
Primary feeders and laterals & 1 MVA-10 MVA \\
$3 \emptyset$ distribution transformer and secondary systems & $50 \mathrm{kVA}-3000 \mathrm{kVA}$ \\
$1 \varnothing$ distribution transformer and secondary system & $5 \mathrm{kVA}-100 \mathrm{kVA}$ \\
\hline
\end{tabular}

\subsection{DISTRIBUTION PLANNING AND DESIGN PHILOSOPHY}

The assessment methodology developed in this project is compatible with the technical and economic assessment techniques employed by utility distribution engineers. Applying this methodology correctly requires understanding and consideration of two separate but interrelated processes - distribution system planning and design. Distribution system planning involves establishing standards, policies, and procedures for the future distribution system. Distribution design involves the detailed preparation of technically and economically feasible alternatives by which a future distribution system plan can be achieved. A distribution system design may consist of applying general distribution standards or guidelines used by a utility, or it may be specific. The two processes are interrelated because system planning requires establishing goals, policies, and procedures based on an understanding of the available practical designs. On the other hand, after a specific distribution system plan has been established, the distribution system design standards undergo continuing change based upon the emergence or development of new equipment or advances in technology, such as the solar, wind, and storage technologies considered in this project.

In general, the objective of distribution system planning and design is to develop a distribution system that will provide economical, reliable, and safe electric service to the utility customer. This process of planning and design is typically approached by formulating alternatives for reinforcing and expanding the distribution system and by evaluating these alternatives for economy, reliability, and safety. Economy is achieved by selecting the least costly design alternative meeting appropriate power quality, reliability and safety criteria. Those criteria are generally achieved through distribution system design standards and operating procedures derived from utility operating philosophy and experience. 
Distribution planning and design is as much an art as a science. The methods and philosophies vary for the seven utilities in this study as they do for other utilities throughout the United States. A number of factors influence the different utility distribution design standards. First, the utilities face a range of different design situations:

- State and local regulations differ. For example, California utilities must design according to CA PUC General Order 128 for underground design and CA PUC General Order 95 for overhead line design, while utilities in other states generally design in accordance with the National Electric Safety Code..$^{4-6}$

- Ambient design conditions differ significantly throughout the United States.

- Basic distribution system designs differ. For example, different standard voltages, transformer sizes, and ratings are commonly used by different utilities.

- Different load and population densities affect distribution designs. For example, for one utility, residential distribution design standards may anticipate houses on 1- to 10-acre lots; more metropolitan utility residential distribution design standards may provide for quarteracre or smaller lots.

Second, the distribution design philosophy varies for different utilities:

- Overcurrent and overvoltage protection requirements for underground, overhead, and combined underground and overhead distribution circuits may vary significantly for different utilities based on differences in protection philosophy and lightning incidence level.

- Reliability requirements may vary significantly for different utilities based on differing utility reliability philosophy and established service levels. The application of manual vs. automatic switching and of radial, loop or parallel feeder configurations varies significantly for different utilities, based primarily on different reliability design philosophies and past experience.

Third, economics differ among different utilities, often having a significant impact on the various utility distribution design standards. Some of the important economic differences are as follows:

- The cost of utility system electrical losses can vary significantly from utility to utility, because the cost of losses is a function of the utility generation type as well as of the electrical characteristics of the distribution circuits. The cost of losses varies significantly among the utilities in this study.

- Installation costs of distribution facilities vary significantly among the different utilities. Generation, transmission, and environmental externality costs and assumptions also can vary significantly from utility to utility. 
- Economic assumptions vary significantly from utility to utility, even though PWRR methodology is employed by most utilities. In particular, annual fixed-charge rates may vary because of differences in state and local taxes and because of differences in financing costs between public and privately owned utilities.

Consequently, the review and interpretation of distribution standards and design philosophies of the seven different utilities in this project was a key factor in applying our assessment methodology and in quantifying distribution benefits for the various utilities.

\subsection{DISTRIBUTION SYSTEM BENEFITS}

There are a number of potential utility system benefits (and costs) associated with the installation of distributed renewable energy sources. Distribution system benefits are site-specific in that the applicability and the magnitude of these benefits are directly related to the site-specific distribution system loading and configuration, as well as to the physical location of the renewable energy sources installed in the distribution system.

The following sections describe various potential site-specific distribution system benefits associated with the strategic installation of distributed PV and WT in utility distribution systems.

\subsubsection{Distribution Facility Deferral}

The addition of new distribution facilities is generally based on the distribution system design standards and philosophy and on the need to maintain appropriate distribution system reliability criteria. Distribution system reliability, which varies from utility to utility, typically is based on meeting expected peak distribution system loading conditions, which vary among sites for different types of distribution systems. Distribution system planning requirements also vary for different primary and secondary levels of aggregation within a distribution system. End-use service reliability criteria such as total annual customer-minutes of interruption may also be used as a basis for adding new distribution facilities in some utilities.

As the peak load grows on a heavily loaded distribution system, a schedule of new distribution facility capital investments (e.g., new lines, transformer additions, transferring load to other feeders) is developed to meet the specified utility distribution system reliability criteria. Since PV and WT (and battery storage) are modular and come in $\mathrm{kW}$ and MW sizes compatible with distribution facility ratings, these renewable resources can be strategically distributed throughout the heavily loaded distribution system or installed at the end of a feeder to reduce peak feeder or distribution substation loads. They can defer distribution facility additions, resulting in a distribution facility deferral benefit. To reduce annual peak loads and defer the distribution facility additions, the renewable energy source output must shave the annual peak load.

The assessment methodology performs chronological hourly distribution system modeling with and without PV or WT during the annual peak day, and for weekdays and weekend days in each month, to determine $\mathrm{kW}$ peak reduction and distribution deferral benefits. Annual load duration curves were not used since they cannot provide the seasonal and hourly time-of-day correlation required between solar insolation and time of distribution peak. They also will not provide the information needed to determine battery storage $\mathrm{kW}$ and $\mathrm{kWh}$ requirements to reduce the distribution peak load. Also, in many cases, local distribution peaks may not coincide with total (native) system load. This fact must be carefully considered when combining various distribution, transmission, generation, and environmental benefits. 
Distribution facility deferral benefits generally apply to heavily loaded facilities and generally are very site-specific. The magnitude of the deferral benefit is strongly dependent on the length of the deferral and the cost of the new facilities. Distribution facility deferral benefits are greatest when the load growth rate is low. In addition, when load growth is low, renewable energy capacity can be installed in small increments from year to year as required to cover the load growth, reducing PWRR costs.

\subsubsection{Loss Reduction Benefits}

Relative distribution system primary and secondary system electrical losses with and without renewable energy sources installed are calculated as part of the distribution system assessment methodology. A recent utility system study showed transmission and distribution system losses can total over $9 \%$ of the total generated power, and other information indicates that typical utility losses vary from 7 to $9 \%$ (Ref. 7 ). About $40 \%$ of these losses occur in the distribution system. Since many renewable energy systems are expected to be connected to the distribution secondary system, the benefits from reducing both primary and secondary losses can be included where appropriate.

Annual demand and energy losses are calculated with and without renewable energy sources installed to determine the relative losses. Relative annual energy losses are calculated by running hourly load flows for weekdays and weekend days in each month with and without renewable resources installed, and accumulating the results throughout the year. Relative demand losses are determined using loss reduction at the time of the total (native) system peak load rather than at the time of the local distribution peak load, because demand charges are based on generation capacity requirements.

The relative cost of losses is determined using the utility hourly marginal production costs for the utility during the weekdays and weekend days in each month and over the 30-year study period.

Calculations in this study showed that the full loss-reduction benefit applied only when new distribution facilities were not being deferred. When distributed renewable energy sources were installed, distribution system losses were reduced. However, when new transformers and lines were installed on a distribution system, these new facilities also reduced distribution system losses. Those new distribution facility loss reductions tended to reduce or cancel loss-reduction benefits during years that the new facilities were being deferred by the addition of the renewable energy sources.

\subsubsection{Distribution Voltage and Power Factor Correction Benefits}

Voltage control and power factor correction in distribution systems are the two most common power quality issues addressed as part of distribution system planning and design. Voltage and reactive power (var) control in distribution systems are generally maintained using the following devices:

- fixed and switched shunt capacitors,

- transformer load tap changers (LTC),

- voltage regulators, and

static var controllers (SVC). 
One or more of the first three devices is commonly employed by most utilities to maintain loading conditions. For example, several of the utilities in this study and many other utilities in the United States maintain a $\pm 5 \%$ voltage spread criterion ( $126 \mathrm{~V}$ to $114 \mathrm{~V}$ on a $120 \mathrm{~V}$ base) between the first and last customer on a distribution circuit. In addition, many utilities add fixed and switched shunt capacitors to achieve a power factor correction criterion, (i.e., to correct power factor to unity or near unity at the distribution substation).

Shunt capacitors, LTCs, and voltage regulators typically respond to distribution system voltage fluctuations in the minute-to-minute time frame, which is generally adequate for most present day utility distribution system voltage and var control requirements. SVCs can respond to voltage fluctuations in the millisecond time frame and may be employed to solve voltage flicker or voltage collapse problems. However, SVCs may cost ten times as much as shunt capacitors (i.e., $\$ 120 / \mathrm{kvar}$ vs $\$ 12 / \mathrm{kvar}$ or less).

Installing distributed renewable energy sources can improve distribution system voltage in two ways. First, they can supply real power $(\mathrm{kW})$ during peak loading, reducing peak current flow and reducing voltage drop. Second, they can improve voltage regulation or provide power factor correction, if self-commutated transistor-based inverters or synchronous generators are used. On the other hand, a voltage penalty may occur if line-commutated inverters or induction generators are employed.

\subsubsection{Potential Distribution System Harmonics Impacts}

An emerging concern in both the utility industry and the electrical equipment manufacturing industry involves the increasing impact of non-sinusoidal waveforms on equipment performance. Sources of harmonic distortion are myriad and increasing rapidly, from solid-state variable frequency motor drives and electronic fluorescent ballasts to battery chargers for electric vehicles. The inverters associated with PV generation have the same potential for generating harmonics as do all other solid-state devices.

The Institute of Electrical and Electronics Engineers (IEEE) has recently developed an updated Standard 519 as a guide for managing the addition of harmonic-generating equipment to power systems ${ }^{8}$. The new standard presents a recommended methodology for evaluating new harmonic sources and recognizes that the magnitude of the harmonic contribution of a solid-state device is dependent upon the available short circuit current (SCC) "at the point of common coupling." Obviously, an inverter that may cause no problem at a location with high available SCC could cause a significant problem at a point with lower available SCC. Thus, it will be necessary for those who install PV generation to be alert to this phenomenon and use the new IEEE guidelines to prevent customer problems associated with harmonic effects. It is expected that PV installations,

like other solid-state devices, will be designed to comply with harmonic design limits, and that the costs will be included in PV plant capital investment. The impact of harmonics in distribution system design was not quantified in this study.

\subsubsection{Relaying, Switching, or Sectionalizing Impacts}

Standard distribution system design for the vast majority of applications consists of radial circuits. Although circuit ties may exist for emergency use and may facilitate load transfers, circuits are operated as having a single source. Most utilities have developed protection practices that apply devices such as reclosers, sectionalizers, and branch fuses in a planned sequence intended to minimize the number of customers affected by a primary interruption. 
Presently, most wind generators consist of induction machines. These units require external utility power to operate and will drop off the line quickly if the external source is removed. This feature has led to the general acceptance of these types of generators within the utility industry. Although some concern exists that generators may continue to operate through self-excitation after the source line has been interrupted when load and generation are closely matched, experience has not resulted in many known problems attributed to this cause.

Most PV arrays power solid-state dc/ac inverters, which are designed to operate within a narrow voltage bandwidth. If the voltage drops below the minimum level, conduction ceases instantaneously, the result being the same as with an induction generator.

Distribution circuit interruptions will cause the renewable generators to drop off the line. In many cases, generators outside the interrupted area can also be expected to drop off line, depending on the amount of voltage drop on the line and the sensitivity of the generator and its controls.

These generators can be programmed to restart automatically after external power has been restored. They can also be equipped with time-delay control to postpone restarting until the utility source has operated continuously for some period of time. Hence, significant impacts on distribution system relaying, switching, or sectionalizing costs are not expected for initial PV or WT penetration levels.

\subsubsection{Enhanced Distribution Reliability}

Two recent utility studies have assumed an enhanced distribution system reliability economic benefit associated with the installation of PV on distribution feeders. ${ }^{9-10}$ In one study the resulting economic benefit was small, and in the other the benefit was very large. However, in both studies, the enhanced reliability benefits were described as "soft," which appears to indicate that this benefit may be very difficult to support.

This study, which assesses benefits and costs for seven different utilities from a utility perspective, does not identify enhanced reliability economic benefits for any of the seven utilities. The project team and participating utility distribution engineers and planning personnel were unable to establish a rational basis for establishing or quantifying this potential economic benefit. However, the assessment methodology provides for calculating this potential economic benefit if it applies to a utility. Since this benefit may apply to some distribution systems, it is discussed here.

The discussion of distribution deferral benefits (Sect. 2.5.1) addresses potential economic benefits associated with locating PV, WT, or storage strategically in a distribution system to meet a utility's distribution reliability criteria, in lieu of adding new distribution facilities. There may also be special situations when customers with critical loads may need or desire higher reliability criteria. In these cases, PV, WT, or storage located near the customer's facility may provide enhanced reliability, if the renewable energy source can increase availability by reducing customer outage time.

A commonly used conventional method of providing enhanced reliability is to install a second feed to the customer (or customers). The customer is then charged a premium for the enhanced reliability service at a rate that allows the utility to recover the additional cost associated with providing the second feed to the customer. The customer would generally not be charged a premium based on the value of service to the customer. Thus, when determining potential economic benefits from the utility perspective, the additional cost, rather than value of service, is the basis typically used to quantify the benefits. If a significantly larger value-of-service premium were assumed when determining economic benefits compared with costs, the utility might never recover 
its additional cost to provide the enhanced reliability. Hence, value of service probably would be used only for determining benefits associated with some utility strategic plan.

The second aspect of the enhanced reliability issue is to determine whether strategically placed PV or WT can actually reduce customer outage minutes on a distribution system for a given utility. For many utilities, many of the distribution system outages occur during storms, or at night when there is no solar insolation. Hence, PV power may not always be present during outages. Also, outages may occur when there is no wind or too much wind, and WT may not be operating.

Assuming that distribution outages occur when PV or WT are operating, these strategically located generators would typically require ride-through capability, automatic switchgear, and output control to allow isolated operation during a disturbance to provide a level of enhanced reliability comparable to providing a second feed to the customer.

The previous two studies determined enhanced reliability benefits for PV without providing for isolated operation during a disturbance. ${ }^{9-10}$ The rationale was that when a disturbance occurred on a feeder with weak ties, the PV would trip with the rest of the circuit. With PV installed, the load in the unfaulted portion could be transferred to an adjacent feeder while repairs were made, reducing outage duration and providing enhanced reliability to the unfaulted portion of the feeder. Without PV, it evidently was assumed that some of the load could not be picked up until repairs were complete.

In this study, distribution reliability criteria of most of the seven utilities included provision for normally open ties to adjacent feeders. For all the utilities studied in this project, these ties provided the capability to transfer feeder loads to adjacent feeders during a disturbance independent of whether PV was installed on the feeder. Hence, PV did not enhance distribution system reliability. Since PV was tripped off during a feeder outage, tie capability to transfer loads to adjacent feeders was not affected by the installation of PV. Thus, the analysis in this study showed that without isolated operation capability, PV did not actually increase availability on any of the utilities evaluated in this project, and no potential enhanced distribution reliability benefits were assigned.

\subsection{ENERGY DISPLACEMENT AND CAPACITY VALUE BENEFITS}

PV, WT, and storage strategically located in a utility distribution system will provide energy displacement benefits and, in many cases, generation capacity value benefits. Energy displacement and capacity value benefits are nonsite-specific in that these generation system benefits are independent of the specific location of the PV and WT in a utility system.

\subsubsection{Energy Displacement Benefits}

Energy displacement benefits are generally determined by evaluating the relative generation system operating costs with and without the PV or WT installed. Operating costs can vary significantly from utility to utility. Within a utility, operating costs can vary significantly throughout the year, on an hourly basis throughout a day, on a daily basis throughout a week, and on a seasonal basis throughout the year. Hence, the hourly PV or WT energy displacement value can vary significantly throughout the year, depending on both utility operating costs and solar insolation or wind speed.

The assessment methodology provides for evaluating chronological hourly energy displacement modeling for weekdays and weekend days in each month. Energy displacement values are determined using time of day incremental (or marginal) utility operating costs obtained from 
utility production simulations and using corresponding hourly PV or WT performance. This approach is valid for small PV and WT penetration compared to the total utility size, which is the case for this study. For large PV or WT penetration levels, energy displacement value should be calculated using a production cost program.

When storage is added, additional load leveling benefits may be obtained if the incremental operating costs during the day are significantly higher than the incremental operating costs at night. To justify a battery storage charge/discharge cycle economically, the daily incremental cost spread must exceed the battery storage charge/discharge turnaround efficiency. For battery storage, the turnaround efficiency is typically $70-80 \%$.

\subsubsection{Capacity Value Benefits}

Presently, determining generation capacity value benefits of intermittent renewable energy resources is a very sensitive subject to many utilities. Generally, in order for PV or WT to obtain capacity credit and defer other new generation additions, a utility must need new generation capacity in the time frame being studied. For example, PV or WT cannot obtain capacity credit or might not be allowed in the rate base if a utility already has excess capacity installed, even though PV or WT may further increase generation system reliability.

Also, to obtain capacity credit, PV or WT must meet the utility's generation reliability criteria for installing new capacity. Generation system reliability criteria used to determine the required installed generation capacity consist of both deterministic criteria such as percentage of reserve, and probabilistic criteria such as loss of load probability. These criteria vary from utility to utility.

The assessment methodology provides for evaluating generation capacity value in three ways. One way is to determine the relative economic benefit associated with differences in generation expansion plans in the study period with and without PV or WT. Another way is to input an annual capacity value in $\$ / \mathrm{kW}$-year based on the annual carrying charges associated with the installed cost of a combustion turbine or some other type of generation. The third way is to calculate the annual capacity value using up to four different mills/kwh values, based on utility reliability and PV or WT performance during various on-peak and off-peak periods throughout the year.

\subsection{TRANSMISSION SYSTEM BENEFITS}

Renewable energy sources and storage installed in utility distribution systems can also provide bulk transmission and subtransmission system benefits, in addition to local distribution system benefits.

\subsubsection{Transmission Facility Deferral}

Transmission and subtransmission reliability criteria generally vary significantly from the distribution system reliability criteria discussed previously. Transmission and subtransmission system reliability is generally determined by performing appropriate contingency analysis during peak load conditions, or during maximum power transfer conditions as appropriate. Strategically placed PV, WT, and storage can be used to reduce power flows during these contingencies and defer the addition of new transmission lines and bulk power transformers, as well as distribution facilities. Like distribution deferral benefits, transmission and subtransmission facility deferral benefits 
generally apply to heavily loaded facilities and generally are site-specific. The magnitude of the deferral benefit is strongly dependent on the length of the deferral and the cost of the new facilities.

As with distribution facility deferral, the transmission and subtransmission deferral benefit is greatest when the load growth rate is low. In those cases, the PV, WT, and storage capacity can be installed in small increments from year to year as required to cover the load growth.

The assessment methodology provides two ways to include transmission facility deferral benefits. If specific line and transformer deferrals can be identified, relative transmission expansion plans with and without renewable energy sources can be specified to determine the deferral benefit. If specific transmission facilities cannot be identified, general transmission costs in $\$ / \mathrm{kW}$ of (native) system peak load can be used, if available.

Many utilities presently use general $\$ / \mathrm{kW}$ transmission costs in integrated resource plans when evaluating demand-side management (DSM). These data, where available, may also be used for renewable energy sources and storage installed in distribution systems. However, if site-specific transmission line or transformer deferral opportunities can be identified for specific PV, WT, and storage applications, larger and more accurate site-specific transmission facility deferral benefits may be attained.

\subsubsection{Transmission Loss Reduction Benefits}

The assessment methodology provides for including transmission loss reduction benefits and other potential transmission benefits such as stability where they can be identified. Many utilities use general cost of transmission losses in integrated resource plans when evaluating DSM. Cost data for both demand and energy losses may be available. These data may also be applied to PV, WT, and storage installed in the distribution system.

\subsection{ENVIRONMENTAL AND OTHER APPLICABLE BENEFTTS}

Consideration of environmental and other applicable issues is becoming an important factor in electric utility resource planning. These external issues or externalities can have considerable impact on utility economic evaluation, when external costs for environmental emissions are applied during new resource evaluations.

\subsubsection{Energy Policy Act and Clean Air Act Amendments}

The assessment methodology provides for considering the Energy Policy Act of 1992 (EPACT) and the Clean Air Act Amendments of 1990 (CAAA) which have been passed at the national level. ${ }^{11,12}$ Basically, for publicly owned utilities, EPACT provides for a $1.5 \mathrm{k} / \mathrm{kWh}$ (adjusted for inflation) renewable energy production incentive which is available for the first 10 years of operation for PV or WT. The production incentive expires in 20 years.

For privately owned companies, EPACT provides for a $1.5 \mathrm{k} / \mathrm{kWh}$ after-tax credit adjusted for inflation, which applies to the first 10 years of operation for WT installed before 1999. This applies to investor owned utilities, EPACT also provides a $10 \%$ investment tax credit for PV installations with no expiration date. This $10 \% \mathrm{PV}$ investment tax credit does not apply directly to investor owned utilities. However, it appears that a utility could set up a subsidiary company and lease the PV equipment back to take advantage of this tax credit. 
CAAA may also result in significant economic benefits for $\mathrm{PV}$ and $\mathrm{WT}$ due to $\mathrm{SO}_{2}$ emission reductions when PV or WT is installed. The value of the economic benefit will be a direct function of the future market price of $\mathrm{SO}_{2}$ allowances and the type of fuel displaced.

\subsubsection{Externality Costs}

The assessment methodology provides for considering appropriate environmental (or other) externality costs. The procedure used to quantify externality costs varies significantly from state to state, and in some states there is no acceptable procedure to quantify externality costs.

In this study, two of the utilities, Southern California Edison (SCE) and Green Mountain Power (GMP) supplied procedures to quantify externality costs. The SCE procedure, which is discussed in Sect. 4, results in benefits for both PV and WT, and was based on their latest filing with the California Public Utility Commission (early 1993). The GMP procedure results in benefits only for DSM resources, and does not apply to PV or WT. The other utilities did not quantify externalities as part of their planning process.

\subsubsection{Other Potential PV and WT Benefits}

The assessment methodology also provides for considering potential environmental and other applicable benefits. For example, significant benefits for PV and WT may occur if a monetary benefit is used to reduce greenhouse gas emissions such as $\mathrm{CO}_{2}$. 


\section{RENEWABLE ENERGY SOURCE COST AND PERFORMANCE}

This section presents renewable energy source cost and performance assumptions for PV, WT, and battery storage installed in distribution systems. PV was assumed to be installed in both rural and urban distribution systems. WT applications were restricted to rural distribution circuits because of expected institutional barriers, land requirements, and wind resource limitations associated with installing WT in densely populated urban areas.

This study considers utility interconnected PV and WT applications. Thus, storage, which increases PV and WT capital investment, is not a requirement for PV or WT systems. In this study, battery storage is considered for interconnected PV or WT applications only when the increased cost can be justified by larger utility system benefits.

\subsection{SOLAR RESOURCE}

As indicated in the previous section, per unit PV costs strongly depend on the amount of energy generated by the PV plant. The major factor in determining the amount of energy that can be generated by a PV plant is the solar insolation available at the site in question; the more insolation available, the lower the cost per kilowatt hour, all other factors being equal.

"Insolation" refers to solar energy density, measured in watt hours or kilowatt hours per square meter; "irradiance" refers to power density, measured in watts or kilowatts per square meter. Five measurements of insolation are commonly used: global horizontal, global fixed-orientation, global single-axis tracking, global two-axis tracking, and direct normal. Global horizontal comprises the most widely recorded solar data set, but the remaining four correspond to the module orientations most often used to generate electricity. Global insolation is that which falls on a surface from all directions, whereas direct normal is that which comes in parallel rays directly from the sun. The insolation available to a PV plant depends on the tracking mode adopted and on whether the plant consists of flat plate modules (which respond to global radiation) or of concentrator modules (which use only the direct normal component of the global radiation). PV with flat plate modules is assumed for this study.

Solar data can now be estimated with a moderate degree of certainty throughout the country. Global horizontal measurements (SOLMET data from 26 sites in the United States.) and estimates (so-called ERSATZ data based on hours of sunshine, temperature measurements, and cloud cover estimates from another 222 sites, mainly in the United States) together formed the largest single solar data set available in the United States at the beginning of this study. ${ }^{13,14}$ Dozens of other solar insolation measurement programs are known to be operating. ${ }^{15}$ In 1992, the National Renewable Energy Laboratory published summaries of data based on measurements through $1990 .^{16}$ This new data set is the or National Solar Radiation Data Base (NSRDB).

Hourly estimates of insolation, ambient temperature, and wind speed for the 8760 hours of a "typical" year are available in computer-readable format. ${ }^{17}$ These typical meteorological year (TMY) data, based on the old SOLMET and ERSATZ data, are often used in estimating PV plant output. Comparison of the new NSRDB data with TMY data show only slight differences between the two data sets at the sites considered for the utility applications in this study, as shown in Table 3.1. All NSRDB sites are primary (measured) except Knoxville, and all TMY sites are SOLMET (measured) except Burlington and Knoxville.

TMY data were used with Sandia's PVFORM program to determine PV performance for the individual utility case studies. ${ }^{18}$ 
Table 3.1. Comparison of global radiation annual average daily radiation $\left(\mathrm{kWh} / \mathrm{m}^{2}\right)$

\begin{tabular}{lccc}
\hline Location & $\begin{array}{c}\text { SOLMET/ } \\
\text { ERSATZ }\end{array}$ & NRSDB & $\%$ Change \\
\hline Daggett, California & 5.81 & 5.78 & -1 \\
Burlington, Vermont & 3.22 & 3.72 & 16 \\
Albuquerque, New Mexico & 5.76 & 5.57 & -13 \\
Atlanta, Georgia & 4.24 & 4.58 & 8 \\
Miami, Florida & 4.64 & 4.83 & 4 \\
Knoxville, Tennessee & 4.01 & 4.23 & 5 \\
\hline
\end{tabular}

\subsection{PV POWER PLANT DESIGN ISSUES}

In addition to solar insolation, several other PV plant design issues affect plant economics. These include the type of tracking employed, the location of the trackers relative to each other, the type and cost of modules installed, and balance-of-plant considerations such as the power conditioning unit.

With respect to the hourly output pattern from a PV plant, tracking is the most significant design issue. Assuming that flat plate rather than concentrator modules are employed, there are three choices: fixed orientation (no tracking at all), single-axis tracking, or two-axis tracking. Fixed orientation is the least expensive because there are no moving parts, but it also captures the least energy. Single axis tracking -in which the modules are mounted on a north-south axis that orients the modules east in the morning, straight up at noon and west in the evening - offers greater energy capture than fixed orientation, but it is more expensive to construct. Two-axis tracking offers even more energy capture than single axis tracking, but because it orients the modules toward the sun during all daylight hours, it is also the most costly to construct.

The relative amounts of energy captured with the three tracking options vary from one location to another because the relative amounts of indirect (reflected) and direct insolation differ. In addition, the time pattern of PV plant output differs among the types of tracking. Two-axis tracking offers the broadest and squarest daily output pattern. To meet the evening peak loads, it is possible to orient fixed modules somewhat to the west rather than directly south so that their peak output occurs later in the day, or to adjust the tilt to capture more energy in the summer. Similarly, the axis in single-axis tracking modules can be oriented slightly counterclockwise from north-south to provide greater output on winter afternoons (the sun sets south of direct west in the winter).

The appropriate specification of power conditioning units for distribution system applications is important because of the need to meet appropriate power quality standards and because of possible var support. The PV plant output voltage and current wave shapes should meet harmonic requirements in IEEE Standard 519. The need to provide var support, resulting in selfcommutated vs line-commutated inverter designs, may also significantly affect PV capital investment.

The greatest unknown and most crucial factor in the future adoption of PV power generation is the cost and efficiency of PV modules, which presently comprises more than half the cost of any 
PV system. Module costs as of 1992 were $\$ 4$ to $\$ 5$ dollars per watt in large quantities for single crystal technology. Several other technologies are under active development, and a 1992 study by Bechtel projected that these module costs will fall to about $\$ 2$ per watt at a single factory production volume of $25 \mathrm{MW}$ per year, or to $\$ 1$ at $100 \mathrm{MW}$ per year. ${ }^{19}$ In the Bechtel study, module costs for Czochralski single crystal (CZ) are compared with cost for thin-film amorphous silicon (a-Si), cadmium telluride (CdTe), copper indium diselenide (CIS), edge-defined film growth (EFG), polycrystalline (Poly), and dendritic web (Web). The study shows that both module costs and module efficiencies are important. For example, $\mathrm{CZ}$ at $\$ 1$ per watt and less efficient a-Si at $\$ 0.60$ per watt were both projected to have the same PV plant energy cost because the additional structure and wiring necessary for the less efficient a-Si modules is more costly.

\subsection{PV COST AND PERFORMANCE ASSUMPTIONS}

The PV cost assumptions shown in Table 3.2 and used for the utility case studies were based on the best available, most recent data.

Table 3.2. PV plant cost assumptions

\begin{tabular}{ll}
\hline \multicolumn{2}{c}{ Capital investment } \\
\hline Fixed orientation & $\$ 7070 / \mathrm{kW}$ \\
Two-axis tracking & $\$ 8270 / \mathrm{kW}$ \\
Operation and maintenance & $0.6 \mathrm{k} / \mathrm{kWh}$ \\
\hline
\end{tabular}

The PV capital investment assumption for fixed-orientation PV systems was based on the turnkey installed cost of 100 4-kW flat plate single-crystal silicon PV systems supplied to the Sacramento Municipal Utility District (SMUD).$^{20}$ This cost and recent studies represent a significant reduction in PV installed costs compared with previous PV system costs. ${ }^{19,21}$ The average PVUSA PV system cost was about $\$ 10,000 / \mathrm{kW}$, and Pacific Gas \& Electric's $500 \mathrm{~kW}$ Kerman plant with single-axis tracking cost about $\$ 11,200 / \mathrm{kW}^{22}$ Two-axis tracking PV systems were assumed to cost $\$ 1,200 / \mathrm{kW}$ more than fixed-orientation systems for this study. PV operation and maintenance costs were based on an Electric Power Research Institute survey. ${ }^{23}$

PV system performance was determined by assuming the following configuration per $\mathrm{kW}$ of installed PV in the PVFORM program configuration:

$$
\begin{aligned}
& \text { Array area }=10 \mathrm{~m}^{2} . \\
& \text { - } \\
& \text { Net PV rating }=1 \mathrm{~kW} @ 20^{\circ} \mathrm{C} \text {, NOCT } 40^{\circ} \mathrm{C} \text {. } \\
& \text { Net plant efficiency }=10 \% .
\end{aligned}
$$

This assumed configuration allows the PV system to attain rated $\mathrm{kW}$ output during high solar insolation conditions in most of the utility case studies, and the net plant efficiency of $10 \%$ includes both typical module efficiency of about $11 \%$ and power conditioning system efficiency of about $90 \%$. This study was performed using net $\mathrm{PV}$ plant $\mathrm{kW}$ ratings and net $\mathrm{PV}$ plant efficiency, which is compatible with utility practice when rating other types of utility generation. 


\subsection{WIND RESOURCE}

Like PV, WT costs strongly depend on the amount of energy generated by the WT plant. The more energy generated, the lower the cost per $\mathrm{kWh}$. However, while solar insolation is more equally distributed throughout a region, the magnitude of wind resources is much more site-specific. And areas of adequate wind resources for WT applications are expected to be more limited in a region than areas for PV applications.

Depending upon its location, WT power output is often less predictable than solar power output. Predictability is better where the wind blows in response to a regularly occurring climatic pattern, For example, California mountain passes between the cool coast areas and the hotter desert or central valley inland areas.

Preliminary screening of prospective sites is even more helpful in analyzing wind power than it is in solar. Similar to the situation with PV, greater energy output corresponds with lower levelized energy cost. Therefore, areas with more energetic wind resources are the first places to look for cost-effective wind installations. One widely used measurement standard for preliminary screening of wind sites is described in the Wind Energy Resource Atlas. ${ }^{24}$

However, detailed site-specific hourly wind speed data are generally required to assess potential WT impacts on utility distribution systems. These data are combined with the power curve for a WT design to determine hourly WT performance. The hourly electric output is then accumulated to determine annual energy production and WT capacity factor.

\subsection{WT PLANT DESIGN ISSUES}

The most significant specifications for a WT are its electrical $\mathrm{kW}$ rating and its power curve, which is determined primarily by the rotor size. Wind turbines now in commercial operation range in size up to $500 \mathrm{~kW}$. Most wind turbines installed in the mid-1980s were in the $100-\mathrm{kW}$ range. More recent designs between 250 and $500 \mathrm{~kW}$ have evolved and are now presently available. Note that WT sizes up to $500 \mathrm{~kW}$ are compatible with utility distribution system ratings. However, smaller WTs do not require large cranes for service.

Figure 3.1 presents a typical WT power curve for a $50 \mathrm{~kW} \mathrm{WT}$. Note that a WT may generate power at $\mathrm{kW}$ levels significantly above the $\mathrm{kW}$ rating during high wind conditions and will deliver no energy when the wind is above cut-out. WT power curves vary significantly for different WT designs.

Horizontal axis machines comprise the large majority of designs presently operating. Almost all wind turbines used for commercial power generation use two- or three-blade rotors. A few experimental designs in Europe use a single blade. Lighter weight United States designs like the ESI-80, Bergey, and Northern Power Systems use two blades and generally use higher speed rotors, whereas the heavier European designs like Bonus, Nordtank, and Micon turbines use three blades. 


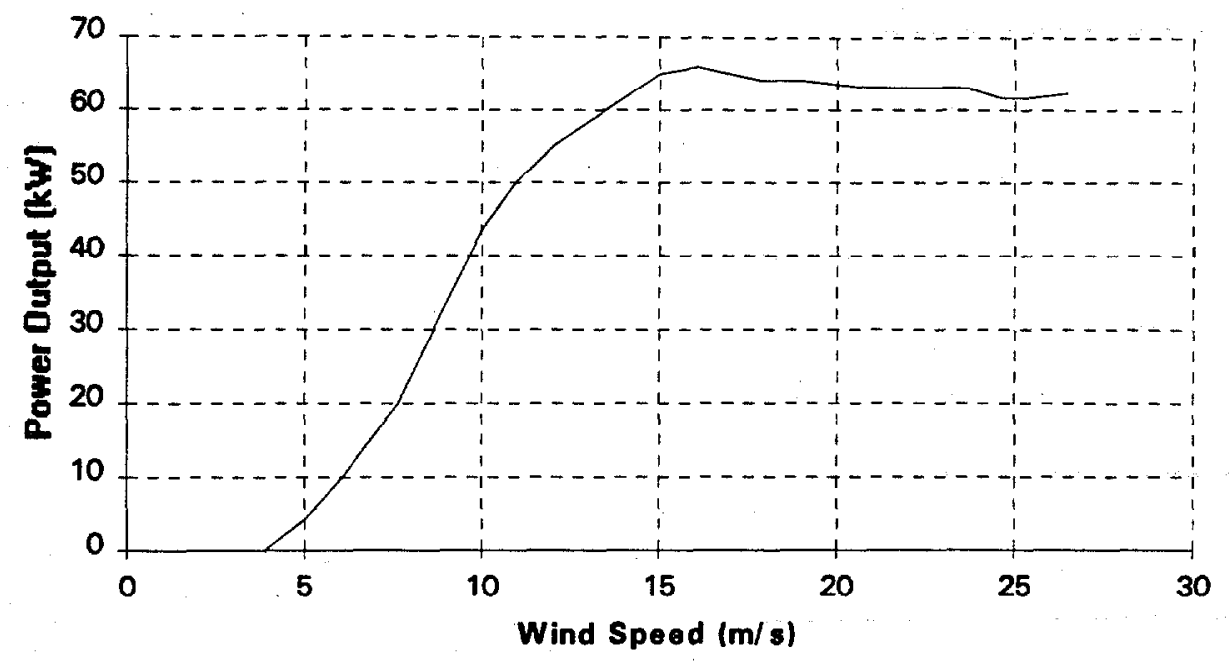

Fig. 3.1. Representative 50-kW wind turbine power curve.

\subsection{WT COST AND PERFORMANCE ASSUMPTIONS}

The WT cost assumptions used in the utility case studies are shown in Table 3.3. The capital investment and operation and maintenance costs were based on the cost and performance of current commercial wind turbines determined in EPRI studies..$^{3,25}$

Table 3.3. Wind turbine plant cost assumptions

\begin{tabular}{ll}
\hline Capital investment & $\$ 1013 / \mathrm{kW}$ \\
Operation and maintenance & $0.7 \notin / \mathrm{kWh}$ \\
\hline
\end{tabular}

In the utility case studies, WT performance was based on site-specific WT electrical data for representative WT sites in the utility service area.

\subsection{BATTERY STORAGE COST AND PERFORMANCE ASSUMPTIONS}

Battery storage cost and performance assumptions in Table 3.4 were derived for a 3-hour lead acid battery storage plant, based on published EPRI Technical Assessment Guide assumptions. ${ }^{3}$ The EPRI capital investment assumption is in 1989 dollars and reflects the use of heavy-duty batteries expected to cycle frequently throughout the year. Operation and maintenance costs were neglected. Battery plant turnaround efficiency of $75 \%$ was assumed, which is compatible with existing battery storage plant experience.

Battery storage plant capital investment would likely be reduced by about $\$ 200 / \mathrm{kW}$ for applications with PV because a dc/ac converter is not required when batteries are added to a PV plant. Another $\$ 200 / \mathrm{kW}$ capital investment reduction probably could be obtained if the battery plant did not have to cycle frequently, reflecting the use of light-duty batteries. 
Table 3.4. Battery storage cost and performance assumptions

\begin{tabular}{lc}
\hline Capital investment-3-hour battery plant & $\$ 950 / \mathrm{kW}$ \\
Turnaround efficiency & $75 \%$ \\
\hline
\end{tabular}




\section{4. 'SOUTHERN CALIFORNIA EDISON CASE STUDY}

This section presents the results of the SCE case study. SCE's distribution system and design practices are presented. Representative PV and WT performance characteristics in the SCE service area are described. Various SCE benefits quantified are described, and pertinent assumptions are discussed. The case study results are then presented and summarized for the SCE system. The information contained in this report was the result of available information from the consultant and SCE staff in 1992 and early 1993. These data are changing continuously. Updated data on gas price load forecast, CT full value, incremental energy value (IER), environmental values and other pertinent information which will affect the values of distributed resources and results of this case study should be obtained from SCE. This report was prepared by ZECO as an account of a subcontract to the Oak Ridge National Laboratory. SCE makes no warranty or representation whatsoever expressed or implied with respect to the use of any information, method, process, or similar item disclosed in this report.

\subsection{DISTRIBUTION SYSTEM DESCRIPTION AND DESIGN PRACTICES}

Most subtransmission at SCE is $69 \mathrm{kV}$, although $115 \mathrm{kV}$ is also used in some areas.

SCE's substation design philosophy differs significantly from that of the other utilities represented in this study. Its efforts have resulted in a system consisting generally of more than one incoming line to a substation, which, in turn, consists of more than one transformer. The representative substation to serve a suburban area we have selected consists of two incoming lines feeding a 44.8-MVA transformer bank (two 22.4-MVA 65C FA transformers connected in parallel). No more than two three-phase transformers are banked together, in order to limit the maximum available SCC to 20,000 A or less. This substation design is expandable in 22.4-MVA increments to the substation's ultimate maximum rating of either $90 \mathrm{MVA}$ or $180 \mathrm{MVA}$, or, with newer transformers rated $28 \mathrm{MVA}$ as high as $224 \mathrm{MVA}$ (No distribution substations have been expanded beyond 112 MVA). SCE practice is to load these units up to $130 \%$ of nameplate rating during normal peak periods. During emergencies, overloads up to $145 \%$ are acceptable for short periods.

SCE does not generally install voltage regulating equipment in its substations. However, switched substation capacitors are installed, and generally sized to compensate for the peak var losses through the substation transformers. Fixed and switched capacitor banks are installed on the distribution system; they have the dual goals of maintaining adequate circuit voltage and of correcting the distribution system to unity power factor at peak, calculated at the substation highvoltage bus. Temperature controls are extensively used to operate the switched banks, although voltage and time controls are also used to a lesser extent. The California Public Utilities Commission has established the voltage utilization range between $114 \mathrm{~V}$ minimum and $120 \mathrm{~V}$ maximum for residential and commercial circuits. These restrictions do not apply to circuits serving agricultural and industrial loads.

SCE currently uses two distribution voltages, $12,000 \mathrm{~V}$ and $16,340 \mathrm{~V}$, depending on geographic location. The $12-\mathrm{kV}$ system is larger and has been used in this study.

The average circuit peak load is designed for approximately $400-450 \mathrm{~A}$ based on a standard configuration of six $12-\mathrm{kV}$ circuits per $44.8-\mathrm{MVA}$ transformer bank, loaded to $130 \%$ of nameplate rating.

Utilities regulated by the California Public Utilities Commission are subject to General Orders 95 and 128, which specify requirements for overhead and underground line construction, respectively. These orders supersede the National Electric Safety Code and have resulted in 
significantly different construction practices in certain areas, particularly regarding overhead fourwire three-phase lines. Although four-wire distribution is used extensively, the neutral is considered a primary conductor and is insulated for primary voltage. Overhead distribution transformers are connected phase-to-phase rather than phase-to-neutral.

The SCE system is heavily summer peaking; much refrigerated air conditioning is used by both residential and commercial customers.

Standard overhead conductor sizes are $\# 4,1 / 0,336.4 \mathrm{kcmil}$, and $653.9 \mathrm{kcmil}$ ACSR. Standard primary underground cable sizes are $\# 2,1 / 0,350 \mathrm{kcmil}, 750 \mathrm{kcmil}$, and $1,000 \mathrm{kcmil} \mathrm{A1}$. The standard insulation thickness is 220 mils of cross-linked polyethylene for both $12-\mathrm{kV}$ and $16-\mathrm{kV}$ applications.

Residential underground construction consists of direct-buried primary cables on fused laterals serving a number of unfused four-wire $(6.9-\mathrm{kV}$ or $9.3-\mathrm{kV})$ pad-mounted transformers. Typical design demand loads are 4 to $5 \mathrm{kVA}$ per home, diversified over the number of homes served by a transformer (8-20). Voltage drop from the transformer to the customer's meter is limited to $3 \%$ for new installations and 5\% for existing overhead-served installations. In addition, SCE limits flicker to $5 \%$ on underground installations (including transformer, secondary, and service) and $7 \%$ on overhead installations.

Much new distribution line construction is underground, ranging from new circuits leaving substations to new construction in commercial areas. SCE also has an extensive program of converting existing overhead lines to underground at utility expense, as mandated by the California Public Utilities Commission. These underground lines are installed in rigid ducts. Pad-mounted transformers and aboveground air-insulated switches are installed where space is available. Where totally underground facilities are necessary, submersible transformers and $\mathrm{SF}_{6}$-insulated switchgear are currently used. A summary of SCE's distribution design practices is presented in Table 4.1.

\subsection{PV AND WT PERFORMANCE CHARACTERISTICS}

Per-kW PV performance assumptions for the SCE case study were based on SOLMET data for Daggett, which is located in Southern California. This site is representative of expected solar insolation in SCE's inland valley service areas. Table 4.2 presents a summary of expected annual performance for a $10-\mathrm{m}^{2}$ PV system rated at $1 \mathrm{~kW}$, assuming fixed orientation at the site latitude of $34.9^{\circ}$ and assuming two-axis tracking. The fixed-orientation PV system capacity factor is about $25 \%$, and the capacity factor of the two-axis tracking PV system is about $33.8 \%$. Monthly performance for the two PV system configurations is presented in Fig. 4.1.

Table 4.2. Ten square meter, 1-kW PV at Dagget, California

\begin{tabular}{lc}
\hline Configuration & $\begin{array}{c}\text { Annual capacity } \\
\text { factor (\%) }\end{array}$ \\
\hline Fixed tilt $34.9^{\circ}$ & 25.0 \\
Two-axis tracking & 33.8 \\
\hline
\end{tabular}


Table 4.l. SCE distribution design practices

\section{Substation:}

Subtransmission voltage

Minimum number of incoming lines

Standard transformer size

Normal operating limit

Emergency operating limit

Standard transformer bank size

Minimum number of transformers

Maximum substation size

Voltage regulation

Maximum short circuit duty

Substation capacitors?

Peak load characteristic

$69 / 115 \mathrm{kV}$

2

22.4 MVA, FA, $65^{\circ} \mathrm{C}$

$130 \%$

$145 \%$

2.22.4 MVA

2

90-180 MVA

none

$20,000 \mathrm{~A}$

yes-to correct peak, var losses

summer

\section{Circuit design:}

\section{Voltage}

Power factor correction goal

Comply with NESC?

Peak design load

Ties with adjacent circuits?

Field voltage regulation practices

Tapped transformers?

Design transformer loading

Average transformer loading

Design voltage criteria

Design voltage drop

Flicker voltage drop criteria
$12 \mathrm{kV} / 16 \mathrm{kV}$

unity at peak load

no-California PUC regulations $400 \mathrm{~A}$

yes

switched capacitors

no

to $200 \%$ of name plate. ( 5 zones)
114-120 V(California PUC) $5 \%$ total $5 \%$

Circuit protection practices:

Extensive use of field reclosers?

Fused laterals?

no (except fire hazard areas)

Overhead lines:

yes for underground residential taps overhead now being installed

Maximum number of circuits per pole line

Typical primary conductor sizes

Secondary \& service conductor sizes

no restriction

\#4, 1/0,336.4 \& 653.9 ACSR

$\# 4, \# 2,1 / 0,4 / 0$ triplex

Underground lines:

Installation method, residential

Installation method, feeders

Typical primary conductor sizes

Secondary \& service conductor sizes

Primary cable insulation

Switching equipment

direct buried/flex duct 5 -in. duct

$\# 2,1 / 0,350,750,1000 \mathrm{kcmil}$

$\# 2,1 / 0,350,750 \mathrm{kcmil}$

$220 \mathrm{mil} \mathrm{clp}$

$\mathrm{SF}_{6}$ (formerly oil), air

Unique concerns:

brush fire hazards;

regulatory construction requirements 


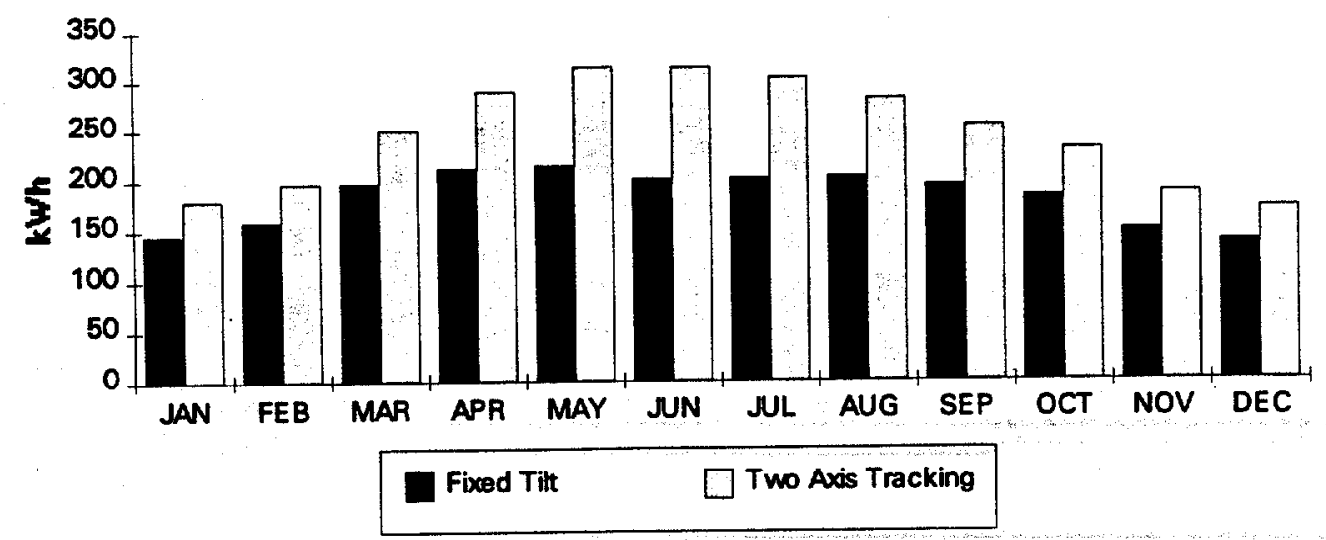

Fig. 4.1. PV system monthly performance per kilowatt.

Figure 4.2 shows the hourly performance for the fixed-orientation 1-kW PV system for the peak solar insolation day and average solar insolation day in April and in June. On April peak days when the solar insolation is high, the PV system can attain $1 \mathrm{~kW}$ output; on the average day, the PV system can attain over $0.9 \mathrm{~kW}$ output. In June, which represents the SCE summer peak period, the PV system does not attain full output.
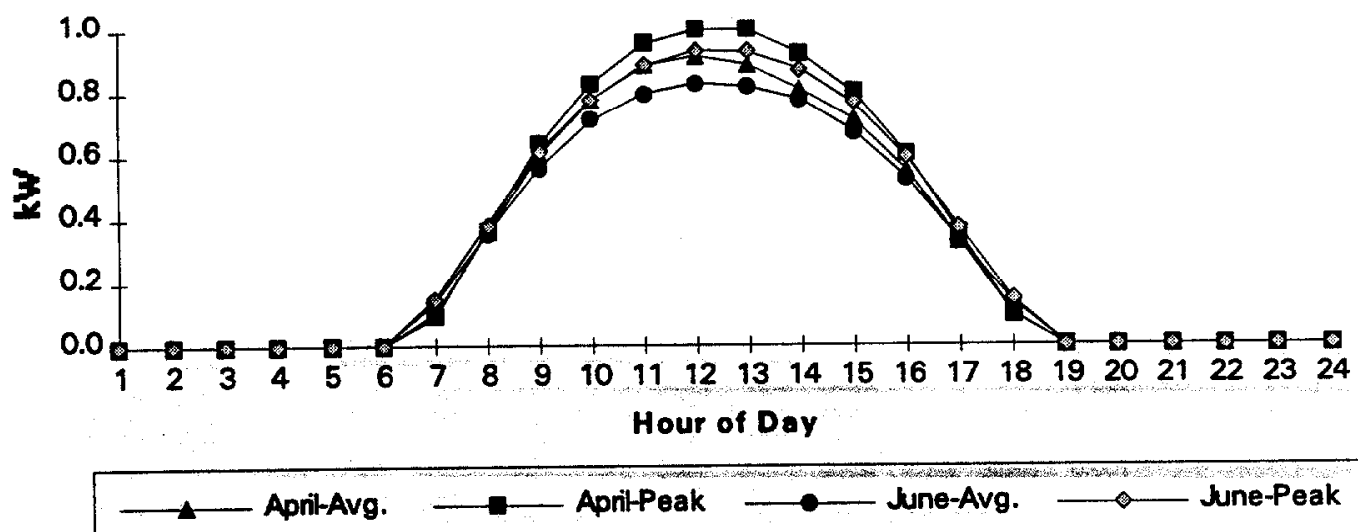

Fig. 4.2. Fixed-orientation $P V$ daily output per $\mathrm{kW}$ 
Figure 4.3 shows the corresponding hourly performance for the two-axis tracking $1 \mathrm{~kW} \mathrm{PV}$ system for June and April. Two-axis tracking provides significantly better PV performance, but at a higher PV capital investment.

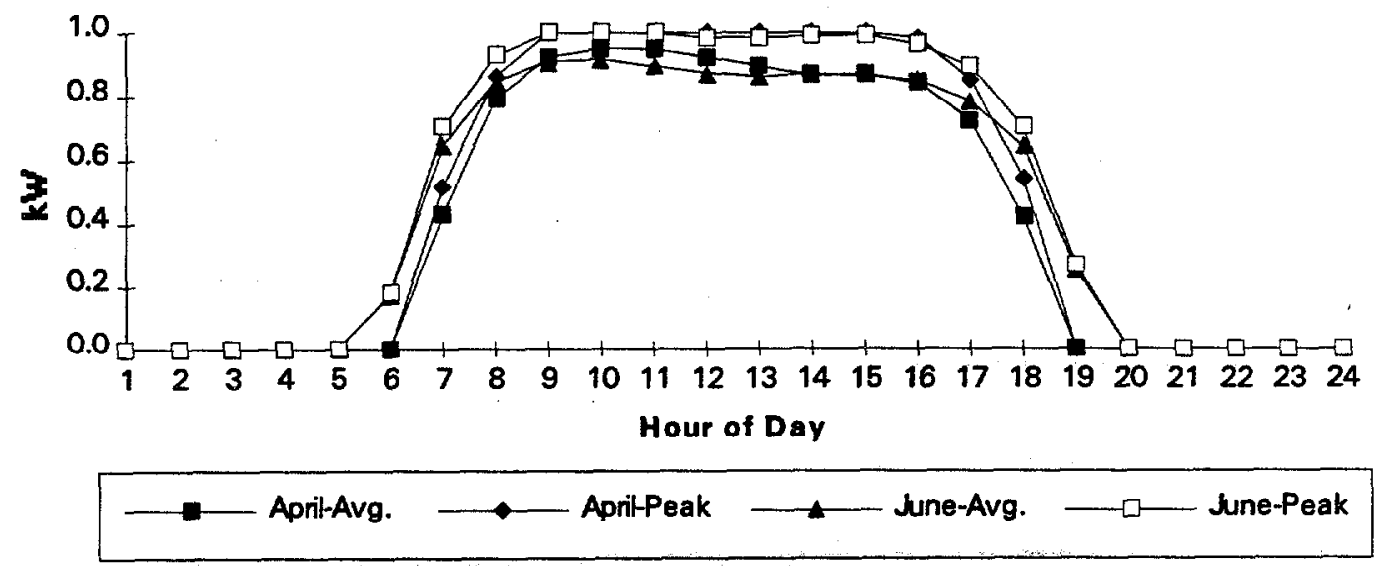

Fig. 4.3. Two-axis tracking PV daily output per $\mathrm{kW}$.

Per-kW WT performance assumptions for the SCE case study were based on hourly kW performance data from a wind turbine located in San Gorgonio. The capacity factor is $43.2 \%$.

Figure 4.4 presents the monthly performance for the San Gorgonio WT on a per-kW basis.

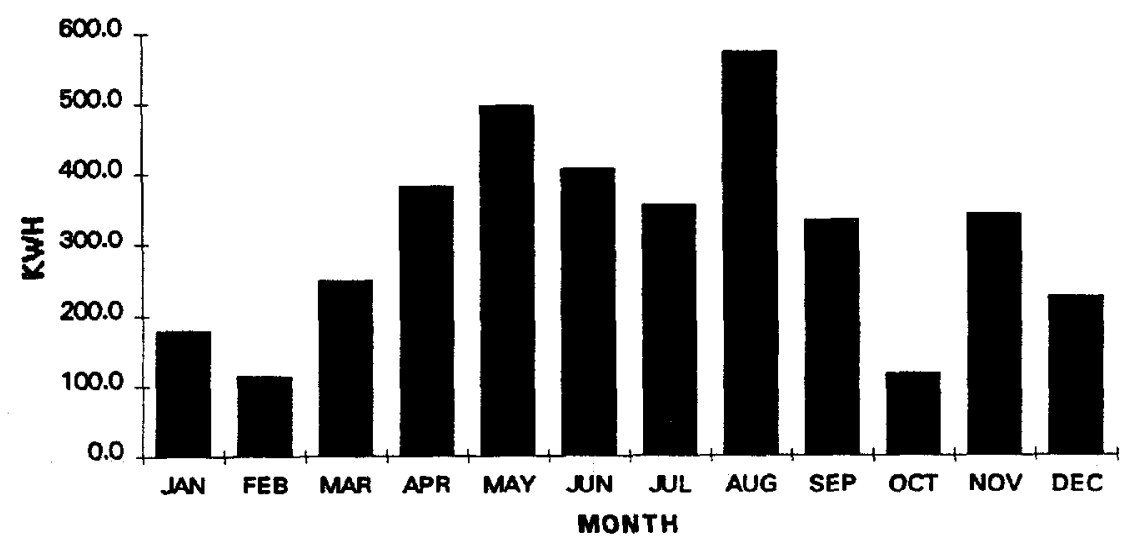

Fig. 4.4. WT system monthly performance per $\mathbf{k W}$. 
Figure 4.5 shows the average hourly per-kW performance for the WT system in June, July, August, and September, the peak summer months. This plot shows a significant range in hourly performance throughout the SCE summer peak period for this wind site, and indicates relatively inconsistent output compared to PV.

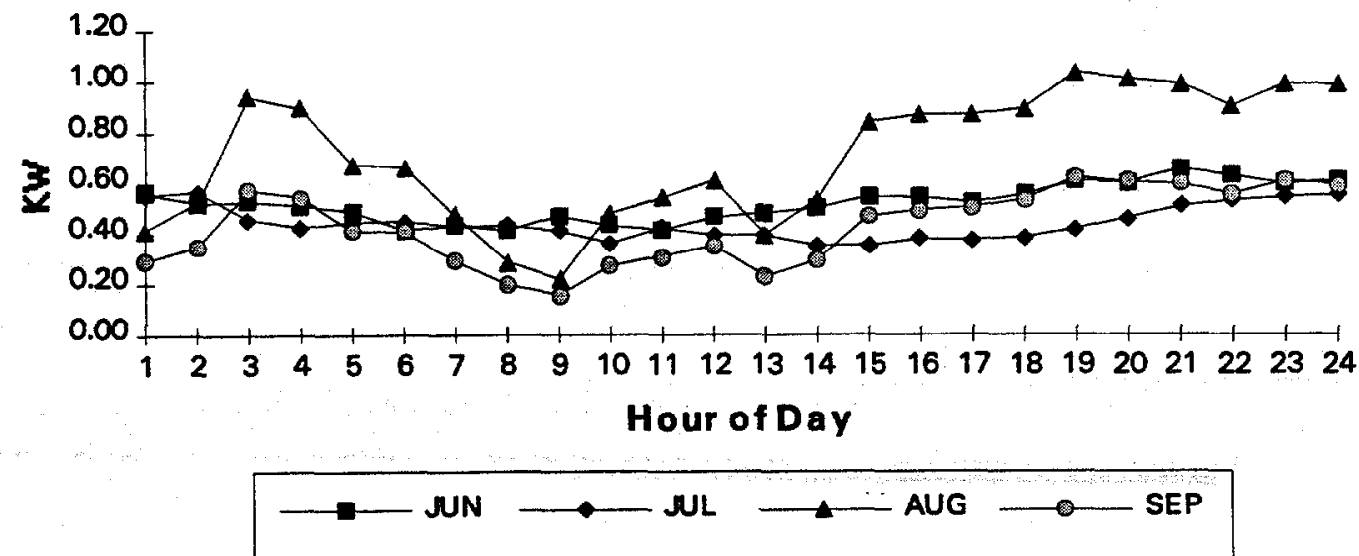

Fig. 4.5. WT daily output per $k W$.

\subsection{ASSUMPTIONS AND BENEFITS QUANTIFIED}

The following assumptions were obtained from interaction with SCE distribution engineers and planning personnel. They are compatible with financial assumptions and cost estimates used by SCE in early 1993. General financial assumptions used for the SCE case study are listed in Table 4.3.

Table 4.3. SCE financial assumptions ${ }^{b}$

\begin{tabular}{lc}
\hline Parameter & Assumption \\
\hline Discount rate & $11 \%$ \\
Levelized fixed charge rate-all CI & $16.4 \%$ \\
First year fixed charge rate-all CI & $10.5 \%$ \\
Escalation rate-everything but fuel & $4.0 \%$ \\
Escalation rate-fuel & $8.0 \%$ \\
\hline
\end{tabular}

b As the result of economy and regulatory changes since the inception of this report, these values have changed. SCE should be contacted for more recent data. 
The following benefits were quantified in the SCE case study:

distribution facility deferral,

distribution losses,

voltage regulation and power factor correction,

generation capacity,

energy displacement value,

transmission capacity,

transmission losses,

EPACT production tax credit for WT, and

environmental externalities.

Distribution facilities deferred in the SCE case study include the following:

- the addition of a third 22.4-MVA transformer plus associated new underground feeder additions, at an existing urban area 44.8-MVA distribution substation;

upgrading an existing 15-MVA rural distribution substation to 28 MVA by replacing the 15MVA bank with two 14-MVA transformers plus associated new overhead feeder additions; and

replacing a pad-mounted or buried 50-kVA distribution transformer serving a residential secondary system with a 75-kVA transformer.

Total installed cost assumptions for the distribution facilities are presented in Table 4.4.

Table 4.4. Distribution facility cost assumptions ${ }^{b}$

\begin{tabular}{|c|c|}
\hline Item & $\begin{array}{c}\text { Total installed cost } \\
1992 \$\end{array}$ \\
\hline $\begin{array}{l}\text { Add third 22.4-MVA transformer to existing } \\
\text { urban 44.8-MVA substation }\end{array}$ & $\$ 2.8 \mathrm{M}$ \\
\hline $\begin{array}{l}\text { Replace existing 15-MVA rural substation } \\
\text { bank with two 14-MVA transformers }\end{array}$ & $\$ 3 \mathrm{M}$ \\
\hline $\begin{array}{l}\text { Add new underground } 1000-\mathrm{kcmil} 12-\mathrm{kV} \\
\text { feeder }\end{array}$ & $\$ 250 \mathrm{k} / \mathrm{mi}$ \\
\hline Add new overhead $336-\mathrm{kcmil} 12-\mathrm{kV}$ feeder & $\$ 35 \mathrm{k} / \mathrm{mi}$ \\
\hline Install a 75-kVA distribution transformer & $\$ 1814$ \\
\hline
\end{tabular}

Relative distribution losses with and without renewable energy sources were calculated hourly for work days and weekend days in each month. The annual cost of losses was then determined using appropriate marginal energy costs and annual demand charges, which were also used to calculate annual energy displacement value and generation capacity value. 
SCE maintains a unity power factor correction policy at the distribution substation. PV with line-commutated inverters and WT with induction generators that require vars would incur a penalty. PV with line-commutated inverters and WT with induction generators were assumed to be designed for 0.9 power factor. Self-commuted PV or WT with synchronous generators or variable speed generators would not incur this penalty and possibly would obtain a benefit if appropriate utility var control were incorporated in its design. The cost of fixed or switched shunt capacitors for power factor correction for SCE was assumed to be $\$ 12 / \mathrm{kvar}$. In addition, on long rural lines with line voltage regulators, a $\$ 2000$ charge per regulator was assumed to upgrade the regulators to allow them to regulate voltage properly during potential backfeed conditions when distributed PV or WT is installed.

This study considers small PV and WT penetration levels compared with the total SCE system load. Thus, for this study, SCE supplied estimated future hourly incremental (marginal) energy values for summer and winter season on-peak, mid-peak, off-peak, and super off-peak time periods, which were used to calculate energy displacement value for PV and WT. In 1998, the incremental energy costs ranged from $49.1 \mathrm{mills} / \mathrm{kWh}$ during on-peak periods to $30 \mathrm{mills} / \mathrm{kWh}$ during super off-peak periods.

In this study, capacity rating for PV was determined by observing $\mathrm{kW}$ demand reduction during the summer peak load period. The daily load shape in per unit (p.u.) annual peak load for the SCE 1990 summer and winter peak days is shown in Fig.4.6. A capacity rating of $80 \%$ of the nameplate PV kW was used for fixed-orientation and $90 \%$ for two-axis tracking PV. A rating of $25 \%$ of the nameplate $\mathrm{kW}$ capacity was used for WT capacity rating, which is compatible with the capacity rating presently assigned to wind turbines by SCE.
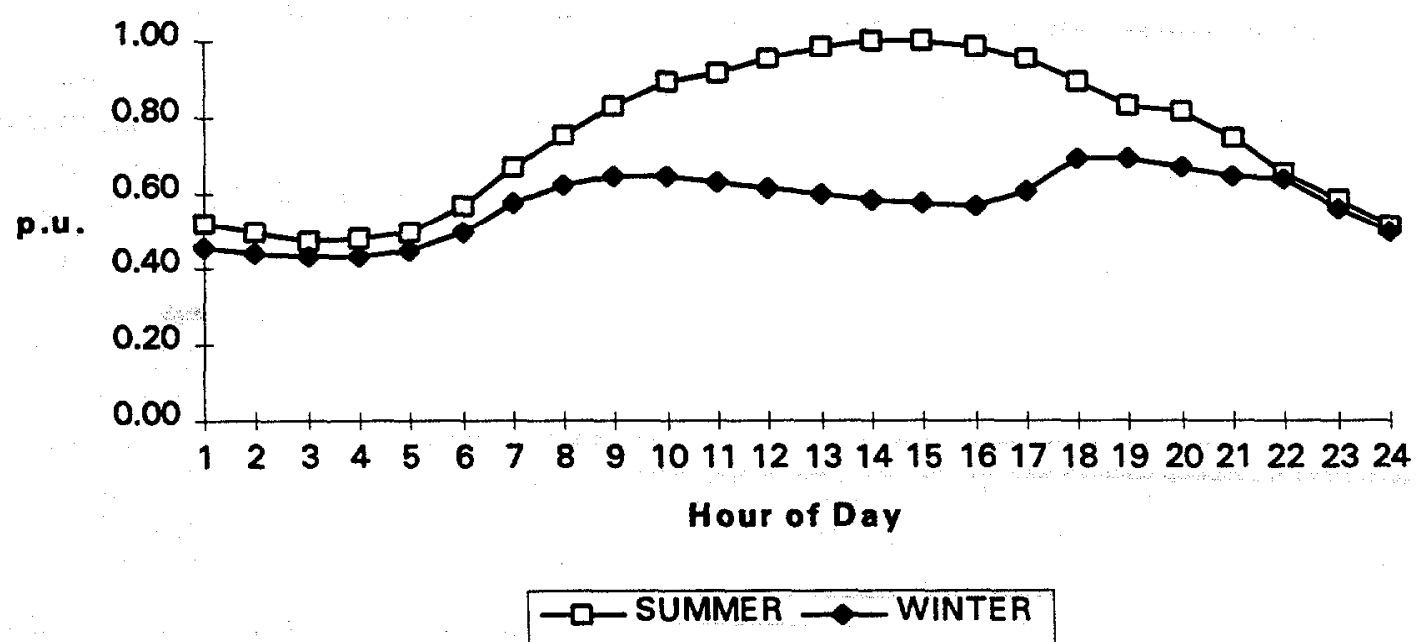

Fig. 4.6. SCE 1990 summer and winter peak day load shape.

SCE presently has a resource plan that extends out past the year 2000. Some of the planned new resource additions are renewable resources. For this study, it was assumed that potential distributed PV and WT additions could be considered part of these planned resources and be assigned full capacity value in 1998 , and thereafter.

The magnitude of the annual $\$ / \mathrm{kW}$-year capacity value was based on the projected annual cost of a combustion turbine, which in 1998 dollars is assumed to be $\$ 90.63 / \mathrm{kW}$-year. If PV and 
WT cannot be considered part of the planned renewables, the annual capacity value would have to be reduced until the mid 2000 s when SCE needs additional capacity to meet its $16 \%$ reserve criteria.

Transmission system benefits were derived from SCE-supplied general transmission system assumptions, used in integrated resource planning studies comparing demand side and supply side resources in early 1993. This study assumed a transmission marginal capital investment cost of $\$ 34.56 / \mathrm{kW}$-year in 1988 dollars as reported in $1993 \mathrm{ECAC}$ settlement. This value does include all those expenditures that would not be deferrable by distributed resources. The real deferred T\&D cost for distributed resources was not available when these analyses were conducted. Transmission system demand losses were assumed to be $3.3 \%$ of the annual peak load, and transmission system energy losses were assumed to be $2.6 \%$ of the energy displacement value.

Several potential environmental and other applicable benefits were included in this study. EPACT wind benefits were assumed to apply as discussed in Sect. 2 . An escalated $1.5 \mathrm{c} / \mathrm{kWh}$ benefit for the first 10 years of operation was applied for WT. In addition, environmental externality benefits were calculated, assuming a potential environmental externality value of about 11 mills/kWh in 1998 and escalating this value throughout the study period as discussed earlier. The environmental externality assumption is based on information provided by SCE using preliminary damage-based residual emission values presented in the California Energy Commission draft final 1992 Electricity Report. ${ }^{26}$ The environmental externality assumptions in this study are based on the best available data as of early 1993. The values are not final and are subject to change.

\subsection{BENEFIT-COST RESULTS}

\subsubsection{Suburban Distribution Systems}

Impacts on utility residential secondary systems are considered first. A representative SCE 120/240 V single-phase residential secondary system, shown in Fig. 4.7, was used for this study. A 50-kVA 6.9-kV/120-240 V distribution transformer serves 12 houses with air conditioning in an inland valley using $350 \mathrm{kcmil}, 4 / 0 \mathrm{awg}$ and $1 / 0 \mathrm{awg}$ underground conductors. The peak individual house load would typically be about $10 \mathrm{kVA}$, and the coincident load for the 12 houses together would generally be about $5 \mathrm{kVA}$ per house, totaling $60 \mathrm{kVA}$ at a power factor of approximately $85 \%$. The 50-kVA distribution transformer would be either pad-mounted or buried.

If the load on a residential secondary system increase, the 50-kVA transformer would be changed out at about $80 \mathrm{kVA}$ in SCE's inland valleys. The standard secondary system cables are sized to provide for adequate current carrying capability for significant larger amounts of residential load growth before change-out is required. Hence, from a practical perspective, only the distribution transformer is a candidate for replacement and deferral by the addition of PV in heavily loaded SCE residential secondary systems.

Figure 4.8 presents a representative SCE residential load shape during the summer peak day for a residential secondary system distribution transformer heavily loaded to $80 \mathrm{kVA}$ or about 68.4 $\mathrm{kW}$ at $85 \%$ power factor. The resulting peak day load shape is also presented assuming that $24 \mathrm{~kW}$ ( $2 \mathrm{~kW}$ per house) and $48 \mathrm{~kW}$ ( $4 \mathrm{~kW}$ peak hours) of fixed-orientation PV were installed on this system and are operating at the average hourly output during the month of June (Sect. 4.2). Comparing the daily residential load shape with corresponding PV hourly load shape, the PV output does not correlate well, as the residential load peaks too late in the day. However, there is some load reduction. When $24 \mathrm{~kW}$ of PV is installed, the peak load is reduced $7.2 \mathrm{~kW}$. When $48 \mathrm{~kW}$ of PV is installed, the peak load is reduced about $8.8 \mathrm{~kW}$. 


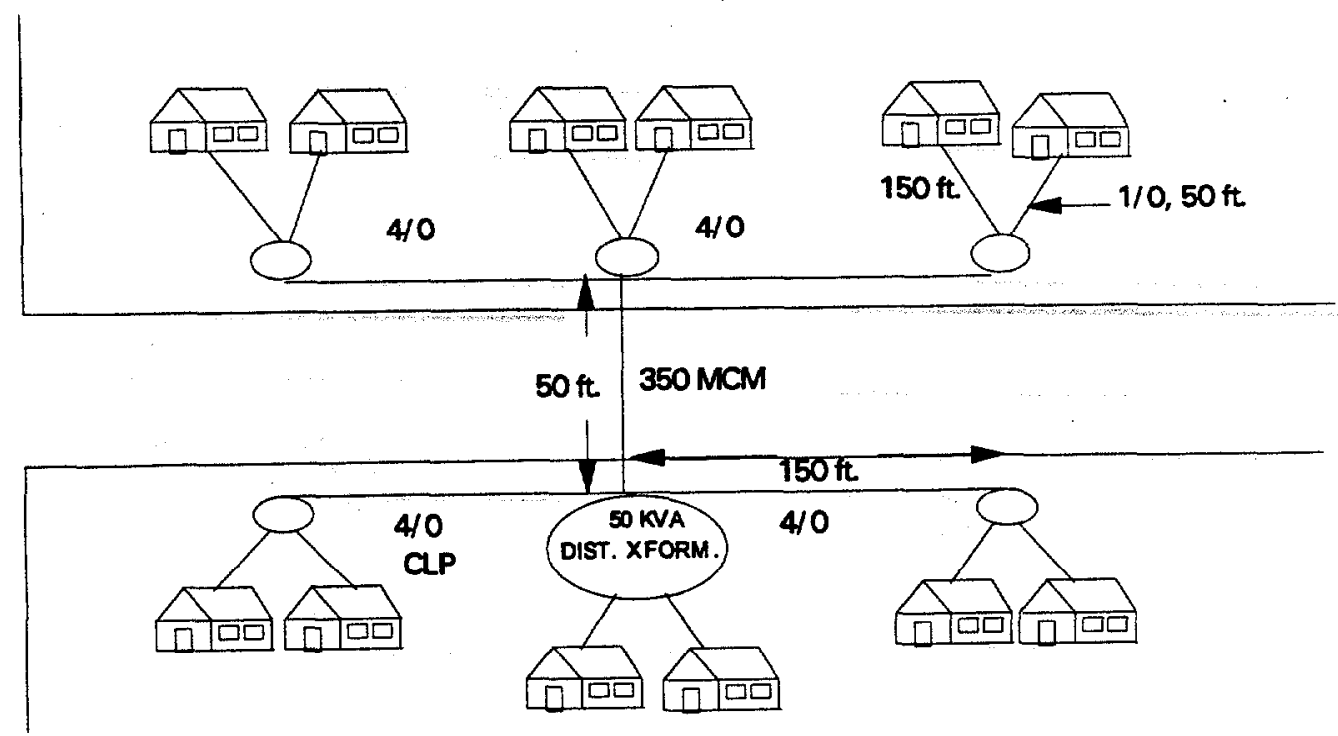

Fig. 4.7. Representative underground $120 / 240 \mathrm{~V}$ residential secondary system.

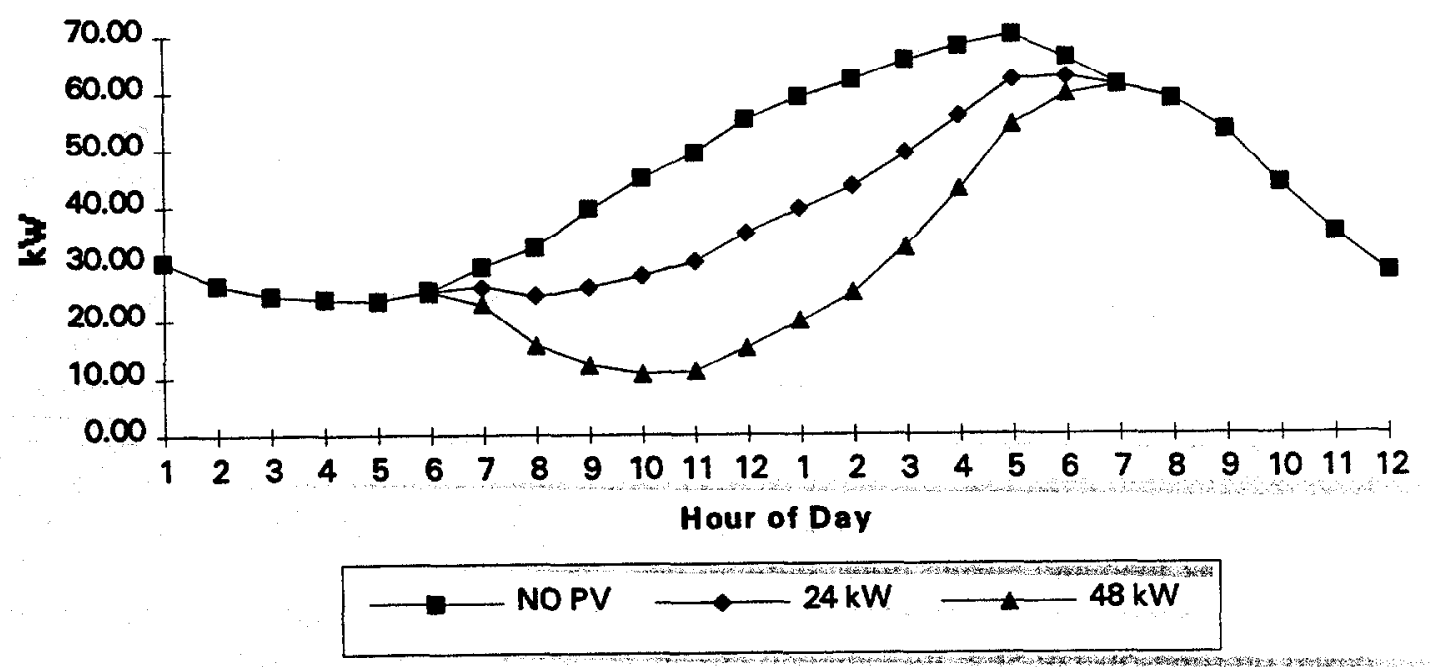

Fig. 4.8. Representative residential load shape during summer peak day.

The resulting potential SCE residential secondary system benefits in PWRR and $\$ / \mathrm{kW}$ for a PV penetration level of $24 \mathrm{~kW}$ are presented in Table 4.5. Distribution deferral facility benefits result from deferring the change-out of the 50-kVA distribution transformer for 5 years. The 
distribution deferral benefits are small, since the transformer change-out costs less than $\$ 2000$, (Sect. 4.3), and potential distribution primary system facility deferral benefits are not included. Assuming that the PV systems use less expensive line-commutated inverters results in only a small voltage and var control penalty.

Table 4.5. Benefit and cost resultsresidential secondary system, $24 \mathrm{~kW}$ fixed-orientation $\mathrm{PV}^{\mathrm{b}}$

\begin{tabular}{lcc}
\hline & PWRR $\$^{\mathbf{a}}$ & $\$ / \mathrm{kW}$ \\
\hline \multicolumn{1}{c}{ Cost } & & \\
Capital investment & 241,927 & 7,070 \\
Operating cost & 4,793 & 140 \\
Total cost & $\mathbf{2 4 6 , 7 1 9}$ & $\mathbf{7 , 2 1 0}$ \\
$\quad$ Benefits & & \\
Distribution facility deferral & 656 & 19 \\
Distribution losses & 933 & 27 \\
Voltage regulation & -126 & -4 \\
Transmission facility deferral & 9,638 & 282 \\
Transmission losses & 1305 & 38 \\
Generation capacity deferral & 21,337 & 624 \\
Energy displacement & 37,962 & 1,109 \\
Environmental externalities & 11,514 & 336 \\
Total benefits & $\mathbf{8 3 , 2 1 8}$ & $\mathbf{2 , 4 3 2}$ \\
& & \\
Benefit-to-cost ratio & $\mathbf{0 . 3 4}$ & \\
\hline
\end{tabular}

PWRR $=$ Present worth of revenue requirements

b As the result of economy and regulatory changes since the inception of this report, these values have changed. SCE should be contacted for more recent data.

Significant transmission deferral benefits occur even though the PV is installed at the distribution level. For this case and all of the following SCE cases, the PV kW capacity is derated to $80 \%$ of nameplate rating when determining transmission capacity benefits as well as generation capacity benefits. Peak transmission loading is assumed to occur in the early afternoon when the total SCE system peak load occurs (Fig. 4.5). Although PV output correlates well with the system peak, the $20 \%$ PV nameplate $\mathrm{kW}$ derating is compatible with the reduced PV output at annual system peak load and during other summer peak days.

A large energy displacement benefit is obtained. This benefit is nonsite-specific and is based on time-of-day SCE incremental energy costs and corresponding PV performance. A large generation capacity benefit applies based on the excellent correlation between PV output and SCE system peak load.

When environmental externalities are applied, the total PV benefits are $\$ 2432 / \mathrm{kW}$. This large benefit applies when only a few $\mathrm{kW}$ of PV are installed, and without considering potential distribution primary system benefits.

If the PV penetration is increased to $48 \mathrm{~kW}$, the distribution facility deferral benefits and loss benefits are each reduced about $\$ 7 / \mathrm{kW}$. And there is negligible impact on the other benefits. 
Current PV costs, including operation and maintenance (O\&M), for fixed-orientation PV are significantly higher than the combined benefits, resulting in a benefit-to-cost ratio of 0.34 . In this case, for PV to be a cost effective option, the PV capital investment and O\&M must be reduced to less than the $\$ 2432 / \mathrm{kW}$ benefits when potential distribution primary benefits are not included.

A representative suburban distribution three-phase primary system is shown in Fig. 4.9. The distribution substation transformer bank consists of two 69/12-kV 22.4-MVA transformers serving six $12-\mathrm{kV}$ feeders. Each $12-\mathrm{kV}$ feeder is assumed to be 4.5 miles long. As shown in the figure, each feeder contains a short 1000-kcmil underground getaway, and the rest of the line consists of standard 653-kcmil and 336-kcmil ACSR overhead construction. Single-phase and three-phase laterals are tapped off the three-phase main feeders to serve commercial and residential loads in the vicinity. Laterals are lightly loaded. A typical three-phase 1/0-lateral may serve about $1500 \mathrm{kVA}$ of commercial loads, and single-phase laterals may serve about seven distribution transformers with a total coincident peak load of about $350 \mathrm{kVA}$.

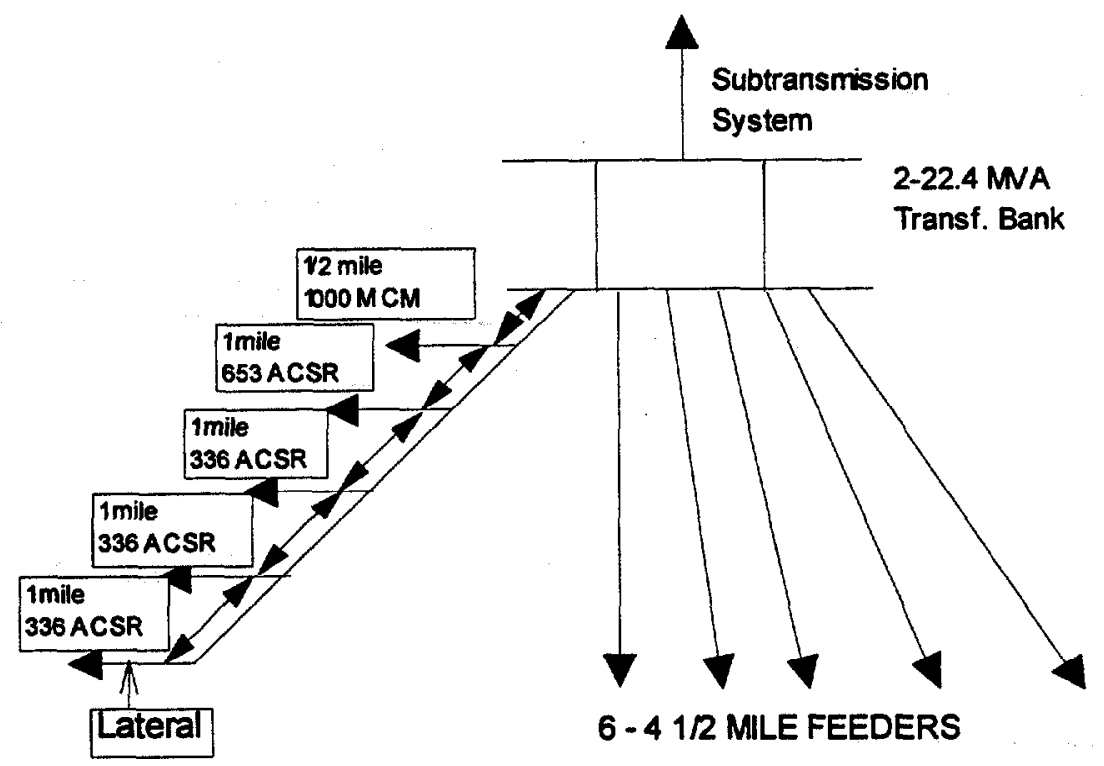

Fig. 4.9. Representative suburban distribution primary system.

A number of SCE commercial loads are strongly summer peaking with daily load shapes which correlate well with daily PV output characteristics. Examples of commercial loads with good correlation are small and large office buildings, small retail stores, and warehouses, (Fig. 4.10.) In addition, schools, colleges, health clinics, and hospital load shapes correlate well with PV output.

Figure 4.11 presents a representative commercial load shape during the summer peak day for a heavily loaded suburban distribution system containing six three-phase feeders serving small office buildings. The resulting substation transformer bank peak load is about $54 \mathrm{MW}$, and the peak feeder loads are about $9 \mathrm{MW}$ each. The resulting commercial summer peak day load shape is also presented, assuming that $10 \%(5.4 \mathrm{MW})$ through $50 \%(27 \mathrm{MW})$ penetration of fixed-orientation PV was distributed throughout the six feeders. Figures 4.12 and 4.13 present the same information except that in Fig. 4.12, the suburban distribution system serves a mix of 50\% commercial and $50 \%$ residential loads, and in Fig. 4.13, the suburban distribution system serves residential loads. 
Figure 4.14 shows the resulting suburban distribution substation peak load reduction for various levels of PV penetration, and mixes of commercial and residential loads served. Since PV output correlates well with SCE's commercial load shape, it is the best PV application for the full range of PV penetration, and the residential load shape is the worst. However, for a 50-50 mixed commercial load shape, the first $10 \%$ PV penetration results in practically the same peak load reduction as the $100 \%$ commercial load shape. Hence, on a distribution system serving mixed commercial and residential loads, the first $10 \%$ of PV penetration can be installed on the residential secondary system as well as on commercial buildings and still obtain large distribution system peak reduction at the distribution primary level.

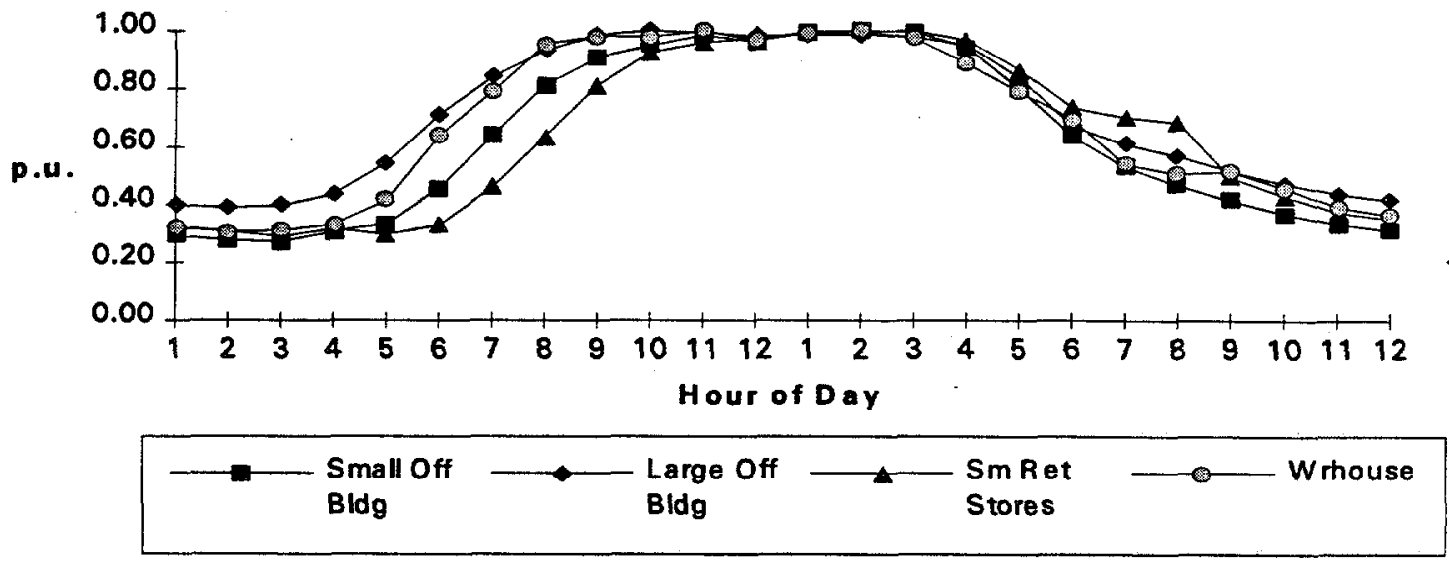

Fig. 4.10. Example of commercial loads which correlate nicely with PV output.

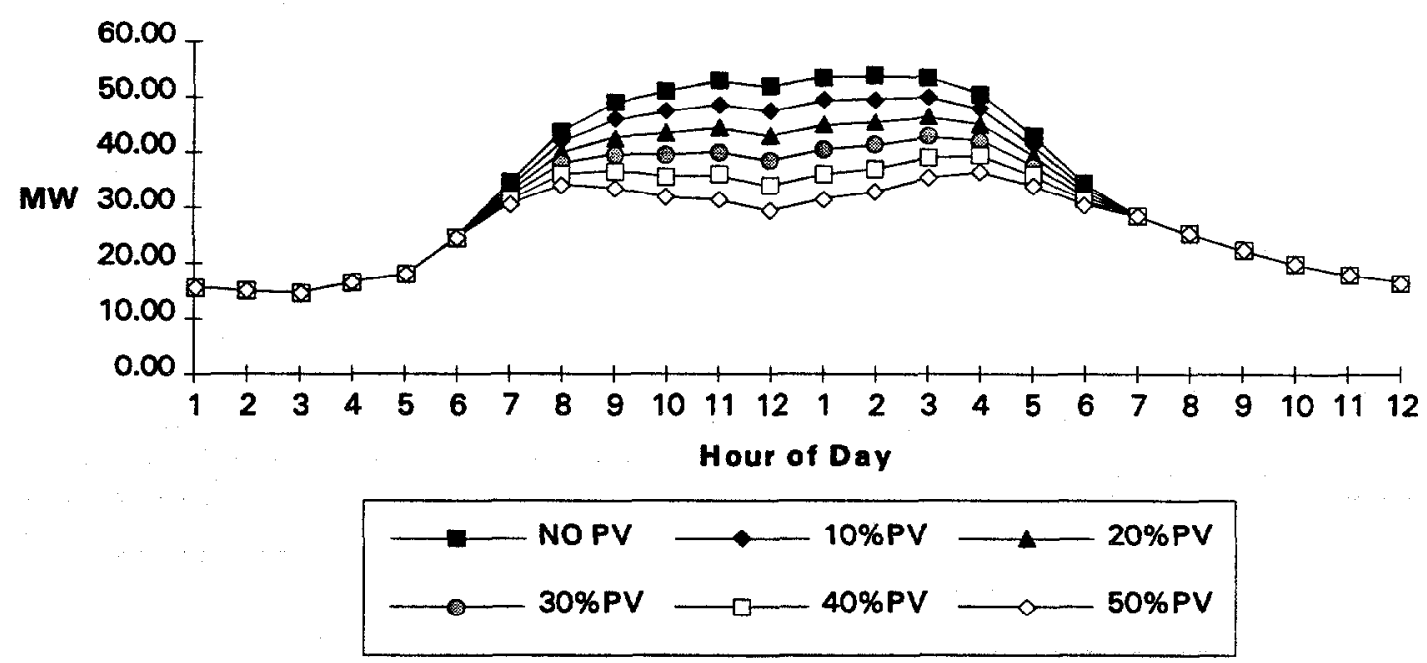

Fig. 4.11. PV impact on summer peak for commercial loads. 


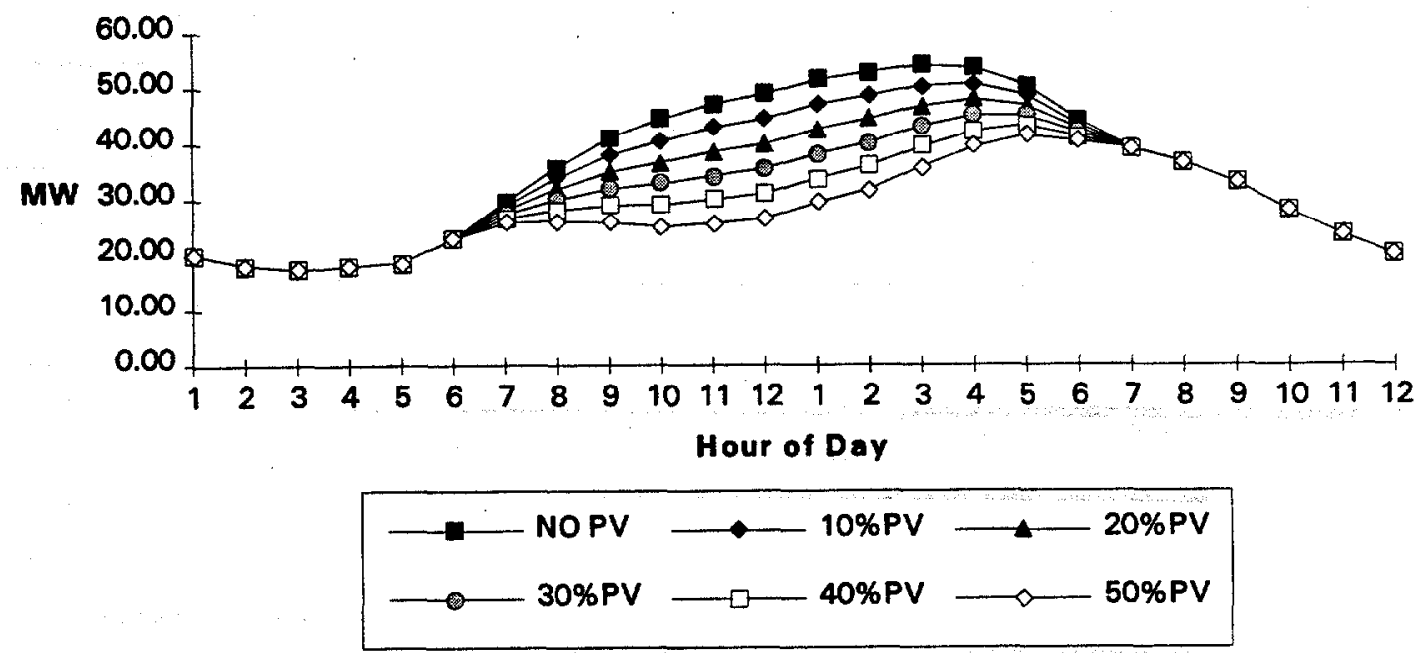

Fig. 4.12. PV impact on summer peak for mixed commercial and residential loads.
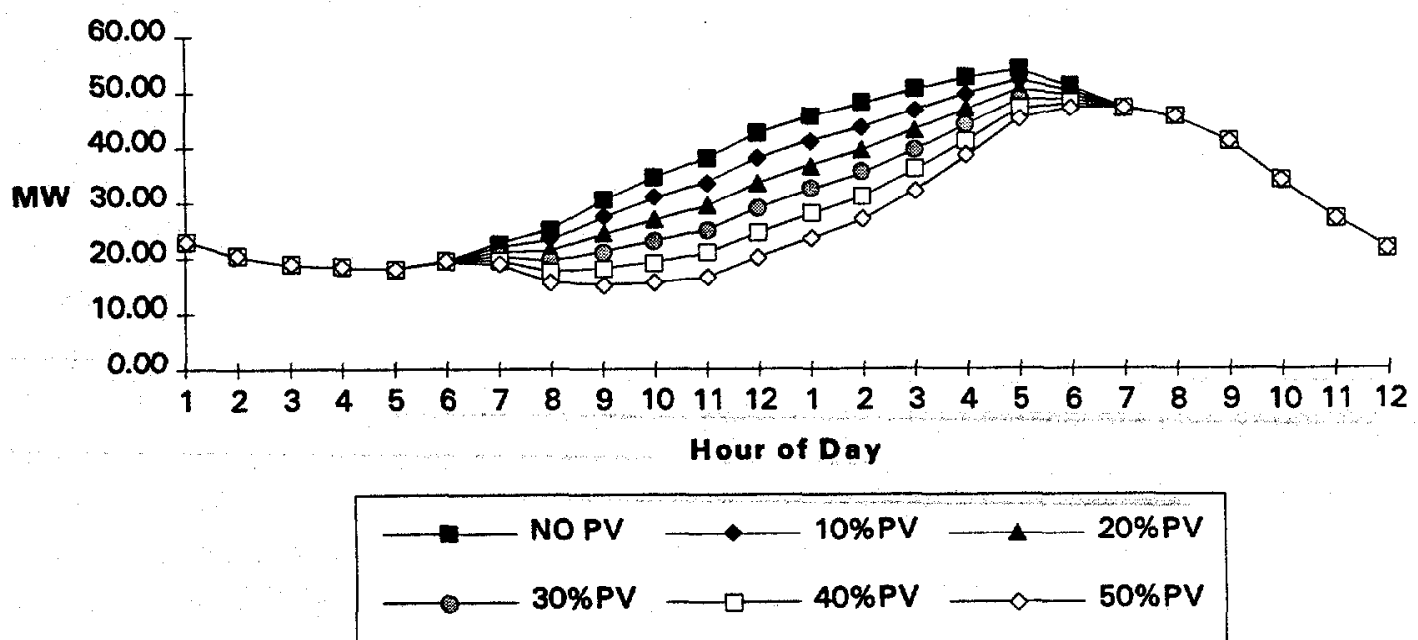

Fig. 4.13. PV impact on summer peak for residential loads. 


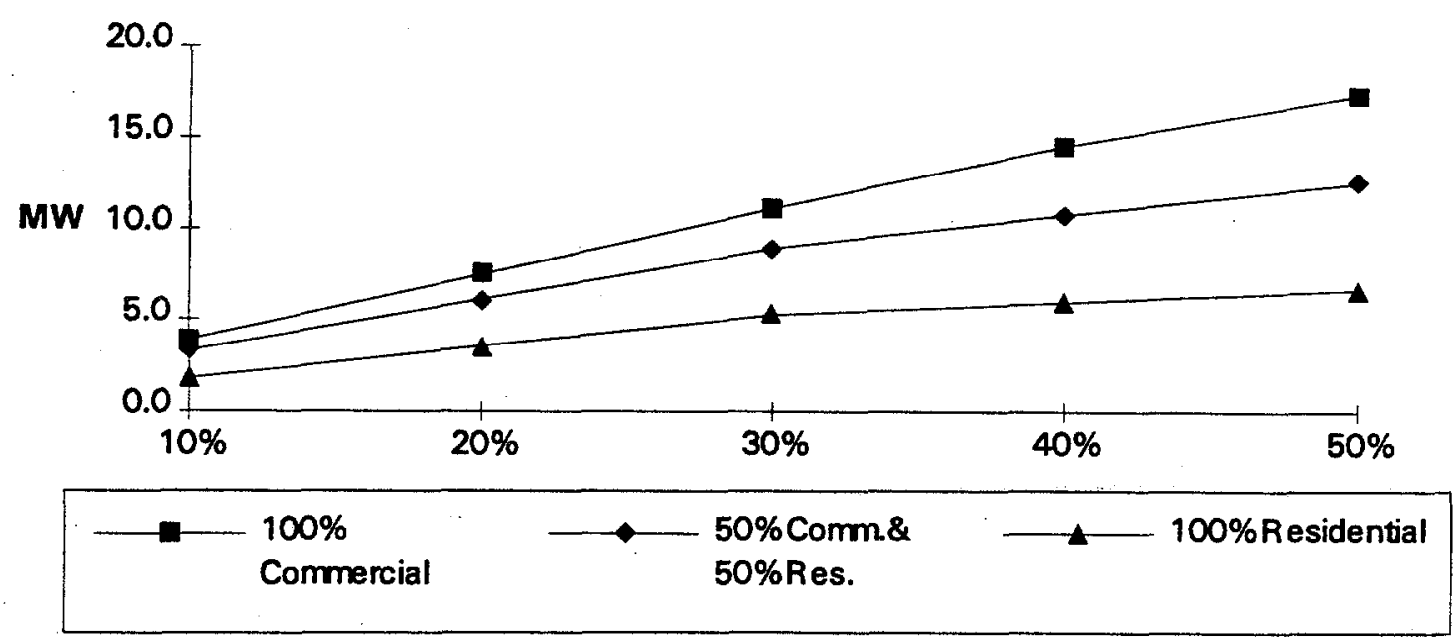

Fig. 4.14. Magnitude of summer peak reduction for various load shapes.

Assuming that the representative heavily loaded suburban distribution system annual peak load grows at $2 \%$ per year, similar to SCE's projected total system load growth rate, $10 \%$ fixedorientation PV penetration can defer the addition of a third 22.4-MVA transformer and associated feeder additions for 3 years if the load shape is commercial or mixed commercial and residential, and 2 years if the load shape is residential. These distribution facilities are significantly more expensive than secondary system distribution transformers and result in much larger distribution system deferral benefits.

Table 4.6 presents the resulting potential benefits and costs for a heavily loaded suburban distribution system with $10 \%$ PV penetration of distributed fixed-orientation PV and a mixed commercial and residential load shape. For the $100 \%$ commercial load shape and the mixed commercial and residential load shape, the total distribution benefits are essentially the same. For the residential load shape, distribution facility deferral benefits are reduced $\$ 58 / \mathrm{kW}$. Generation, transmission, and environmental benefits are similar, and the fixed PV costs remain the same, on a per $\mathrm{kW}$ basis, for commercial and residential load shapes.

In this case, combined PV benefits are $\$ 2628 / \mathrm{kW}$ for $10 \% \mathrm{PV}$ penetration resulting in a benefit-to-cost ratio of 0.36 . When potential distribution primary and secondary benefits are considered, distributed fixed orientation (roof top) PV is expected to be cost-effective on the SCE system when the PV capital investment plus O\&M is less than the combined $\$ 2628 / \mathrm{kW}$ benefits, assuming average system peak load growth of about $2 \%$ per year.

For a slow growing, heavily loaded suburban distribution system, distribution system benefits can be increased significantly. Assuming the mixed 50\% commercial-50\% residential load shape and $10 \%$ fixed-orientation PV penetration, combined system benefits can be increased from $\$ 2628 / \mathrm{kW}$ to $\$ 2775 / \mathrm{kW}$ if the suburban distribution load growth is $1 \%$ per year rather than $2 \%$ per year, and to $\$ 2997 / \mathrm{kW}$ if the load growth is $0.5 \%$ per year. 
Table 4.6. Benefit and cost results-10\% PV penetration in heavily loaded SCE suburban distribution system, distributed fixed-orientation $P^{b}$

\begin{tabular}{lcc}
\hline & PWRR \$ & \$/kW \\
\hline \multicolumn{1}{c}{ Cost } & & \\
\hline Capital investment & $54,591,664$ & 7,070 \\
Operating cost & $1,081,482$ & 140 \\
Total cost & $\mathbf{5 5 , 6 7 3 , 1 4 6}$ & $\mathbf{7 , 2 1 0}$ \\
$\quad$ Benefits & & \\
Distribution facility deferral & $1,439,282$ & 186 \\
Distribution losses & 407,947 & 53 \\
Voltage regulation & $-28,356$ & -4 \\
Transmission facility deferral & $2,174,869$ & 282 \\
Transmission losses & 294,591 & 38 \\
Generation capacity deferral & $4,814,671$ & 624 \\
Energy displacement & $\mathbf{8 , 5 7 0 , 0 1 2}$ & 1,110 \\
Environmental externalities & $2,619,607$ & 339 \\
Total benefits & $\mathbf{2 0 , 2 9 2 , 6 2 3}$ & $\mathbf{2 , 6 2 8}$ \\
& & \\
Benefit-to-cost ratio & $\mathbf{0 . 3 6}$ & \\
\hline PWRR = Present worth of revenue requirements & \\
As the result of economy and regulatory changes since the inception of this report, these values have \\
changed. SCE should be contacted for more recent data.
\end{tabular}

If the distributed PV is assumed to be added modularly during the distribution facility deferral period, the resulting combined benefits can be larger and the PV costs can be lower. For $2 \%$ load growth, the PV can be added over 3 years, resulting in a total combined benefit increase to $\$ 2652 / \mathrm{kW}$ and a total reduction in PV costs to $\$ 7173 / \mathrm{kW}$. For $1 \%$ load growth, the PV can be added over 6 years, resulting in a total combined benefit increase to $\$ 2856 / \mathrm{kW}$, and a total reduction in PV costs to $\$ 7112 / \mathrm{kW}$. For $0.5 \%$ load growth, the PV can be added over 12 years, resulting in a total combined benefit increase to $\$ 3237 / \mathrm{kW}$ and a total reduction in PV costs to $\$ 6960 / \mathrm{kW}$. In this best slow distribution growth/modular PV addition case, the benefit-cost ratio is 0.47 .

Large MW-scale PV can be installed at the end of feeders in lieu of adding distributed PV. This may require up to about 10 acres of land per MW of PV installed, which may not be available in many suburban areas. Large PV plants can be fixed-orientation, or single- or two-axis tracking. To determine the relative performance, a two-axis tracking case was evaluated for the mixed commercial and residential load shape and with $10 \%$ PV penetration (Table 4.7). For two-axis tracking, about $\$ 700 / \mathrm{kW}$ more in benefits was obtained compared with fixed-orientation PV. These larger benefits reflected the increase in PV plant capacity factor from $25 \%$ to $33 \%$. In addition, the two-axis plant was assigned a capacity rating of $90 \%$ of nameplate $\mathrm{kW}$, as opposed to the $80 \%$ rating assigned to fixed-orientation PV. On the other hand, the PV plant was assumed to cost $\$ 1200 / \mathrm{kW}$ more than a similar size fixed-orientation PV plant. This additional cost is significantly more than the additional $\$ 700 / \mathrm{kW}$ benefit obtained. Although the benefit-to-cost ratio is higher for the twoaxis PV plant, the additional benefits do not justify the significantly larger additional cost to install a two-axis tracking plant assumed in this study. 
Table 4.7. Benefit and cost results-10\% PV penetration in heavily loaded suburban distribution system, large two-axis tracking $\mathbf{P V}^{\mathbf{b}}$

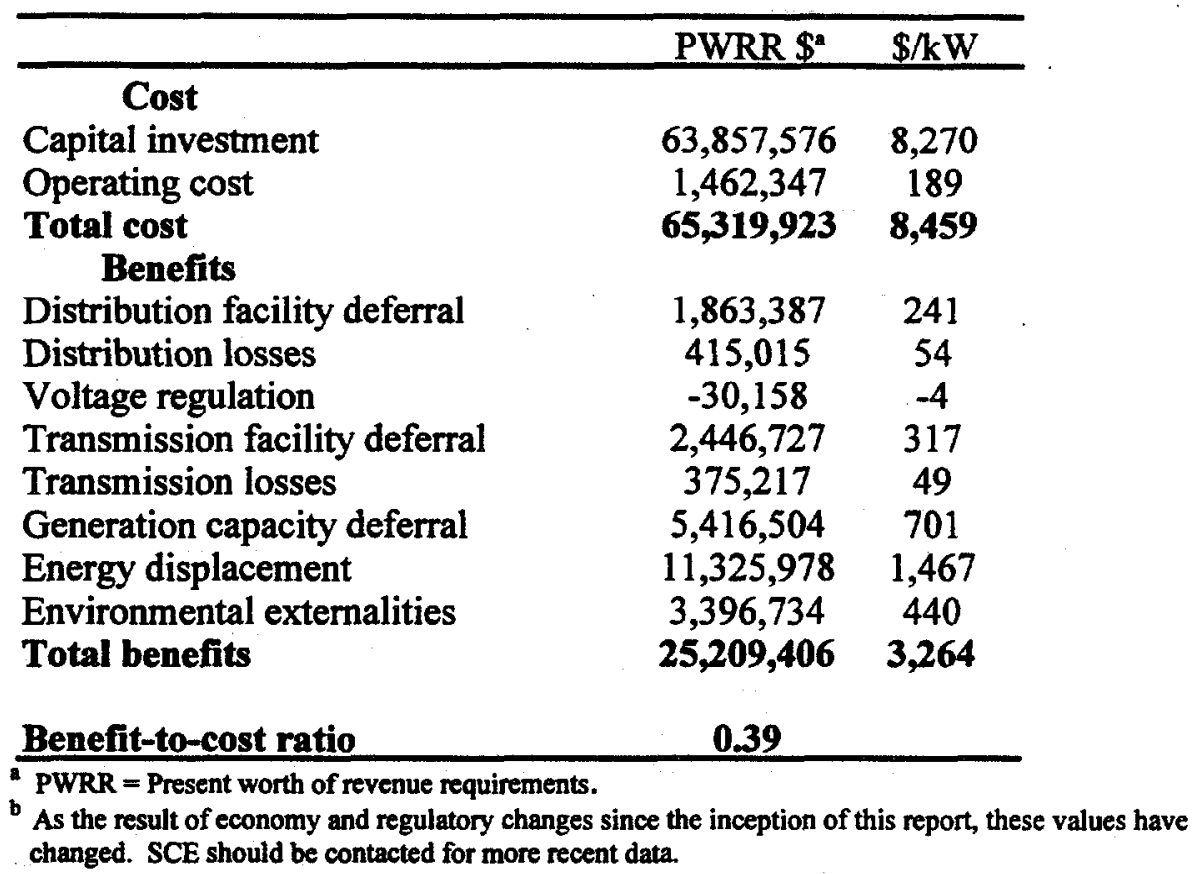

\subsubsection{Rural Distribution Systems}

A representative SCE rural distribution system is shown in Fig. 4.15. The distribution substation consists of a 69/12-kV 15-MVA transformer bank serving four feeders. The rural feeders generally are overhead construction and range from about 5 to 10 miles in length. Much of the existing SCE rural feeder mileage may consist of copper conductors.

Figure 4.16 presents a representative agricultural and water pumping load shape for the summer peak day, as well as for average weekdays and weekend days in the summer, which is representative of many SCE rural loads. There is some limited potential for PV to reduce peak loads for this rural load shape because of the large night loads. WT is not expected to reduce rural peak loads, based on the large hourly fluctuations in WT output during the summer months.

In this study, a 2-MW PV plant and $2 \mathrm{MW}$ of WT were assumed to be installed on this heavily loaded representative rural distribution system near the end of the feeders, assuming the system has the agricultural and water pumping load shape discussed above. Both fixed orientation and two-axis tracking PV were evaluated, assuming the same output characteristics used for the suburban distribution. The WT output was based on the San Gorgonio WT performance data.

Adding either a fixed-orientation or two-axis tracking 2-MW PV system reduces the annual rural system peak load by about $1 \mathrm{MW}$. Adding the PV can defer the upgrade of the 15-kVA transformer bank to two 14-kVA transformers by 2 years. With this load shape, adding additional PV capacity will not provide any additional peak reduction. 


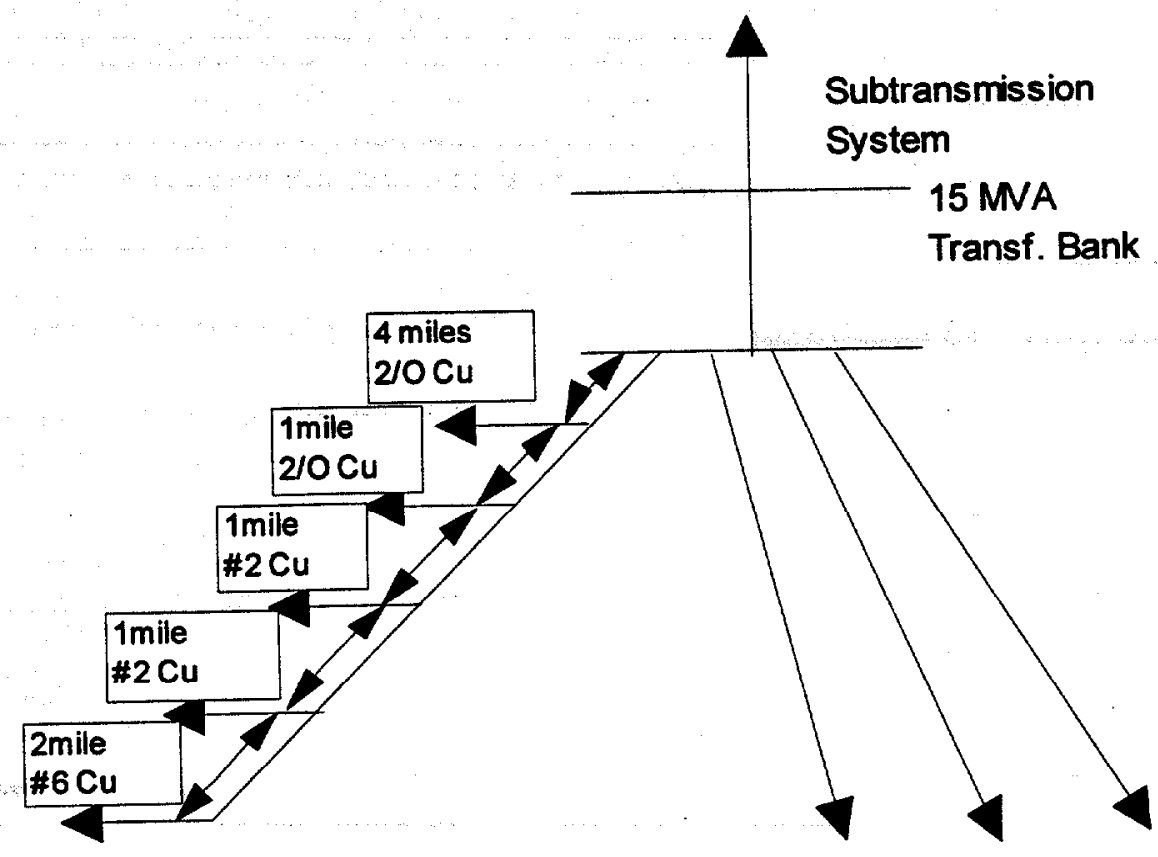

3 - 10 MILE FEEDERS

Fig. 4.15. Representative rural distribution system.

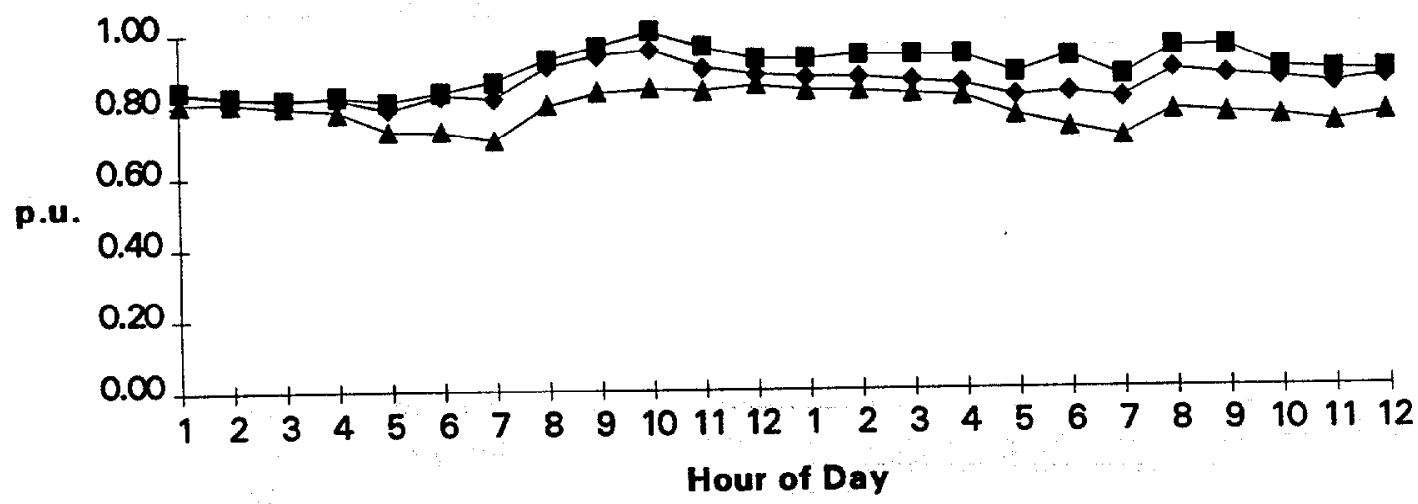

Fig. 4.16. Rural agricultural and water pumping load shape. 
The resulting potential benefits and costs associated with the addition of $2 \mathrm{MW}$ of fixedorientation and two-axis tracking PV are presented in Tables 4.8 and 4.9 respectively. Total combined benefits are $\$ 2803 / \mathrm{kW}$ for fixed-orientation PV and $\$ 3435 / \mathrm{kW}$ for two-axis tracking PV. The resulting distribution system benefits can be large for rural PV applications, as well as for suburban applications. In particular, the distribution loss benefits can be significantly larger for rural than for suburban PV applications because of the longer rural feeders. Generation, transmission, and environmental benefits are the same for rural as for the suburban distribution PV applications on a $\$ / \mathrm{kW}$ basis. PV costs are also assumed to be the same for both rural and suburban PV applications in this study. However, land costs may be significantly less for MW-scale PV installed in rural areas.

Table 4.10 presents the benefits and costs results for a 2-MW windfarm installed near the end of a rural feeder. Total combined benefits are $\$ 2936 / \mathrm{kW}$, and WT capital investment plus O\&M was only $\$ 1272 / \mathrm{kW}$.

Because of the hourly fluctuations in WT output, no correlation with distribution system peak was observed. Hence, for wind, no distribution facility deferral is allowed. However, large distribution loss benefits were attained.

Transmission benefits associated with WT were relatively low compared with PV because of the relatively low WT capacity rating, which is $25 \%$ of nameplate $\mathrm{kW}$.

Energy displacement value and environmental benefits for WT are large compared with PV because of the high $42.3 \%$ WT capacity factor. Generation capacity value is smaller, again because of the low WT capacity rating. The EPACT tax credit benefits are significant for WT.

The resulting WT benefit-to-cost ratio of 2.31 is significantly above 1.0. Hence, WT is clearly a cost-effective alternative for rural SCE distribution system applications.

Table 4.8. Benefits and costs-2-MW PV at end of rural feeder, fixed-orientation PV

\begin{tabular}{lcc}
\hline & PWRR \$a & $\$ / \mathrm{kW}$ \\
\hline \multicolumn{1}{c}{ Cost } & & \\
Capital investment & $20,160,557$ & 7,070 \\
Operating cost & 399,389 & 140 \\
Total cost & $\mathbf{2 0 , 5 5 9 , 9 4 6}$ & $\mathbf{7 , 2 1 0}$ \\
$\quad$ Benefits & & \\
Distribution facility deferral & 756,908 & 265 \\
Distribution losses & 417,197 & 146 \\
Voltage regulation & $-12,274$ & -4 \\
Transmission facility deferral & $\mathbf{8 0 3 , 1 7 3}$ & 282 \\
Transmission losses & 108,727 & 38 \\
Generation capacity deferral & $1,778,045$ & 624 \\
Energy displacement & $3,162,386$ & 1,109 \\
Environmental externalities & $\mathbf{9 8 0 , 0 3 3}$ & 344 \\
Total benefits & $\mathbf{7 , 9 9 4 , 1 9 6}$ & $\mathbf{2 , 8 0 3}$ \\
& & \\
Benefit-to-cost ratio & $\mathbf{0 . 3 9}$ & \\
\hline
\end{tabular}

PWRR = Present worth of revenue requirements.

b As the result of economy and regulatory changes since the inception of this report, these values have changed. SCE should be contacted for more recent data. 
Table 4.9. Benefits and costs-2-MW PV at end of rural feeder, two-axis tracking $\mathbf{P V}^{\mathrm{b}}$

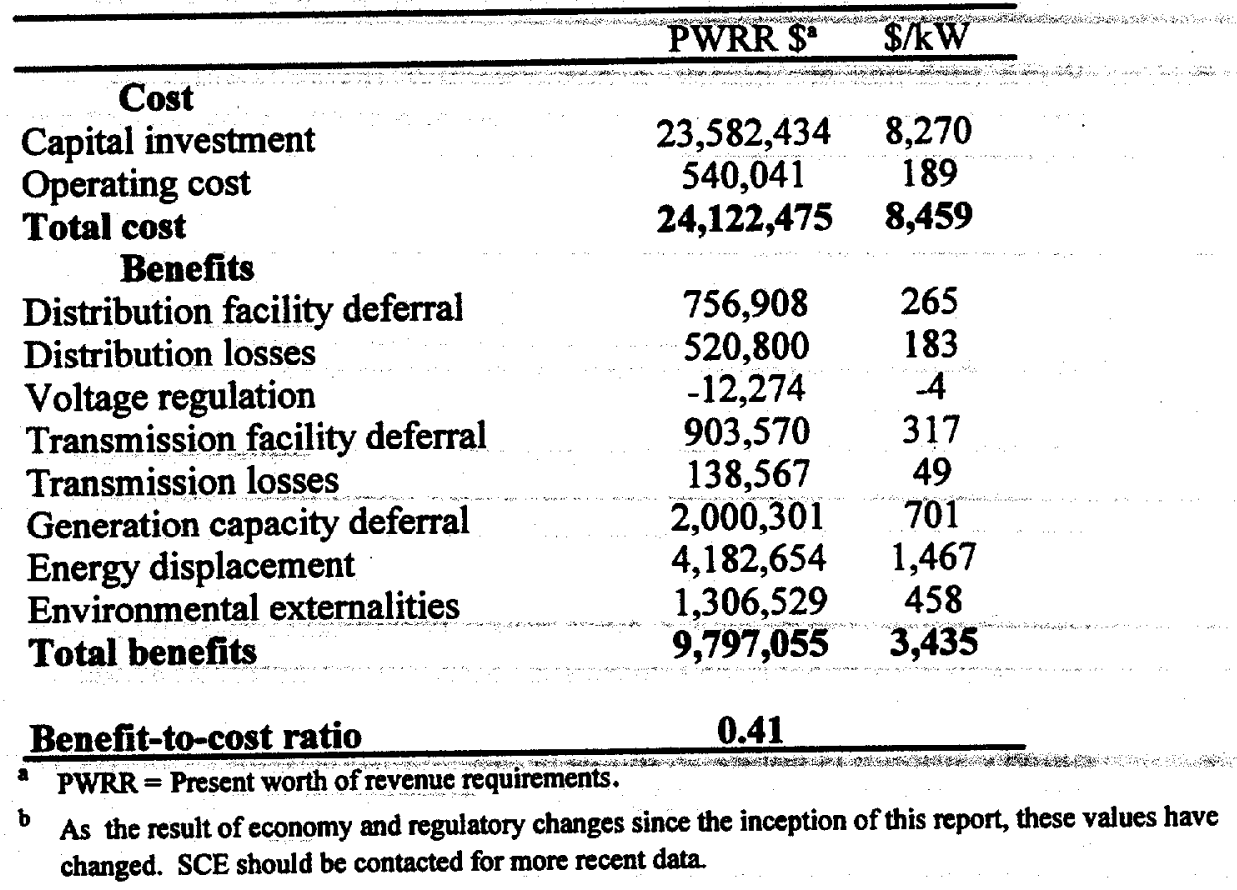

Table 4.10. Benefits and costs-2-MW windfarm at the end of rural feeder

\begin{tabular}{|c|c|c|}
\hline & PWRR \$ & $\$ / \mathbf{k W}$ \\
\hline $\begin{array}{l}\quad \text { Cost } \\
\text { Capital investment } \\
\text { Operating cost } \\
\text { Total cost } \\
\quad \text { Benefits } \\
\text { Distribution losses } \\
\text { Voltage regulation } \\
\text { Transmission facility deferral } \\
\text { Transmission losses } \\
\text { Generation capacity deferral } \\
\text { Energy displacement } \\
\text { Environmental externalities } \\
\text { Energy Policy Act } \\
\text { Total benefits }\end{array}$ & $\begin{array}{c}2,888,634 \\
738,127 \\
3,626,761 \\
617,823 \\
-12,274 \\
250,992 \\
125,398 \\
555,639 \\
4,504,447 \\
1,482,729 \\
848,180 \\
8,372,935\end{array}$ & $\begin{array}{c}1,013 \\
259 \\
1,272 \\
217 \\
-4 \\
88 \\
44 \\
195 \\
1,580 \\
520 \\
297 \\
2,936\end{array}$ \\
\hline Benefit-to-Cost Ratio & 2.31 & \\
\hline
\end{tabular}




\subsection{CASE STUDY CONCLUSIONS AND OBSERVATIONS}

Some conclusions and observations resulting from this case study are as follows:

- Wind turbines are clearly a cost-effective resource for rural SCE distribution system applications at good wind sites. Case study benefits approach $\$ 3000 / \mathrm{kW}$, and the benefitcost ratio exceeds 2.3 .

- Distributed fixed-orientation PV installed in slow growing SCE suburban distribution systems can obtain benefits approaching $\$ 3300 / \mathrm{kW}$ when the PV is installed modularly, resulting in a benefit-cost ratio of 0.47 .

- PV output has excellent time-of-day correlation with SCE summer peak day commercial load shapes, as well as with the total SCE system load. SCE summer peak day residential loads peak too late in the day for good PV correlation.

- Distributed or MW-scale PV applications will obtain the highest benefits when installed in SCE distribution systems containing primarily commercial loads.

- Battery storage is not expected to be needed to back up PV to obtain distribution deferral benefits, because of the excellent time-of-day correlation between PV output and SCE load shape.

- On mixed SCE commercial and residential distribution systems, distributed PV can be installed on residential roof tops and obtain essentially the same high benefits as commercial applications for the first $10 \%$ PV penetration.

- MW-scale PV plants installed near the end of SCE rural feeders can obtain benefits approaching $\$ 2800 / \mathrm{kW}$ for fixed-orientation and $\$ 3400 / \mathrm{kW}$ for two-axis tracking.

- Two-axis and single-axis tracking increases both PV benefits and costs. For the assumptions in the SCE case study, benefits increase about $\$ 700 / \mathrm{kW}$, while PV capital investment for two-axis tracking increases $\$ 1200 / \mathrm{kW}$. Unless the incremental benefits exceed the incremental costs, tracking may not be the most economic PV design, even though the resulting benefit-to-cost ratio is higher.

- If the $10 \%$ PV EPACT investment tax credit was available to SCE, the PV benefits would increase about $\$ 500 / \mathrm{kW}$ for the assumptions in this study.

- PV capital investment plus O\&M must be less than the previously cited benefits before PV becomes an economically viable resource for the studied applications. 
- The information contained in this report was the result of available information from the consultant and SCE staff in 1992 and early 1993. These data are changing continuously. Updated data on gas price load forecast, CT full value, incremental energy value (IER), environmental values and other pertinent information which will affect the values of distributed resources and results of this case study should be obtained from SCE. This report was prepared by ZECO as an account of a subcontract to the Oak Ridge National Laboratory. SCE makes no warranty or representation whatsoever expressed or implied with respect to the use of any information, method, process, or similar item disclosed in this report. 


\section{GREEN MOUNTAIN POWER}

This section presents the results of the GMP case study. GMP's distribution system and design practices are described. Representative PV and WT performance characteristics in the GMP service area are described. Various GMP benefits quantified are described, and pertinent assumptions are discussed. The case study results are then presented and summarized for the GMP system.

\subsection{DISTRIBUTION SYSTEM DESCRIPTION AND DESIGN PRACTICES}

Transmission service within Vermont is provided by a system owned and operated by all Vermont utilities jointly in proportion to their size. Although several voltage levels exist, we have used $34.5 \mathrm{kV}$ as being representative for GMP. This system is subject to extended low-voltage (as low as $28 \mathrm{kV}$ ) during some operating contingencies.

Vermont utilities are closely regulated by the state under rules that make expansion difficult. Thus, GMP's efforts are concentrated on making its existing systems suffice wherever possible.

System peak loads in Vermont occur during the coldest winter periods.

GMP uses several distribution voltages from $4 \mathrm{kV}$ through $13.8 \mathrm{kV}$. We have used $12.47 \mathrm{kV}$ as most representative throughout their service territory.

GMP's basic substation design includes at least one three-phase transformer. Representative sizes range up to $22 \mathrm{MVA}$, equipped with LTC. Most substations are equipped with supervisory control and data acquisition (SCADA) systems. Many substations also provide service to other utilities, such as local municipalities, as well as to GMP loads. Separate transformers and metering are used where these loads exist. The company designs for a maximum short circuit duty not to exceed 10,000 A. Available duties seldom exceed 7,000 A. GMP designs its substations for normal peak loading of $100 \%$ of nameplate rating. Emergency operating limits are not specified, since generally circuit flexibility has not existed so that line sections could be transferred from one substation to another. A program is underway to install a number of circuit ties so that future transfers will be possible.

Typical peak circuit loads are in the area of 7 MVA, although some circuits are loaded as heavily as 11 MVA.

Construction is in conformance with the National Electric Safety Code. Distribution system construction is almost entirely overhead. Many new residential areas within incorporated cities are provided with underground service, often installed by the developers to GMP's specifications. Standard overhead conductor sizes are $1 / 0$ and $336.4 \mathrm{kcmil} \mathrm{ACSR}$ and $394.5 \mathrm{kcmil} \mathrm{AAC}$. Standard underground cable sizes are \#2,1/0 and $750 \mathrm{kcmil} \mathrm{A1}$ (using 220 -mil crosslinked polyethylene insulation). Pad-mounted transformers and air-insulated pad-mounted switches are used where lines are underground.

The uncorrected power factor of the distribution system is variable. Some shunt capacitors are used for power factor correction. Where switched capacitors are used, straight voltage controls are the rule. GMP does not have an established power factor correction goal.

Overhead distribution transformers are targeted for initial loading to $40-45 \%$ of nameplate. Underground transformers are targeted for $70 \%$ loading on the basis that underground-served homes have less likelihood for growth. Most distribution transformers are purchased without taps. Most growth on the GMP system comes from commercial loads rather than residential.

A summary of GMP's distribution design practices is presented in Table 5.1. 
Table 5.1. GMP distribution design practices

\section{Substation:}

Subtransmission voltage

Minimum number of incoming lines

Standard transformer size

Normal operating limit

Emergency operating limit

Standard transformer bank size

Minimum number of transformers

Maximum substation size

Voltage regulation

Maximum short circuit duty

Substation capacitors?

Peak load characteristic

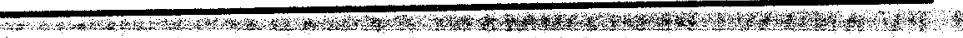

\section{Circuit design:}

Voltage

Power factor correction goal

Comply with NESC?

Peak design load

Ties with adjacent circuits?

Field voltage regulation practices

Tapped transformers?

Design transformer loading

Average transformer loading

Design voltage criteria

Design voltage drop

Flicker voltage drop criteria

\section{$34.5 \mathrm{kV}$}

1

none

$100 \%$

not specified

22 MVA (and smaller)

1

not specified

LTC

7,000-10,000 A maximum

no

winter

Circuit protection practices:

Extensive use of field reclosers?

Fused laterals?

$12.47 \mathrm{kV}$

not specified

yes

7 MVA typical; 11 MVA maximum

no

voltage regulators

no

to $100 \%$ of nameplate

$25-40 \%$

$114-126 \mathrm{~V}$

not specified

Overhead lines:

Maximum number of circuits per pole line

Typical primary conductor sizes

Secondary \& service conductor sizes

yes

yes

Underground lines:

Installation method, residential

Installation method, feeders

Typical primary conductor sizes

Secondary \& service conductor sizes

Primary cable insulation

Switching equipment

\section{2}

1/0, 336.4 ACSR, 394.5 AAC

$\# 6, \# 2,1 / 0,3 / 0$

Unique concerns:

state development and

environmental restrictions;

one statewide transmission system. 


\subsection{PV AND WT PERFORMANCE CHARACTERISTICS}

Per-kW PV performance assumptions for the GMP case study were based on SOLMET data for Burlington, Vermont. This site is representative of expected solar insolation in the GMP service area. Table 5.2 presents a summary of expected annual performance for a $10 \mathrm{~m}^{2} \mathrm{PV}$ system rated at $1 \mathrm{~kW}$, assuming fixed-orientation at the site latitude of $44.5^{\circ}$ and assuming two-axis tracking. The fixed-orientation PV system capacity factor is about $16.4 \%$, and the capacity factor of the two-axis tracking PV system is about $21.2 \%$. Monthly performance for the two PV system configurations is presented in Fig. 5.1.

Table 5.2. Ten square meter, 1-kW PV at Burlington, Vermont

\begin{tabular}{lc}
\hline Configuration & $\begin{array}{c}\text { Annual capacity } \\
\text { Factor (\%) }\end{array}$ \\
\hline Fixed tilt $44.5^{\circ}$ & 16.4 \\
Two-axis tracking & 21.2 \\
\hline
\end{tabular}

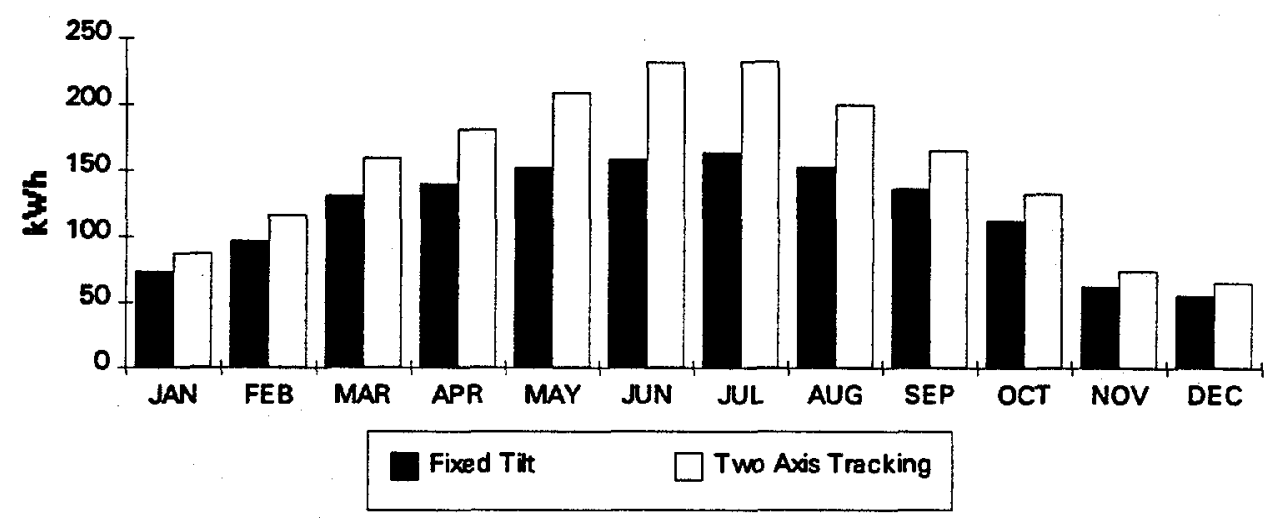

Fig. 5.1. PV system monthly performance per $k W$. 
Figure 5.2 shows the hourly performance for the fixed-orientation 1-kW PV system for the peak solar insolation day and average solar insolation day in April, June, and December. In April, when the solar insolation is high, the PV system can attain 1-kW output. In June and December, during high solar insolation periods, the PV can provide fairly high levels of $\mathrm{kW}$ output. However, the average monthly output on all 3 days is relatively low compared with Southern California. It seems clear from this information that, much of the time, PV output will not correlate with system daily peak loads in all seasons of the year. The average daily performance is especially poor during the winter, which is GMP's peak load season.
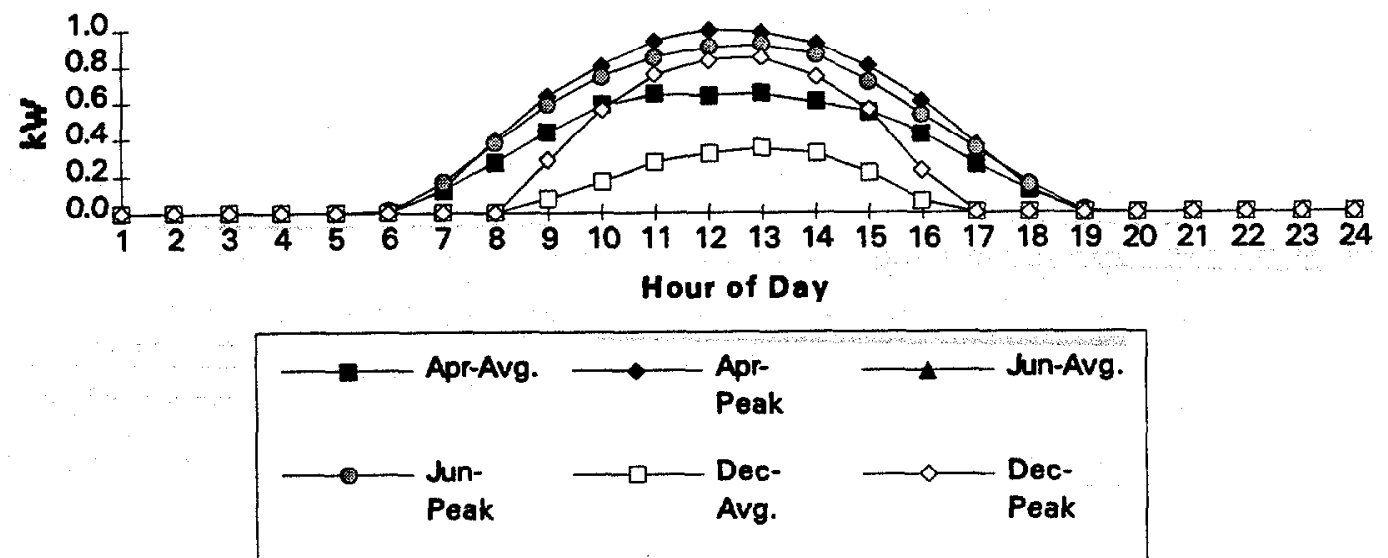

Fig. 5.2. Fixed-orientation PV daily output per $\mathrm{kW}$

Figure 5.3 shows the corresponding hourly performance for the two-axis tracking 1-kW PV system for April, June, and December. This figure shows that two-axis tracking provides somewhat better PV performance. However, the two-axis tracking PV performance is still very poor during the winter. 

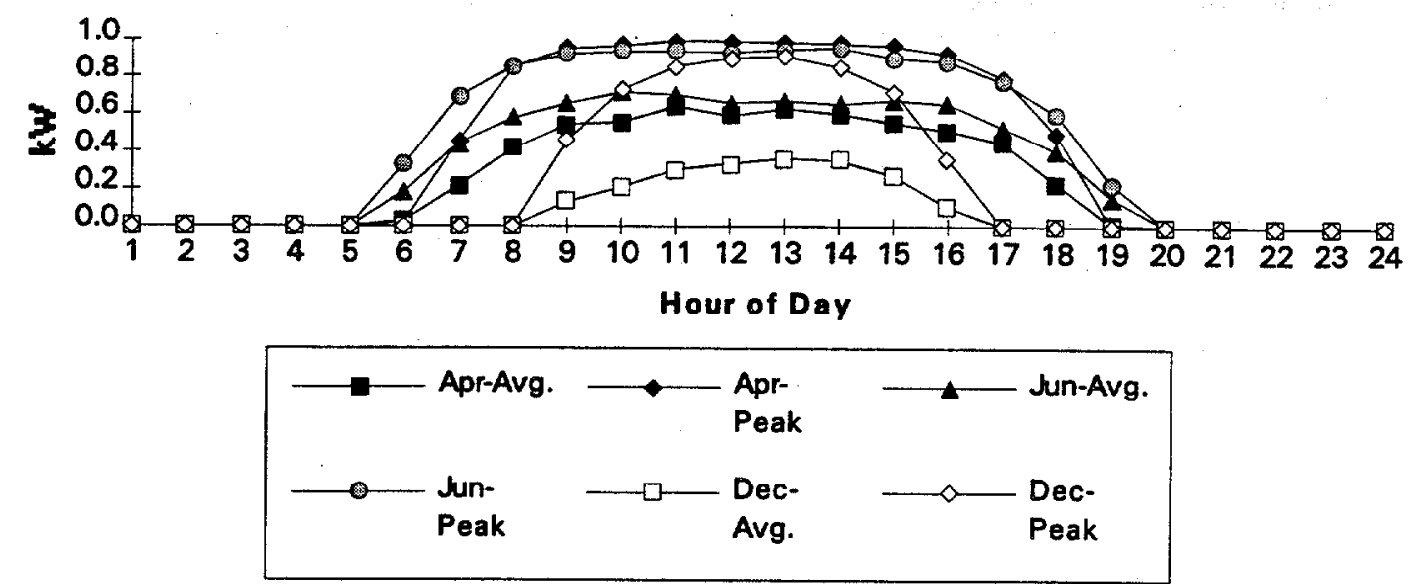

Fig. 5.3. Two-axis tracking $P V$ daily output per $k W$.

Per kW WT performance assumptions for the GMP case study were based on hourly wind data from a mountain wind station located near Searsburg/Readsboro, Vermont. The WT annual capacity factor is about $30 \%$.

Figure 5.4 presents the expected monthly WT performance for the site WT on a per-kW basis. Figure 5.5 shows the average hourly per-kW performance for the WT system in December, January, February, and March, the peak winter months. This plot shows a fairly consistent hourly performance pattern throughout the GMP winter peak period for this wind site.

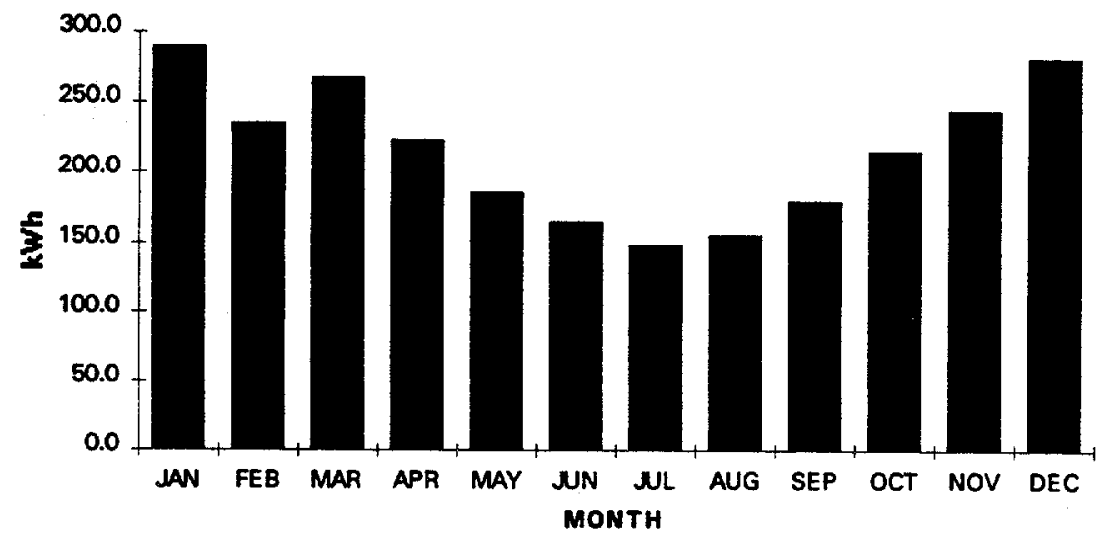

Fig. 5.4. WT system monthly performance per $\mathrm{kW}$. 

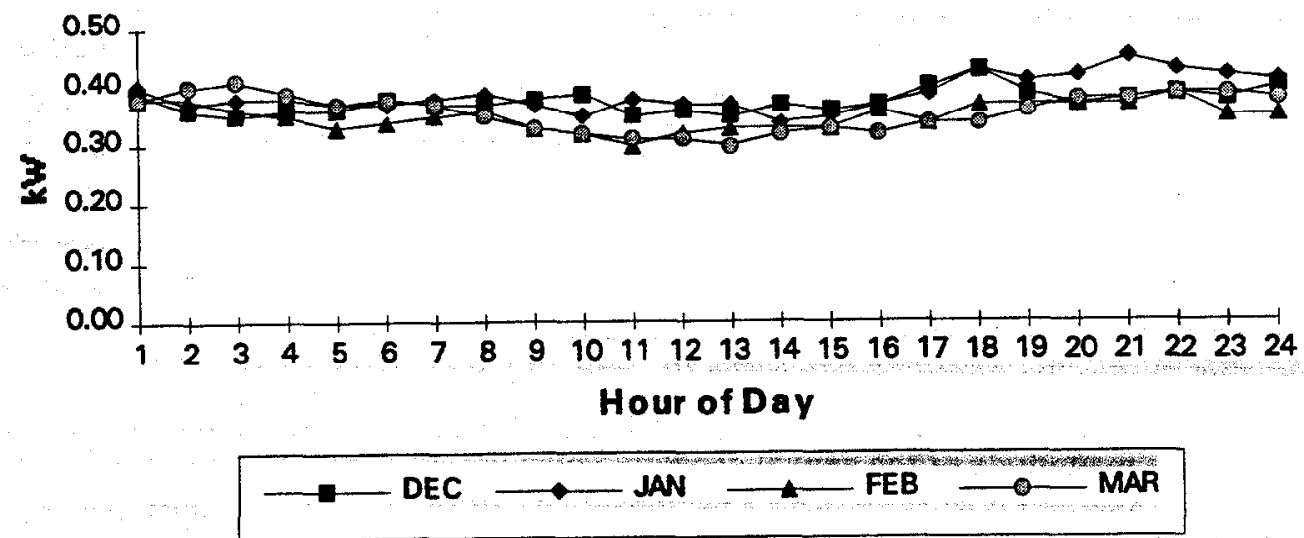

Fig. 5.5. WT daily output per $\mathrm{kW}$.

\subsection{ASSUMPTIONS AND BENEFITS QUANTIFIED}

The following assumptions were obtained from interaction with GMP distribution engineers and planning personnel. They are compatible with financial assumptions and cost estimates used by GMP in early 1993. General financial assumptions used for the GMP case study are listed in Table 5.3.

Table 5.3. GMP financial assumptions

\begin{tabular}{lc}
\hline Parameter & Assumption \\
\hline Discount rate & $11.275 \%$ \\
Levelized fixed charge rate-all CI & $11.75 \%$ \\
Escalation rate & $4.8 \%$ \\
\hline
\end{tabular}

The following benefits were quantified in the GMP case study:

- distribution losses,

- voltage regulation,

- generation capacity,

- energy displacement value including transmission losses,

- transmission capacity, and

- EPACT production tax credit for WT.

Relative distribution losses with and without renewable energy sources were calculated hourly for work days and weekend days in each month. The annual cost of losses was then 
determined using appropriate marginal energy costs and annual demand charges, which were also used to calculate annual energy displacement value and generation capacity value.

On long lines with line voltage regulators, a \$2000 charge per regulator was assumed to upgrade the regulators to allow them to regulate voltage properly during potential backfeed conditions when distributed PV or WT is installed.

This study considers small PV and WT penetration levels compared with the total GMP system load. Thus, for this study, GMP supplied estimated future hourly marginal energy values for summer and winter season on-peak and off-peak time periods, which were used to calculate energy displacement value for PV and WT. In 1998, the marginal energy costs ranged from 55.78 mills $/ \mathrm{kWh}$ during on-peak periods to $27.62 \mathrm{mills} / \mathrm{kWh}$ during off-peak periods. These marginal energy costs varied throughout the 30-year study period as the planned new generation equipment was added and the generation mix changed.

In this study, the capacity rating for PV and WT was determined based on the annual capacity factor, in a manner similar to that used to assign capacity ratings to run-of-river hydropower. The magnitude of the annual capacity value varied throughout the study period and was based on the annual $\$ / \mathrm{kW}$-year cost of the marginal new generation capacity additions. For example, in 1998 the annual capacity value is $\$ 30.91 / \mathrm{kW}$-year. However, in 2003 the annual capacity value is $\$ 118.06 / \mathrm{kW}$-year.

Transmission system benefits were derived from GMP-supplied general transmission system assumptions used in integrated resource planning studies, comparing demand side and supply side resources in early 1993 . In 1998 , the general transmission capital investment cost is $\$ 49.17$ per kWyear. Transmission system demand losses were assumed to be $5.17 \%$ of the annual peak load; and transmission system energy losses, which varied throughout the year, were included in the energy displacement value calculation.

EPACT wind benefits were assumed to apply as discussed in Sect. 2. An escalated $1.5 \notin / \mathrm{kWh}$ benefit for the first 10 years of operation was applied for WT.

Distribution facility deferral benefits were not included, because the PV and WT performance data do not appear to correlate well with the time of annual feeder peaks.

GMP includes environmental externalities as part of its integrated resource plan. All supplyside resource costs are increased by a 5\% environmental externalities adder, and all DSM resource costs are reduced by a $10 \%$ preferential risk adjustment factor. Presently in Vermont, environmental externality benefits apply only to DSM. Hence, potential environmental externality benefits are not included in the GMP benefit calculations.

If the present DSM cost benefits were extended to renewable energy resources, the resulting renewable energy source benefit-cost ratio would be increased $16.7 \%$. Although not included in the case study calculations, these potential benefits will be referred to when discussing the benefit-cost results of the case study.

\subsection{BENEFIT-COST RESULTS}

\subsubsection{Valley Distribution Systems}

In the GMP service area, residential lot sizes are large, sometimes as large as 10 acres. Typically, the distribution secondary system would consist of a distribution transformer serving one or two houses. Distribution secondary losses have been neglected for this case study.

A representative valley distribution primary system would consist of two 10 -mile feeders with standard 336-kcmil conductors connected to a 10-MVA transformer, and with several lateral 
taps. A 10-mile feeder serving a peak load of about 7 MVA would typically contain two line voltage regulators to maintain voltage spread criteria.

GMP is a small utility, so most of its valley feeders serve both commercial and residential loads. A representative commercial-residential feeder load mix is $25 \%$ commercial and $75 \%$ residential.

Figure 5.6 shows the resulting valley feeder load shape during the winter peak day assuming a $25 \%$ commercial and $75 \%$ residential load mix, with and without PV installed. Since the peak load occurs late in the day, adding PV will not reduce the feeder peak. Thus, there is no distribution facility deferral benefit for PV.

Table 5.4 presents the potential benefits and costs for the valley distribution system (two feeders) containing $2 \mathrm{MW}$ of distributed fixed-orientation PV. In this case, total combined PV benefits are $\$ 1444 / \mathrm{kW}$. When $4 \mathrm{MW}$ and $6 \mathrm{MW}$ of distributed PV are added to this system, the distribution system loss benefits are reduced only slightly $(\$ 5 / \mathrm{kW}$ and $\$ 10 / \mathrm{kW}$ respectively), and the rest of the $\$ / \mathrm{kW}$ benefits and costs remain the same. If two large 1-MW PV plants were located at the ends of the feeders rather than distributed throughout the feeders, the resulting total combined benefits increase to $\$ 1475 / \mathrm{kW}$ and a benefit-to-cost ratio of 0.20 . Fixed-orientation PV is expected to be cost-effective on the GMP system when the PV capital investment plus O\&M is less than the combined $\$ 1475 / \mathrm{kW}$ benefits.

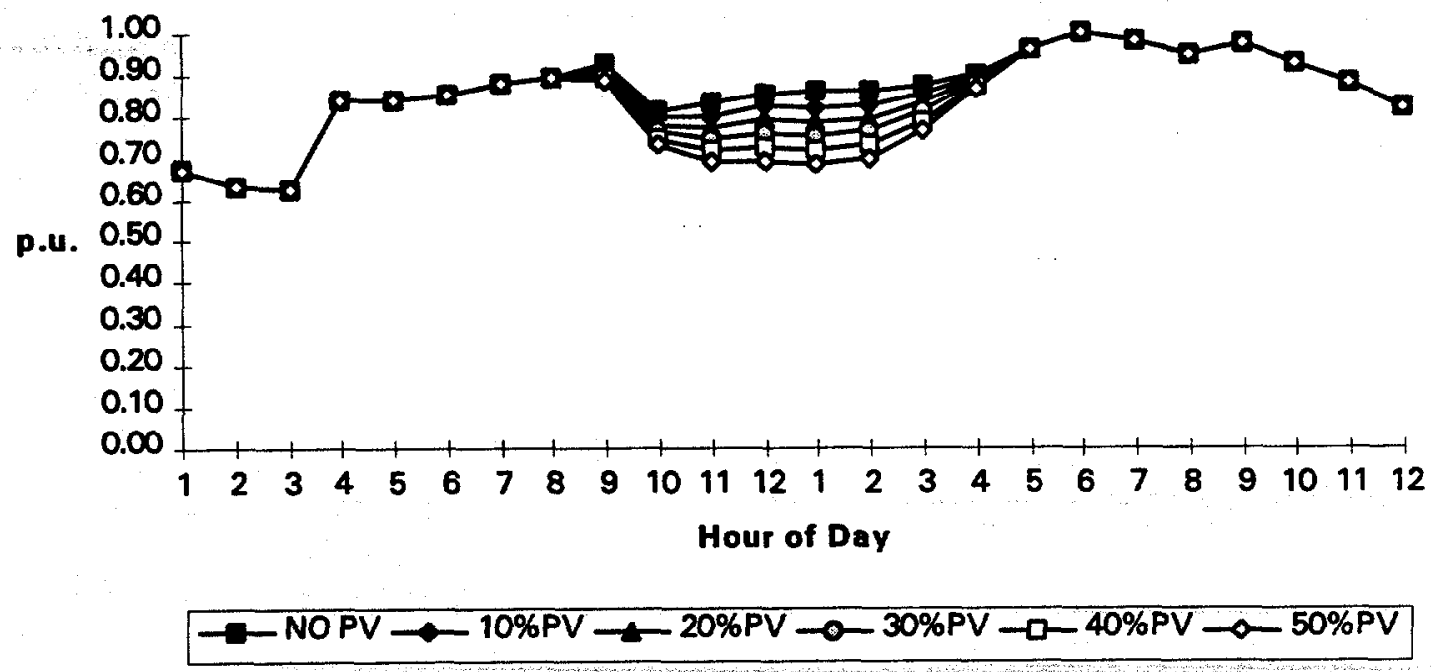

Fig. 5.6. Representative valley feeder load shape for winter peak day. 
Table 5.4. Benefit and cost results—valley system, 2 MW of distributed fixed-orientation PV

\begin{tabular}{lcc}
\hline & PWRR $^{\mathrm{a}}$ & $\mathbf{\$} / \mathrm{kW}$ \\
\hline \multicolumn{1}{c}{ Cost } & & \\
Capital investment & $14,138,054$ & 7,070 \\
Operating cost & 254,780 & 127 \\
Total cost & $\mathbf{1 4 , 3 9 2 , 8 3 4}$ & $\mathbf{7 , 1 9 7}$ \\
\multicolumn{1}{c}{ Benefits } & & \\
Distribution losses & 208,870 & 104 \\
Voltage regulation & $-3,595$ & -2 \\
Transmission capacity & 282,568 & 141 \\
Generation Capacity & 529,783 & 265 \\
Energy displacement including losses & $1,868,911$ & 935 \\
Total benefits & $\mathbf{2 , 8 8 6 , 5 3 7}$ & $\mathbf{1 , 4 4 4}$ \\
& & \\
Benefit-to-cost ratio & $\mathbf{0 . 2 0}$ & \\
\hline
\end{tabular}

Table 5.5 presents additional potential benefits and costs for the valley distribution system. Two large 1-MW PV plants with two-axis tracking are located at the ends of the feeders. In this case, the resulting total combined benefits increase to $\$ 1764 / \mathrm{kW}$ and the benefit-to-cost ratio increases to 0.21 . However, the PV plant was assumed to cost an additional $\$ 1200 / \mathrm{kW}$, and brings in only an additional $\$ 300 / \mathrm{kW}$ in benefits.

WT was not evaluated for GMP valley distribution systems because the wind resource in the valleys is poor. GMP has a few WTs connected to this system in the valleys, and none has a capacity factor above $10 \%$.

Table 5.5. Benefit and cost results-valley system, two 1-MW PV plants with two-axis tracking, end of feeders

\begin{tabular}{lcc}
\hline \multicolumn{1}{c}{ Cost } & PWRR \$ & $\$ / \mathrm{kW}$ \\
\hline \multicolumn{1}{c}{ Capital investment } & $16,537,724$ & $\mathbf{8 , 2 7 0}$ \\
Operating cost & 329,561 & 165 \\
Total cost & $\mathbf{1 6 , 8 6 7 , 2 8 6}$ & $\mathbf{8 , 4 3 5}$ \\
\multicolumn{1}{c}{ Benefits } & & \\
Distribution losses & 324,484 & 162 \\
Voltage regulation & $-3,595$ & -2 \\
Transmission capacity & 282,568 & 141 \\
Generation capacity & 529,783 & 265 \\
Energy displacement including losses & $2,393,831$ & 1,197 \\
Total benefits & $\mathbf{3 , 5 2 7 , 0 7 1}$ & $\mathbf{1 , 7 6 4}$ \\
& & \\
Benefit-to-cost ratio & $\mathbf{0 . 2 1}$ & \\
\hline
\end{tabular}

a Present worth of revenue requirements 


\subsubsection{Mountain Distribution Feeders}

A representative GMP mountain feeder would also be about 10 miles in length and have standard 336-kcmil conductors similar to the valley feeder. However, the feeder load shape can be significantly different. Figure 5.7 presents a representative mountain feeder load shape based on load data supplied by GMP for one of its mountain feeders, which serves a ski resort plus other loads.

Table 5.6 presents the potential benefits and costs for the mountain feeder assuming a 1-MW windfarm is installed at a good wind site (with a $30 \%$ capacity factor). In this mountain case, the combined benefits are $\$ 2458 / \mathrm{kW}$, while the total capital investment plus O\&M costs for a mountain wind farm are only $\$ 1468 / \mathrm{kW}$. The resultant benefit-to-cost ratio is 1.67 . If a $2-\mathrm{MW}$ or $3-\mathrm{MW}$ windfarm were installed, distribution loss benefits would be reduced slightly, $\$ 5 / \mathrm{kW}$ and $\$ 11 / \mathrm{kW}$ respectively, and the rest of the benefits and costs remain the same. Thus, in this case, WT appears to be a cost-effective resource for GMP with a benefit-to-cost ratio significantly greater than one.

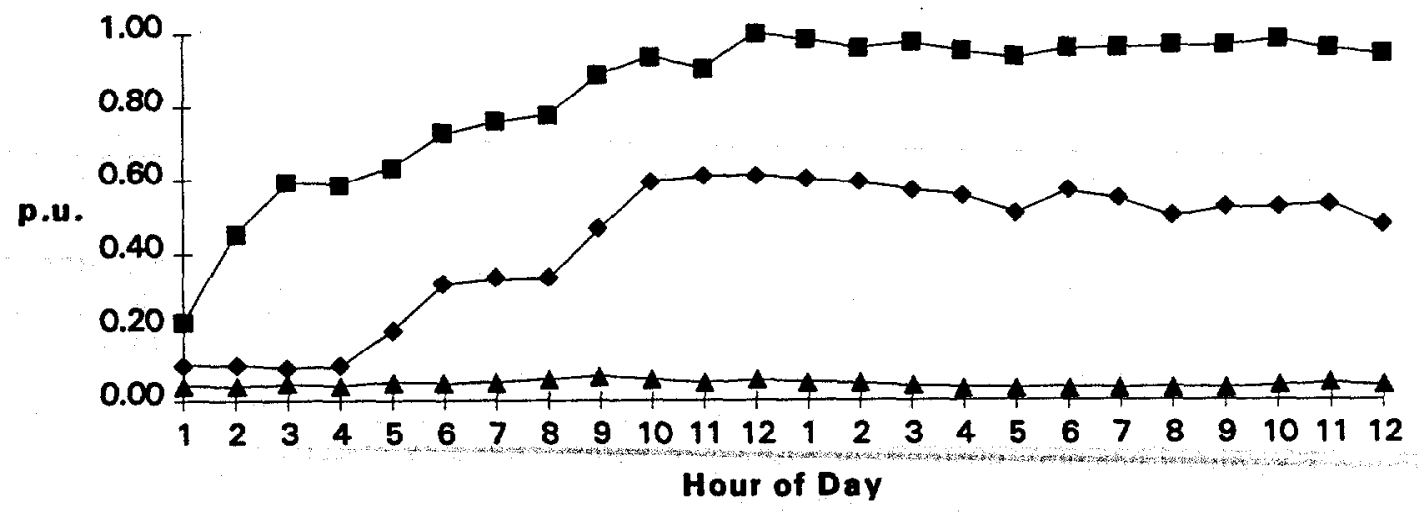

$\longrightarrow$ Winter Peak Day $\longrightarrow$ Avg. Winter Day $\longrightarrow$ Avg. Summer Day

Fig. 5.7. Representative mountain feeder load shape 
Table 5.6. Benefit and cost results-mountain feeder, $1 \mathrm{MW}$ windfarm at end of feeder

\begin{tabular}{lcc}
\hline \multicolumn{1}{c}{ Cost } & PWRR \$ & \$/kW \\
\hline Capital investment & $1,199,835$ & 1,200 \\
Operating cost & 267,686 & 268 \\
Total cost & $\mathbf{1 , 4 6 7 , 5 2 0}$ & $\mathbf{1 , 4 6 8}$ \\
$\quad$ Benefits & & \\
Distribution losses & 60,363 & 60 \\
Voltage regulation & $-1,797$ & -2 \\
Transmission capacity & 199,930 & 200 \\
Generation capacity & 374,847 & 375 \\
Energy displacement including losses & $1,512,402$ & 1,513 \\
Energy Policy Act & 312,099 & 312 \\
Total benefits & $\mathbf{2 , 4 5 7 , 8 4 3}$ & $\mathbf{2 , 4 5 8}$ \\
& & \\
Benefit-to-cost ratio & $\mathbf{1 . 6 7}$ & \\
\hline present worth of revenue requirements & & \\
\hline
\end{tabular}

\subsection{CASE STUDY CONCLUSIONS AND OBSERVATIONS}

Some conclusions and observations resulting from this case study are as follows:

- Wind turbines appear to be a cost-effective resource for mountain GMP distribution system applications at good wind sites. Case study benefits approach $\$ 2500 / \mathrm{kW}$, and the benefitcost ratio approaches 1.7 .

- PV output has poor correlation with GMP winter peak day load shapes.

- Fixed-orientation PV installed in GMP valley distribution systems can attain benefits approaching $\$ 1500 / \mathrm{kW}$, resulting in a benefit-cost ratio of 0.20 .

- Two-axis and single-axis tracking increases both PV benefits and costs. For the assumptions in the GMP case study, benefits increase about $\$ 300 / \mathrm{kW}$, while PV capital investment for two-axis tracking increases $\$ 1200 / \mathrm{kW}$. Unless the incremental benefits exceed the incremental costs, tracking may not be the most economic PV design even though the resulting benefit-to-cost ratio is higher.

- If the same level of environmental externality benefits that are presently applied to DSM were applied to PV and WT, the net effect would be a $16.7 \%$ increase in the benefit-cost ratio.

- If the 10\% EPACT investment tax credit was available to GMP the PV benefits its would increase about $\$ 700 / \mathrm{kW}$ for the assumptions in this study. 
- PV capital investment plus O\&M must be less than the previously cited benefits before PV becomes an economically viable resource.

- Battery storage is sure to be needed to back up PV to attain distribution deferral benefits because of the poor correlation between solar insolation and load correlation. Transportable battery storage, which is used in several applications and the battery costs allocated appropriately, may be a cost-effective option for distribution facility deferral. 


\section{PUBLIC SERVICE COMPANY OF NEW MEXICO}

This section presents the results of the Public Service Company of New Mexico (PNM) case study. PNM distribution system and design practices are described. Representative PV performance characteristics in the PNM service area are described. Various PNM benefits quantified are described, and pertinent assumptions are discussed. The case study results are then presented and summarized for the PNM system.

\subsection{DISTRIBUTION SYSTEM DESCRIPTION AND DESIGN PRACTICES}

The main subtransmission voltage used by PNM is $115 \mathrm{kV}$. One incoming line is generally brought in to a $115 / 12.47 \mathrm{kV}$ substation, equipped with one 22.4-MVA transformer. PNM's anticipated peak loading of this transformer is $67 \%$ of the nameplate rating. The remaining capacity (up to the nameplate rating) is considered as reserve to be used in case of an interruption at an adjacent substation.. Loadings above nameplate rating are permitted under emergency conditions, recognizing the reduction in transformer life caused by such loadings. Substation transformers are equipped with LTCs.

Load growth at PNM has been approximately $2.5 \%$ per year in the Albuquerque area, the largest load territory. The fast-growing area around Santa Fe has recently averaged $4.5 \%$ per year.

The standard substation serves three $12.47-\mathrm{kV}$ circuits. Peak circuit loading under normal conditions is approximately $230 \mathrm{~A}$.

The PNM system design is intended to keep maximum available short circuit duties below $10,000 \mathrm{~A}$. Typical maximum available short circuit duties are around 7,500 A.

The distribution system is designed in compliance with the National Electric Safety Code. Service voltage levels are designed to be maintained within ANSI Standard C84.1 (normal operating range between 114 and $127 \mathrm{~V}$; emergency operating range between 110 and $127 \mathrm{~V}$ ). Voltage levels at the substation LTC are typically set at $122.5 \pm 1.5 \mathrm{~V}$. The primary distribution system is designed for up to $3 \%$ voltage drop and the transformer, secondary, and service portion are designed for a maximum of $4 \%$ voltage drop.

PNM's peak loads occur during the summer, although it also encounters winter peaks that are almost as high. The system uncorrected power factor is approximately $85 \%$, which reflects low saturation levels of refrigerated air conditioning for residential purposes. The power factor correction goal is to improve the power factor as measured on the subtransmission system to at least 98\% (lagging) through the use of fixed and switched capacitors on the distribution system. Capacitors are not generally installed in substations.

The general scenario for applying capacitors is to install fixed units to compensate for var requirements during minimum load conditions (typically a 600-kvar bank applied at or near twothirds the length of the circuit). Switched capacitors controlled by time clocks are then installed to bring the power factor to unity during the winter peak period (typically using 1200-kvar banks located near one-third the circuit length).

Temperature controlled banks are then installed to bring the summer peak power factors to the desired levels. In areas where underground feeders exist, PNM overcorrects adjacent overhead circuits, rather than incur the additional cost of installing pad-mounted or underground capacitors.

PNM's general feeder design uses a single large conductor size throughout the circuit, rather than taper to smaller sizes toward the ends of circuits. This practice is necessary to provide adequate load-carrying capacity during substation interruptions. It also simplifies system design and makes very few distribution system modifications necessary when building new substations. The current 
standard overhead feeder sizes are 795 and $397 \mathrm{kcmil}$. Tap lines are built using smaller conductor sizes.

Service reliability receives ongoing attention at PNM. Considerable effort is put forth to improve on historic levels of availability and to identify cost-effective modifications for the future. The present system average outage duration is $100 \mathrm{~min}$. and the frequency is 0.75 per year.

Underground construction is used mainly in new residential areas. It consists generally of direct-buried $1 / 0$ primary cable (with 220 -mil crosslinked polyethylene insulation) feeding 30 to 40 pad-mounted transformers installed in a loop configuration, which generally stands open at a midpoint. Each transformer has two load-break elbows (incoming and outgoing) and a bayonet fuse.

Typical lot sizes range from 1/8 to $1 / 6$ acre. Home sizes are generally between 1500 and $2500 \mathrm{ft}^{2}$. Peak design demands are $2-3 \mathrm{~kW}$ (diversified over approximately 10 homes per transformer).

Most feeders at PNM are overhead; however, when underground feeders are installed, PNM secures an easement in private property adjacent to the street.

A summary of PNM's distribution design practices is found in Table 6.1.

\subsection{PV PERFORMANCE CHARACTERISTICS}

Per-kW PV performance assumptions for the PNM case study were based on SOLMET data for Albuquerque. This site is representative of expected solar insolation in PNM's service area. Table 6.2 presents a summary of expected annual performance for a $10 \mathrm{~m}^{2} \mathrm{PV}$ system rated at $1 \mathrm{~kW}$, assuming fixed-orientation at the site latitude of $35^{\circ}$, and assuming two-axis tracking. The fixedorientation PV system capacity factor is about $26.3 \%$, and the capacity factor of the two-axis tracking PV system is about $35.1 \%$. Monthly performance for the two PV system configurations is presented in Fig. 6.1. Note that solar insolation in Albuquerque is even better than in Southern California.

Table 6.2. Ten square meter, 1-kW PV at Albuqurque, N.M.

\begin{tabular}{lc}
\hline Configuration & $\begin{array}{c}\text { Annual capacity } \\
\text { factor (\%) }\end{array}$ \\
\hline Fixed tilt $35^{\circ}$ & 26.3 \\
Two-axis tracking & 35.1 \\
\hline
\end{tabular}

Figure 6.2 shows the hourly performance for the fixed-orientation 1-kW PV system for the peak solar insolation day and average solar insolation day in April and in June. In April, when the solar insolation is high, the PV system can attain $1-\mathrm{kW}$ output, and on the average day the PV system can attain over $0.9 \mathrm{~kW}$ output. In June, which represents the PNM summer peak period, the PV system does not attain full output. 
Table 6.1. PNM distribution design practices

\begin{tabular}{|c|c|}
\hline Substation & \\
\hline $\begin{array}{l}\text { Subtransmission voltage } \\
\text { Minimum number of incoming lines } \\
\text { Standard transformer size } \\
\text { Normal operating limit } \\
\text { Emergency operating limit } \\
\text { Standard transformer bank size } \\
\text { Minimum number of transformers } \\
\text { Maximum substation size } \\
\text { Voltage regulation } \\
\text { Maximum short circuit duty } \\
\text { Substation capacitors? } \\
\text { Peak load characteristic }\end{array}$ & $\begin{array}{c}115 \mathrm{kV} \\
1 \\
22.4 \mathrm{MVA} \mathrm{FA} \\
67 \% \\
100 \% \\
22.4 \mathrm{MVA} \\
1 \\
\text { not specified } \\
\text { LTC } \\
10,000 \mathrm{~A} \\
\text { No } \\
\text { summer }\end{array}$ \\
\hline \multicolumn{2}{|l|}{ Circuit design: } \\
\hline $\begin{array}{l}\text { Voltage } \\
\text { Power Factor correction goal } \\
\text { Comply with NESC? } \\
\text { Peak design load } \\
\text { Ties with adjacent circuits } \\
\text { Field voltage regulation practices } \\
\text { Tapped transformers? } \\
\text { Design transformer loading } \\
\text { Average transformer loading } \\
\text { Design voltage criteria } \\
\text { Design voltage drop } \\
\text { Flicker voltage drop criteria }\end{array}$ & $\begin{array}{c}12.47 \mathrm{kV} \\
98 \% \text { at peak on high side } \\
\text { yes } \\
300 \mathrm{~A} \\
\text { yes } \\
\text { no } \\
\text { switched capacitors, field regulators } \\
\text { to } 100 \% \text { of nameplate } \\
114-126 \mathrm{~V} \\
7 \% \\
\text { not specified }\end{array}$ \\
\hline \multicolumn{2}{|l|}{ Circuit protection practices: } \\
\hline $\begin{array}{l}\text { Extensive use of field reclosers? } \\
\text { Fused laterals? } \\
\text { Overhead lines: }\end{array}$ & $\begin{array}{l}\text { yes } \\
\text { yes }\end{array}$ \\
\hline $\begin{array}{l}\text { Maximum number of circuits per pole line } \\
\text { Typical primary conductor sizes } \\
\text { Secondary \& service conductor sizes } \\
\text { Underground lines: }\end{array}$ & $\begin{array}{c}\text { not specified } \\
\# 2,2 / 0 \text { \& } 4 / 0 \text { ACSR, } \\
397 \text { \& 795 AAC } \\
\# 2,2 / 0,4 / 0 \text { triplex }\end{array}$ \\
\hline $\begin{array}{l}\text { Installation method, residential } \\
\text { Installation method, feeders } \\
\text { Typical primary conductor sizes } \\
\text { Secondary \& service conductor sizes } \\
\text { Primary cable insulation } \\
\text { Switching equipment }\end{array}$ & $\begin{array}{c}\text { direct buried } \\
\text { in easement adjacent to } \\
\text { street right-of-way. } \\
1 / 0 \\
\begin{array}{c}1 / 0,4 / 0,350 \mathrm{kcmil} \text { triplex } \\
220 \mathrm{mil} \text { clp } \\
\text { air }\end{array}\end{array}$ \\
\hline Unique concerns: & \\
\hline
\end{tabular}

almost equal summer and winter peaks. 


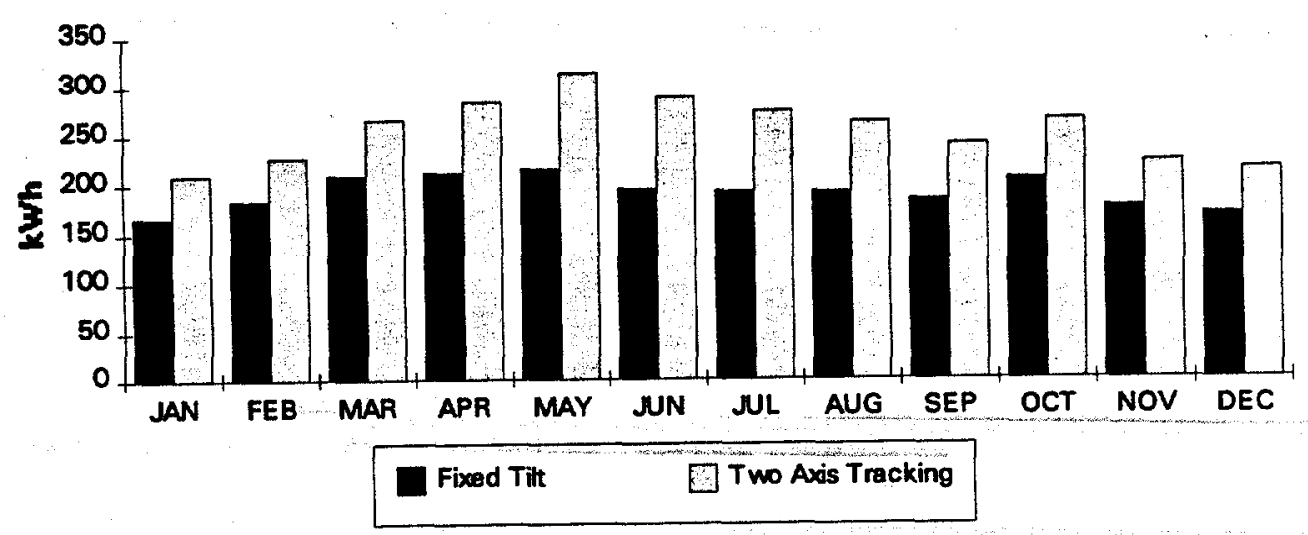

Fig. 6.1. PV system monthly performance per $\mathrm{kW}$.
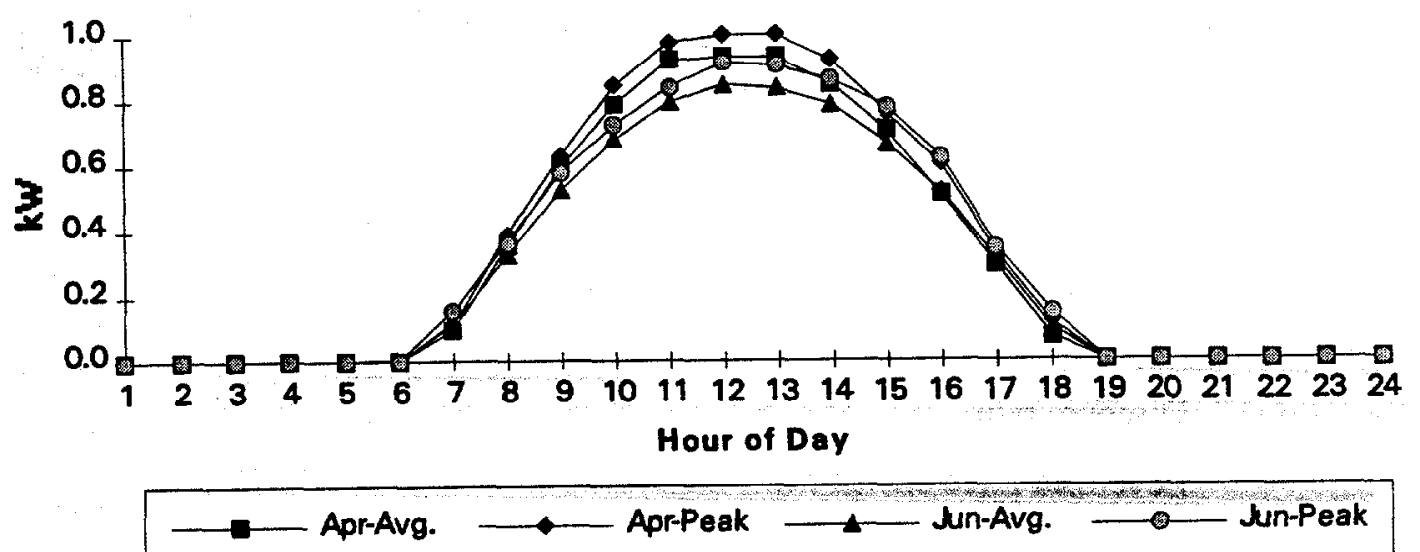

Fig. 6.2. Fixed-orientation $P V$ daily output per $\mathbf{k W}$.

Figure 6.3 shows the corresponding hourly performance for the two-axis tracking 1-kW PV system for June and April. This figure shows that two-axis tracking provides significantly better PV performance. However, this increased PV performance comes at a higher PV capital investment, as discussed earlier. 

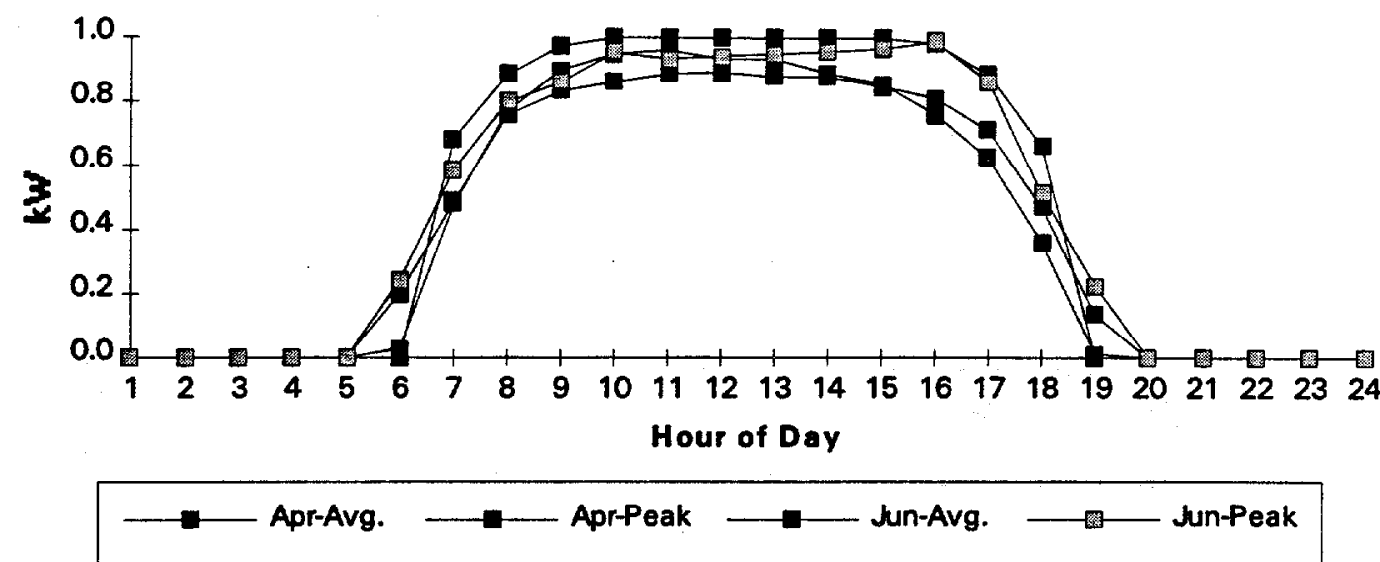

Fig. 6.3. Two-axis tracking PV daily output per $k W$.

Discussion with PNM personnel and review of the wind atlas indicated that poor wind resources can be expected in the PNM service area, but no wind data were available. Therefore, WT was not evaluated for PNM in this study.

\subsection{ASSUMPTIONS AND BENEFITS QUANTIFIED}

The following assumptions were obtained from interaction with PNM distribution engineers and planning personnel. They are compatible with financial assumptions and cost estimates used by PNM in early 1993. General financial assumptions used for the PNM case study are listed in Table 6.3.

Table 6.3. PNM financial assumptions

\begin{tabular}{lc}
\hline Parameter & Assumption \\
\hline Discount rate & $10.95 \%$ \\
Levelized fixed charge rate - all CI & $14.19 \%$ \\
Escalation rate & $5.0 \%$ \\
\hline
\end{tabular}

The following benefits were quantified in the PNM case study:

- distribution facility deferral,

- distribution losses,

- voltage regulation and power factor correction,

- generation capacity, and

- energy displacement value. 
Distribution facilities deferred in the PNM case study include the addition of a second 22.4MVA transformer plus associated new overhead feeder additions at an existing urban area distribution substation. Total installed-cost assumptions for distribution facilities are presented in Table 6.4.

Table 6.4. Distribution facility cost assumptions

\begin{tabular}{lc}
\hline \multicolumn{1}{c}{ Item } & $\begin{array}{c}\text { Total installed cost } \\
(1992 \$)\end{array}$ \\
\hline $\begin{array}{l}\text { Add 2nd 22.4-MVA transformer to existing } \\
\text { urban substation }\end{array}$ & $\$ 1,900,000$ \\
Add new overhead 397 kcmil 12-kV feeder & $\$ 118,800 / \mathrm{mi}$ \\
\hline
\end{tabular}

Relative distribution losses with and without renewable energy sources were calculated hourly for work days and weekend days in each month. The annual cost of losses was then determined using appropriate marginal energy costs and annual demand charges, which were also used to calculate annual energy displacement value and generation capacity value.

PNM maintains a 0.98 power factor correction policy at the distribution substation. PV with line-commutated inverters which require vars would incur a penalty. Line-commutated PV was assumed to be designed for 0.9 power factor. Self-commutated PV would not incur this penalty and possibly would obtain a benefit if appropriate utility var control were incorporated in its design. The cost of fixed or switched shunt capacitors for power factor correction for PNM was assumed to be $\$ 12 /$ kvar.

This study considers small PV penetration levels compared with the total PNM system load. Thus, for this study PNM supplied estimated future hourly incremental (marginal) energy values on a monthly basis for on-peak, and off-peak time periods through the year 2012, which were used to calculate the energy displacement value for PV. After 2012, fuel costs were assumed to increase at $8 \%$ per year. In 1998, the incremental energy costs ranged from a high of 24.9 mills/kWh during on-peak periods to a low of $21.8 \mathrm{mills} / \mathrm{kWh}$ during off-peak periods.

In this study, capacity rating for PV was determined by observing $\mathrm{kW}$ demand reduction during the summer peak load period. PV output correlates well with the PNM system summer peak load shape, which peaks in the early afternoon (Fig. 6.4). A capacity rating of $85 \%$ of the nameplate PV $\mathrm{kW}$ was used for fixed-orientation PV. This rate is slightly higher than the rating used in the SCE case study, reflecting the higher solar insolation in Albuquerque.

The magnitude of the annual $\$ / \mathrm{kW}$-year capacity value was based on the projected annual cost of a combustion turbine, which in 1998 dollars is assumed to be $\$ 118.56 / \mathrm{kW}$-year.

No transmission benefits were available. Hence, no transmission benefits were calculated for PNM.

Environmental externalities are not presently included in PNM planning studies. Hence, potential environmental externalities are not included in the PNM benefit calculations. 


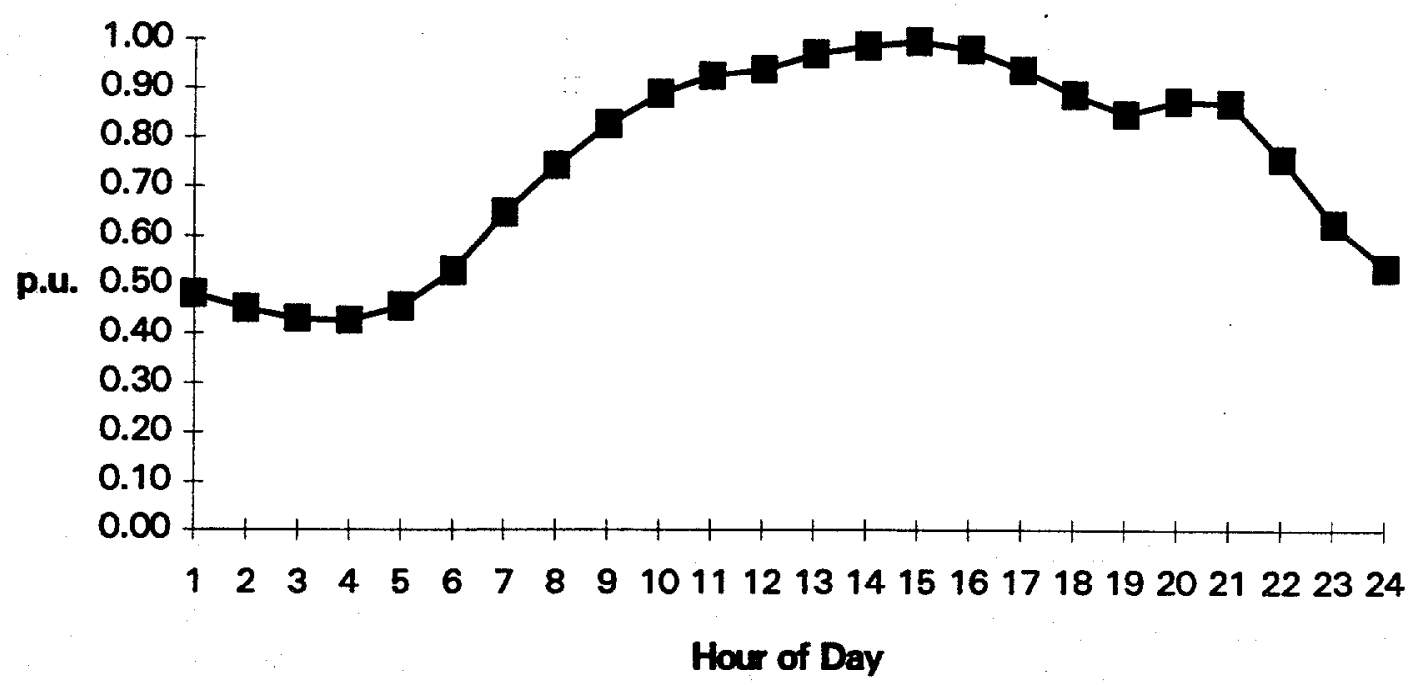

Fig. 6.4. PNM summer peak day load shape.

\subsection{BENEFIT-COST RESULTS}

Residential lot sizes on the PNM system typically vary from $1 / 8$ to $1 / 6$ acre. Coincident peak demands on the PNM system are typically about 2-3 kVA per house, and 10 to 12 houses are served by a 25-kVA distribution transformer. This configuration was used to represent a residential secondary system for the distribution loss calculations in this study.

A representative PNM distribution primary system would consist of three 4-mile feeders with standard 397-kcmil conductors connected to a 22.4-MVA transformer, and with several lateral taps, consisting of $1 / 0$ conductors, which serve local commercial and residential customers. Using PNM distribution design criteria, a second 22.4-MVA transformer would be added when the primary system peak load reached approximately $15 \mathrm{MW}$, as discussed earlier.

PNM supplied load shape data for feeders primarily serving commercial loads, primarily serving residential loads, and serving a mix of commercial and residential loads. The resulting summer commercial, mixed commercial and residential, and residential load shapes are shown in Fig. 6.5, 6.6 and 6.7 respectively. The commercial load shape correlates well with PV output. The residential load shape peak is too late in the evening to correlate well with PV output.

Adding $3 \mathrm{MW}$ of distributed fixed-orientation PV to the representative PNM distribution primary system serving a peak load of $15 \mathrm{MW}$, with the representative commercial load shape, reduces the annual peak load about $2 \mathrm{MW}$. This reduction could defer the addition of a second 22.4MVA transformer for 5 years assuming a load growth rate of $2.5 \%$. If the distribution system had the mixed commercial and residential load shape, the peak load reduction would be about $800 \mathrm{~kW}$, deferring the second transformer addition for 2 years rather than 5 years. If the system had the residential load shape, the second transformer could not be deferred.

Table 6.5 presents potential benefits and costs for the distribution system (three feeders), assuming the commercial load shape and providing $3 \mathrm{MW}$ of distributed fixed-orientation PV. In 
this case, total combined PV benefits are $\$ 2284 / \mathrm{kW}$ and the benefit-cost ratio is .31 . If three large $1 \mathrm{MW}$ PV plants were located at the ends of the feeders rather than distributed throughout the feeders, the distribution loss benefits increase about $\$ 7 / \mathrm{kW}$. If the PV penetration were doubled to $6 \mathrm{MW}$, the peak reduction is only about $2.5 \mathrm{MW}$, resulting in transformer deferral of 6 years rather than 5 years. The resulting distribution deferral benefit for this case is $\$ 183 / \mathrm{kW}$ vs $\$ 314 / \mathrm{kW}$, resulting in significantly less benefit on a $\$ / \mathrm{kW}$ basis. In this case, fixed-orientation $P V$ is expected to be cost-effective on the PNM system when the PV capital investment plus O\&M is less than the combined $\$ 2284 / \mathrm{kW}$ benefits.

Table 6.5. Benefit and cost results-commercial load shape, $3 \mathrm{MW}$ of distributed fixed-orientation $\mathrm{PV}$

\begin{tabular}{lcc}
\hline & PWRR \$a & \$/kW \\
\hline \multicolumn{1}{c}{ Cost } & $26,268,838$ & 7,070 \\
Capital investment & 738,849 & 199 \\
Operating cost & $\mathbf{2 7 , 0 0 7 , 6 8 7}$ & $\mathbf{7 , 2 6 9}$ \\
Total cost & & \\
$\quad$ Benefits & $1,167,864$ & 314 \\
Distribution facility deferral & 112,613 & 30 \\
Distribution losses & $-15,715$ & -4 \\
Voltage regulation & $4,108,796$ & 1,106 \\
Generation capacity & $3,114,443$ & $\mathbf{8 3 8}$ \\
Energy displacement value & $\mathbf{8 , 4 8 9 , 5 6 6}$ & $\mathbf{2 , 2 8 4}$ \\
Total benefits & & \\
Benefit-to-cost ratio & $\mathbf{0 . 3 1}$ & \\
\hline
\end{tabular}

Present worth of revenue requirements

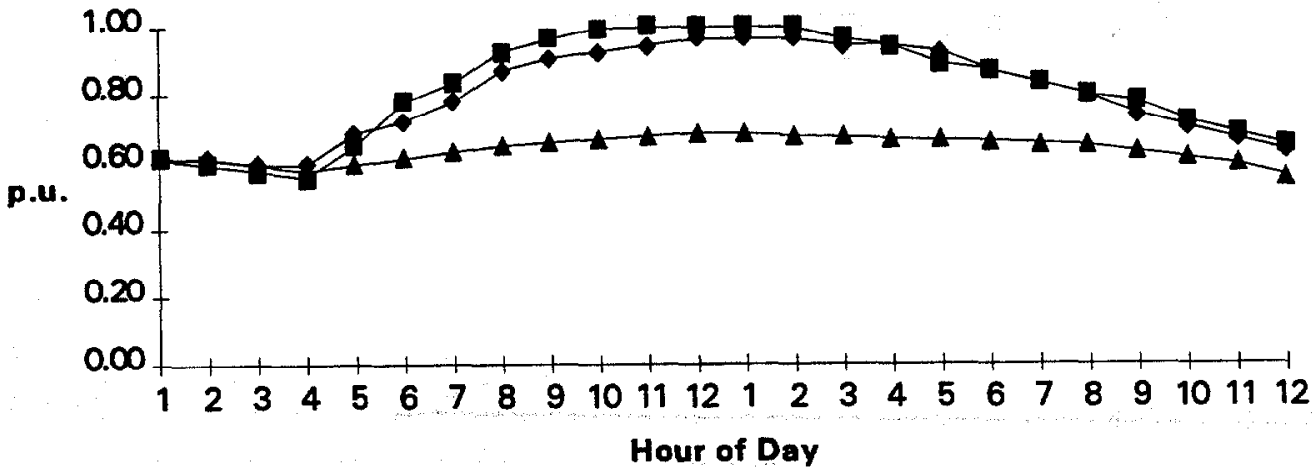

$\longrightarrow$ Summer Peak Day $\longrightarrow$ Avg.Summer
Workday

Avg. Summer Weekend

Fig. 6.5. Representative commercial load shapes. 

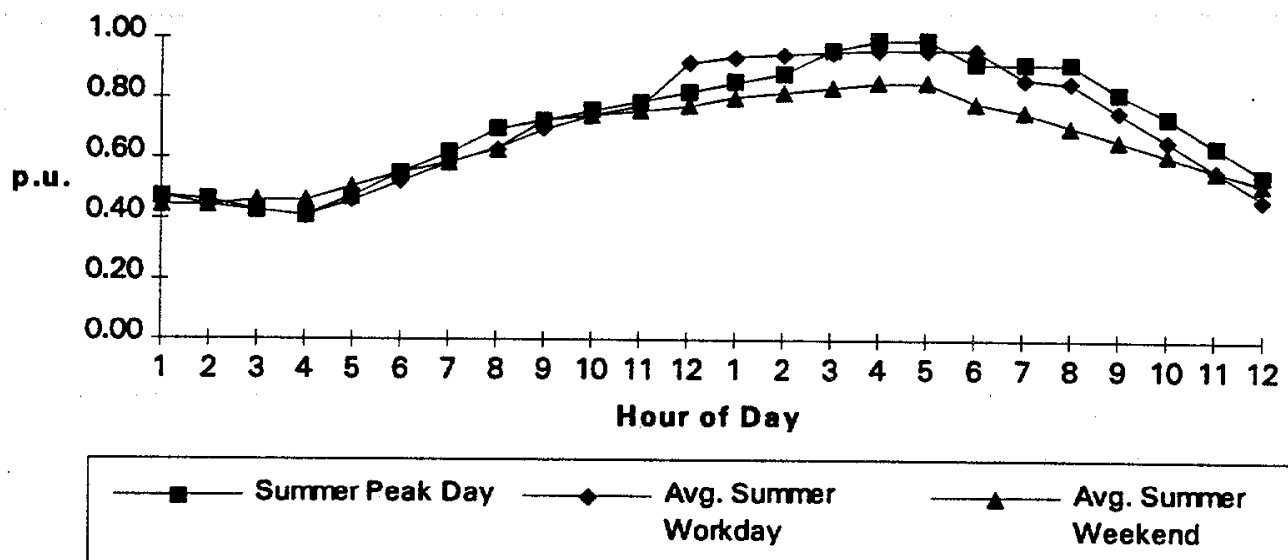

Fig. 6.6. Representative mixed commercial and residential load shapes.

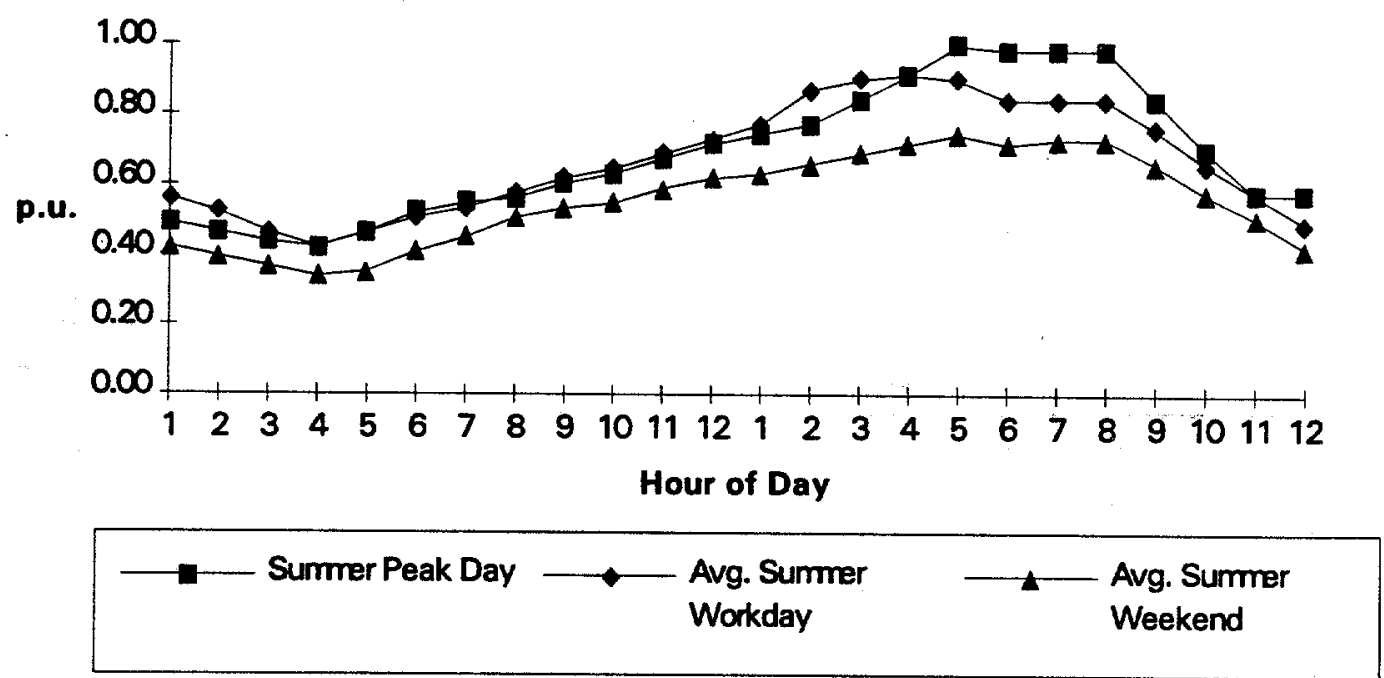

Fig. 6.7. Representative residential load shapes

presents potential benefits and costs for the distribution system assuming the mixed commercial and residential load shape. In this case, total combined PV benefits are $\$ 2129 / \mathrm{kW}$ and the cost-benefit 
ratio is 0.29 . If three large 1-MW PV plants were located at the ends of the feeders rather than distributed throughout the feeders, the distribution loss benefits would increase about $\$ 9 / \mathrm{kW}$. If the PV penetration were doubled to $6 \mathrm{MW}$, the peak reduction would be about $1.1 \mathrm{MW}$, resulting in a transformer deferral of 3 years rather than 2 years. The resulting distribution deferral benefit for this case is $\$ 101 / \mathrm{kW}$ vs $\$ 140 / \mathrm{kW}$, resulting in significantly less benefit on a $\$ / \mathrm{kW}$ basis. In this case, fixed-orientation PV is expected to be cost-effective on the PNM system when the PV capital investment plus O\&M is less than the combined $\$ 2129 / \mathrm{kW}$ benefits.

Table 6.6. Benefit and cost resultsmixed commercial and residential load shape, $3 \mathrm{MW}$ of distributed fixed-orientation $\mathrm{PV}$

\begin{tabular}{lcc}
\hline & PWRR $^{2}$ & $\$ / \mathrm{kW}$ \\
\hline \multicolumn{1}{c}{ Cost } & & \\
Capital investment & $26,268,838$ & 7,070 \\
Operating cost & 738,849 & 199 \\
Total cost & $\mathbf{2 7 , 0 0 7 , 6 8 7}$ & $\mathbf{7 , 2 6 9}$ \\
$\quad$ Benefits & & \\
Distribution facility deferral & 521,351 & 140 \\
Distribution losses & $\mathbf{1 8 2 , 3 1 6}$ & 49 \\
Voltage regulation & $-15,715$ & -4 \\
Generation capacity & $4,108,796$ & 1,106 \\
Energy displacement & $3,114,443$ & $\mathbf{8 3 8}$ \\
Total benefits & $\mathbf{7 , 9 1 1 , 1 9 2}$ & $\mathbf{2 , 1 2 9}$ \\
& & \\
Benefit-to-cost ratio & $\mathbf{0 . 2 9}$ & \\
\hline Present worth of revenue requirements & & \\
\hline
\end{tabular}

Table 6.7 presents potential benefits and costs for the distribution system assuming the residential load shape. In this case, total combined PV benefits are $\$ 2009 / \mathrm{kW}$ and the cost-benefit ratio is 0.28 . If three large $1 \mathrm{MW}$ PV plants were located at the ends of the feeders rather than distributed throughout the feeders, the distribution loss benefits would increase about $\$ 10 / \mathrm{kW}$.

If the distributed PV is assumed to be added modularly during the distribution facility deferral period, the resulting combined benefits can be larger and the PV costs can be lower. Table 6.8 demonstrates these results for the commercial load shape with the PV additions spread over the 5 years. The resulting total combined benefits increase to $\$ 2297 / \mathrm{kW}$, the total PV costs reduce to $\$ 7188 / \mathrm{kW}$, and the resulting benefit-cost ratio is 0.32 .

If the load in the distribution system grows at $1 \%$ rather than at $2.5 \%$, distribution system benefits can be enhanced further. Assuming $1 \%$ load growth, the second transformer addition can be deferred 12 years rather than 5 years. Table 6.9 presents the benefit and cost results assuming that the PV is added modularly over the 12-year period. In this case, the resulting total combined benefits increase to $\$ 2723 / \mathrm{kW}$, the total PV costs reduce to $\$ 7003 / \mathrm{kW}$, and the resulting benefit-cost ratio is 0.39 . 
Table 6.7. Benefit and cost results—residential load shape, 3 MW of distributed fixed-orientation PV

\begin{tabular}{|c|c|c|}
\hline & PWRR & $\$ / \mathrm{kW}$ \\
\hline \multicolumn{3}{|l|}{ Cost } \\
\hline Capital investment & $26,268,838$ & 7,070 \\
\hline Operating cost total cost & $\mathbf{7 3 8 , 8 4 9}$ & 199 \\
\hline Total Cost & $27,007,687$ & 7,269 \\
\hline Benefits & & \\
\hline Distribution facility deferral & 0 & 0 \\
\hline Distribution losses & 259,539 & 70 \\
\hline Voltage regulation & $-15,715$ & -4 \\
\hline Generation capacity & $4,108,796$ & 1,106 \\
\hline Energy displacement & $3,114,443$ & 838 \\
\hline Total benefits & $7,467,063$ & 2,009 \\
\hline Benefit-to-cost ratio & 0.28 & \\
\hline
\end{tabular}

Present worth of revenue requirements

Table 6.8. Benefit and cost results-commercial load shape, modular PV additions

\begin{tabular}{lcc}
\hline & PWRR \$ $^{\mathbf{a}}$ & \$/kW \\
\hline \multicolumn{1}{c}{ Cost } & & \\
Capital investment & $23,346,793$ & 6,995 \\
Operating cost & 645,966 & 194 \\
Total cost & $\mathbf{2 3 , 9 9 2 , 7 5 9}$ & $\mathbf{7 , 1 8 8}$ \\
$\quad$ Benefits & $1,167,864$ & 350 \\
Distribution facility deferral & 100,166 & 30 \\
Distribution losses & $-12,904$ & -4 \\
Voltage regulation & $3,592,266$ & 1,076 \\
Generation capacity & $2,820,741$ & $\mathbf{8 4 5}$ \\
Energy displacement & $\mathbf{7 , 6 6 8 , 1 3 3}$ & $\mathbf{2 , 2 9 7}$ \\
Total benefits & & \\
& $\mathbf{0 . 3 2}$ & \\
Benefit-to-cost ratio & &
\end{tabular}

Present worth of revenue requirements

As in the SCE case study, two-axis tracking PV increases the PNM system benefits, but not by nearly as much as the $\$ 1200 / \mathrm{kW}$ PV cost increase. 
Table 6.9 Benefit and cost results-commercial load shape, modular PV additions - slow $1 \%$ growth

\begin{tabular}{|c|c|c|}
\hline & PWRR & $\$ / \mathrm{kW}$ \\
\hline Cost & & as \\
\hline Capital investment & $19,053,003$ & 6,820 \\
\hline Operating cost & 512,182 & 183 \\
\hline Total cost & $19,565,185$ & 7,003 \\
\hline Benefits & & \\
\hline Distribution facility deferral & $2,366,174$ & 847 \\
\hline Distribution losses & 43,225 & 15 \\
\hline Voltage regulation & $-9,456$ & -3 \\
\hline Generation capacity & $2,848,287$ & 1,020 \\
\hline Energy displacement & $2,358,483$ & 844 \\
\hline Total benefits & $7,606,713$ & 2,723 \\
\hline Benefit-to-cost ratio & 0.39 & \\
\hline
\end{tabular}

\subsection{CASE STUDY CONCLUSIONS AND OBSERVATIONS}

Some conclusions and observations resulting from this case study are as follows:

- Distributed fixed-orientation PV installed in slow (1\%) growing PNM suburban distribution systems can attain benefits approaching $\$ 2800 / \mathrm{kW}$ when the PV is installed modularly, resulting in a benefit-cost ratio of 0.39 .

- PNM benefits do not include potential transmission benefits, which were not available for this study. If transmission benefits were included, it is expected that the total combined benefits would be about the same as for SCE.

- PV output has excellent time-of-day correlation with PNM summer peak day commercial load shapes, as well as with the total PNM system load. PNM summer peak day residential loads peak too late in the day for good PV correlation.

- Distributed or MW-scale PV applications will result in the highest benefits when installed in PNM distribution systems containing primarily commercial loads.

- Battery storage is not expected to be needed to back up PV to attain distribution deferral benefits because of the excellent time-of-day correlation between PV output and PNM load shape.

- If the $10 \%$ EPACT investment tax credit was available to PNM, the PV benefits would increase about $\$ 500 / \mathrm{kW}$ for the assumptions in this study.

PV capital investment plus O\&M must be less than the above benefits before PV becomes an economically viable resource for the applications that were evaluated. 


\section{GEORGIA POWER COMPANY}

This section presents the results of the Georgia Power Company (GPC) case study. GPC distribution system and design practices are described. Representative PV performance characteristics in the GPC service area are described. Various GPC quantified benefits are described and pertinent assumptions are discussed. The case study results are then presented and summarized for the GPC system.

\subsection{DISTRIBUTION SYSTEM DESCRIPTION AND DESIGN PRACTICES}

GPC uses numerous different transmission voltages throughout its system, including $46 \mathrm{kV}$, $69 \mathrm{kV}, 115 \mathrm{kV}$ and $230 \mathrm{kV}$. Bulk power transmission is at 230 and $500 \mathrm{kV}$.

A variety of substation designs have been used; however, the typical current standard in suburban areas consists of one or two three-phase transformers rated 22.4 and 56 MVA FOA 65C. GPC design practice is to load such a transformer to $110 \%$ of its nameplate rating under normal conditions. Under emergency conditions, loading may go as high as $130 \%$ of nameplate. Most large transformers are equipped with LTCs, and the small transformers use individual circuit voltage regulators, generally. Typically, three circuits are fed from one substation transformer.

Peak loads occur during the summer; refrigerated air conditioning is a significant part of the system peak load. Winter peaks are almost as high as summer peaks.

New customers with connected loads of $900 \mathrm{~kW}$ or more have the option of choosing service either from GPC or from any Georgia municipality ("MEAG") or REA agency.

The distribution system is designed in conformance with the National Electric Safety Code. GPC uses two different voltages, $12.47 \mathrm{kV}$ and $24.9 \mathrm{kV}$, both built to the same construction standard to the extent possible. Thus, new $12.47 \mathrm{kV}$ lines have the benefits of overinsulation (in an area subject to high lightning incidence levels), and later conversion of such lines to $24.9 \mathrm{kV}$ is relatively straightforward. The GPC system is also designed to be able to carry the load of most substations from lines sourced from adjacent substations. Circuits are designed to be able to carry up to $600 \mathrm{~A}$. Standard overhead conductor sizes are 1/0,397 kcmil, and $750 \mathrm{kcmil} \mathrm{ACSR}$.

The GPC system is designed for a maximum of $3 \%$ primary voltage drop. Field voltage regulators are installed on few lines. GPC also has established a voltage flicker limit of $6 \%$, in addition to the steady state voltage drop standard. Its uncorrected power factor is approximately $85 \%$. Shunt capacitors are applied for power factor correction, aimed at achieving $97 \%$ (lagging) power factor at the substation low-voltage bus. GPC participates in an agreement whereby all participants are required to maintain at least $93 \%$ power factor on their transmission systems. Distribution voltage capacitors are not generally installed inside substations. Reclosers are used extensively, to minimize areas affected by faults. Typically, three sets of (three) single-phase reclosers are used on a circuit.

GPC's practice is to install only one GPC circuit per pole line to minimize the number of customers affected by a fault. However, because of the large number of municipalities and other competing agencies that share service territory, many pole lines carry more than one circuit.

Underground construction is used mainly in urban areas. Most feeders are overhead; new underground-served developments are served via underground dips from overhead lines. Underground service to new residential developments is straightforward, using pad-mounted transformers and directly buried cable. All low-voltage distribution secondary system cable is either $1 / 0$ or $4 / 0$, installed as individual services only. No secondary systems are used. Primary cable size 
is either $1 / 0$ or $1000 \mathrm{kcmil} \mathrm{A1.} \mathrm{The} \mathrm{standard} \mathrm{cable} \mathrm{insulation} \mathrm{is} 260 \mathrm{mil}$ crosslinked polyethylene, in keeping with their policy of constructing a $25 \mathrm{kV}$ rated system.

A summary of GPC's distribution design practices is presented in Table 7.1.

Table 7.1. GPC distribution design practices

\section{Substation:}

Transmission voltage

Minimum number of incoming lines

Standard transformer size

Normal operating limit

Emergency operating limit

Standard transformer bank size

Minimum number of transformers

Maximum substation size

Voltage regulation

Maximum short circuit duty

Substation capacitors?

Peak load characteristic

$46,69,115,230 \mathrm{kV}$

$22.4,33,46.7,56 \mathrm{MVA}$, FOA, $65^{\circ} \mathrm{C}$

$110 \%$

$130 \%$

$22.4,33,46.7,56$ MVA

1

(2) 56 MVA's, typically

individual circuit regulators.

$10,000 \mathrm{~A}$

no

summer

\section{Circuit design:}

Voltage

Power factor correction goal

Comply with NESC?

Peak design load

Ties with adjacent circuits

Field voltage regulation practices

Tapped transformers?

Design transformer loading

Average transformer loading

Design voltage criteria

Design voltage drop

Flicker voltage drop criteria
$12.47 \mathrm{kV}, 20 \mathrm{kV}$ and $25 \mathrm{kV}$

$97 \%$ at peak,substation bus. yes

$600 \mathrm{~A}$ - can carry load

from adjacent substation circuits

yes

capacitors and a few pole mounted regulators

No

to $125 \%$ of nameplate

$114-126 \mathrm{~V}$

$<3 \%$

$6 \%$

Circuit protection practices:

Extensive use of field reclosers?
Fused laterals?

Overhead lines:

Maximum number of GPC circuits per pole line

Typical primary conductor sizes

$1 / 0,397,750$ ACSR

Underground lines:

Installation method, residential

Installation method, feeders

Typical primary conductor sizes

Secondary \& service conductor sizes

Primary cable insulation

Switching equipment

Unique concerns:

direct buried

in street right-of-way

$1 / 0,1,000 \mathrm{kcmil}$

$1 / 0,4 / 0$, no secondaries 260 mil clp

L.B. Elbows, man/auto switching cubicles and vacuum switches 


\subsection{PV PERFORMANCE CHARACTERISTICS}

Per-kW PV performance assumptions for the GPC case study were based on SOLMET data for Atlanta. This site is representative of expected solar insolation in the GPC service area. Table 7.2 presents a summary of expected annual performance for a $10-\mathrm{m}^{2} \mathrm{PV}$ system rated at $1 \mathrm{~kW}$, assuming fixed-orientation at the site latitude of $33.7^{\circ}$, and assuming two-axis tracking. The fixedorientation PV system capacity factor is about $18.2 \%$, and the capacity factor of the two-axis tracking PV system is about $23.3 \%$. Monthly performance for the two PV system configurations is presented in Fig. 7.1.

Table 7.2. Ten square meter, 1-kW PV at Atlanta, Georgia

\begin{tabular}{lc}
\hline Configuration & $\begin{array}{c}\text { Annual capacity } \\
\text { factor (\%) }\end{array}$ \\
\hline Fixed tilt $33.7^{\circ}$ & 18.2 \\
Two-axis tracking & 23.3 \\
\hline
\end{tabular}

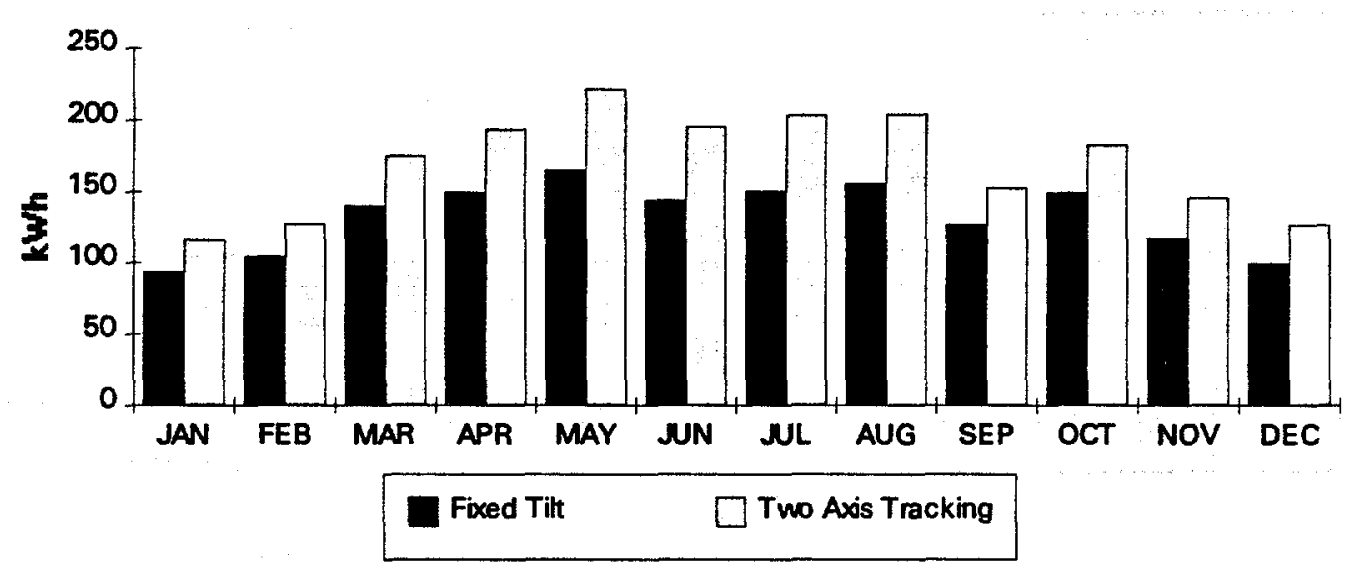

Fig. 7.1. PV system monthly performance per $\mathrm{kW}$.

Figure 7.2 shows the hourly performance for the fixed-orientation 1-kW PV system for the peak solar insolation day and average solar insolation day in April and June. In April, when the solar insolation is high, the PV system can attain 1-kW output. In June, during high solar insolation periods, the PV can provide fairly high levels of $\mathrm{kW}$ output. However, the average monthly output in both June and April is relatively low compared with SCE and PNM. It seems clear from this 
information that, for many days, PV output will not correlate with system daily peak loads during the summer peak season.

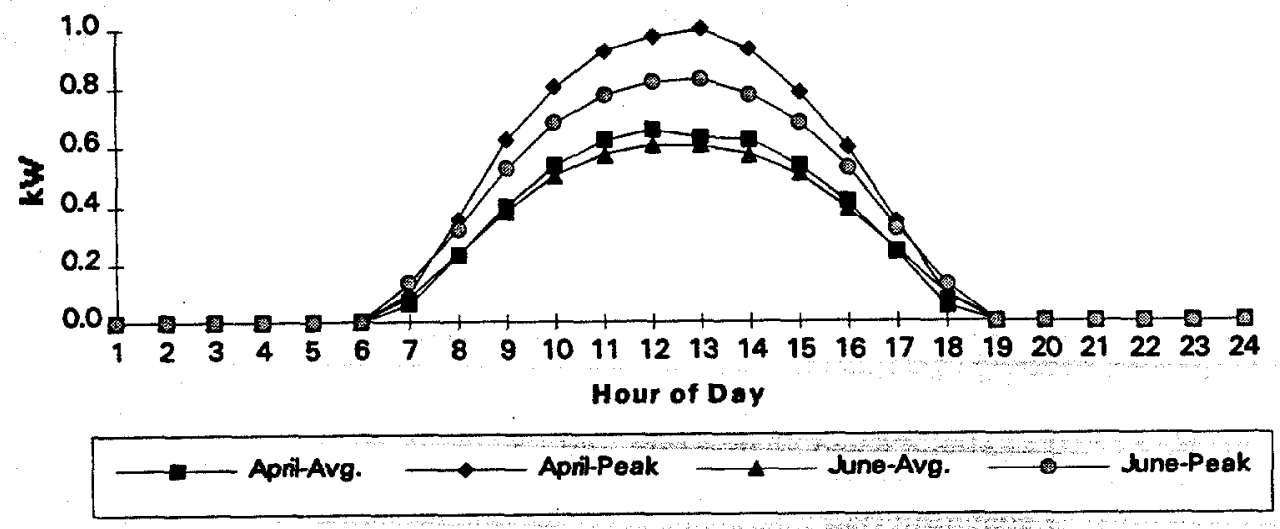

Fig. 7.2. Fixed-orientation PV daily output per $k W$.

Figure 7.3 shows the corresponding hourly performance for the two-axis tracking 1-kW PV system for April and June. This figure shows that two-axis tracking provides somewhat better PV performance. However, average monthly performance for the two-axis tracking PV is still low compared with SCE and PNM. Again, even with two-axis tracking, it's likely that on many days PV performance will not correlate with daily peak loads during the summer peak season.
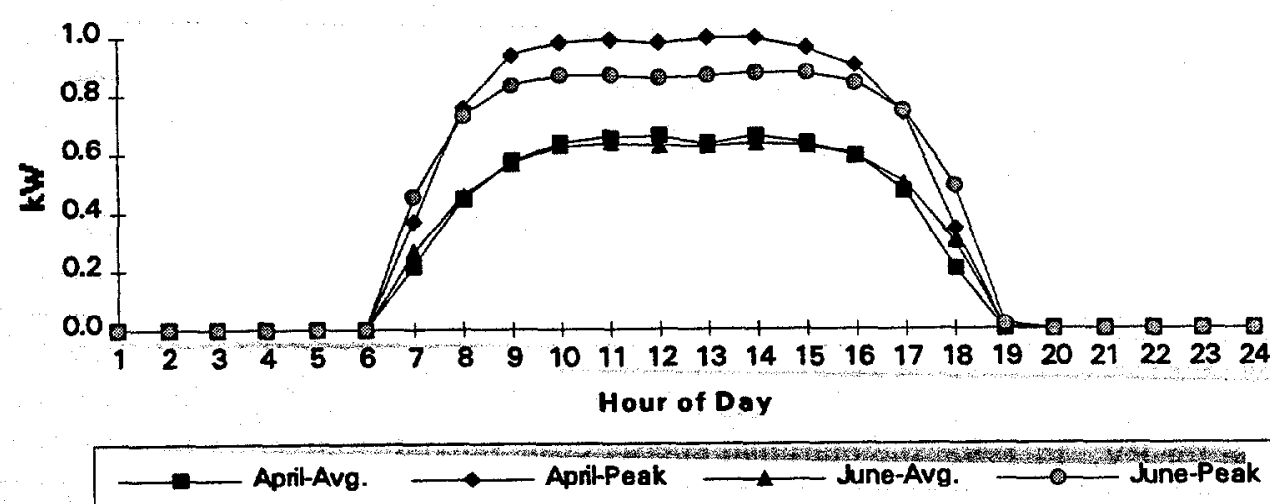

Fig. 7.3. Two-axis tracking PV daily output per $k W$. 
Discussions with GPC personnel and review of the wind atlas indicated that poor wind resources can be expected in the GPC service area, and no wind data were available. Thus WT was not evaluated for GPC in this study.

\subsection{ASSUMPTIONS AND BENEFITS QUANTIFIED}

The following assumptions were obtained from interaction with GPC distribution engineers and planning personnel. They are compatible with financial assumptions and cost estimates used by GPC in early 1993. General financial assumptions used for the GPC case study are listed in Table 7.3.

Table 7.3. GPC financial assumptions

\begin{tabular}{lc}
\hline Parameter & Assumption \\
\hline Discount rate & $9.3 \%$ \\
Levelized fixed charge rate - all CI & $12.6 \%$ \\
Escalation rate & $3.7 \%$ \\
\hline
\end{tabular}

The following benefits were quantified in the GPC case study:

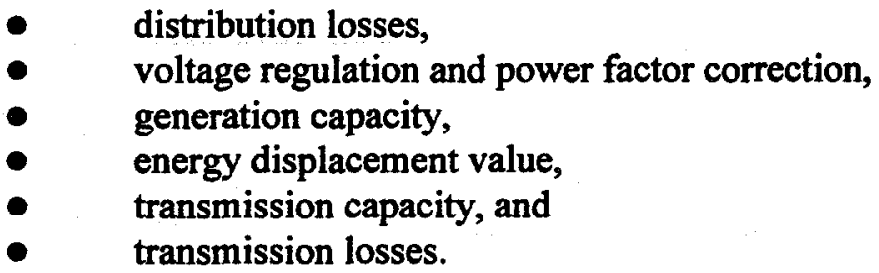

Relative distribution losses with and without renewable energy sources were calculated hourly for work days and weekend days in each month. The annual cost of losses was then determined using appropriate marginal energy costs and annual demand charges, which were also used to calculate annual energy displacement value and generation capacity value.

GPC maintains a 0.97 power factor correction policy at the distribution substation. PV with line-commutated inverters which require vars would incur a penalty. Line-commutated PV was assumed to be designed for 0.9 power factor. Self-commuted PV would not incur this penalty and possibly would obtain a benefit if appropriate utility var control were incorporated in its design. The cost of fixed or switched shunt capacitors for power factor correction for GPC was assumed to be $\$ 6 / \mathrm{kvar}$.

This study considers small PV penetration levels compared with the total GPC system load. Thus, for this study GPC supplied estimated future hourly marginal energy values for summer and winter season on-peak, and off-peak time periods, which were used to calculate energy displacement value for PV. In 1998, the marginal energy costs ranged from $37.53 \mathrm{mills} / \mathrm{kWh}$ during on-peak periods to 21.72 mills $/ \mathrm{kWh}$ during off-peak periods. These marginal energy costs varied throughout the 30-year study period. Seasonal on-peak and off-peak marginal costs were supplied through 2003. After 2003, the marginal energy costs were escalated at $5.25 \%$, which is $1.5 \%$ above the assumed inflation rate of $3.7 \%$. 
The generation capacity rating for PV was assumed to be $60 \%$ of nameplate PV.kW. This factor was determined by observing average PV performance during the daily GPC system summer peak load periods. GPC summer daily load shapes are shown in Fig. 7.4.
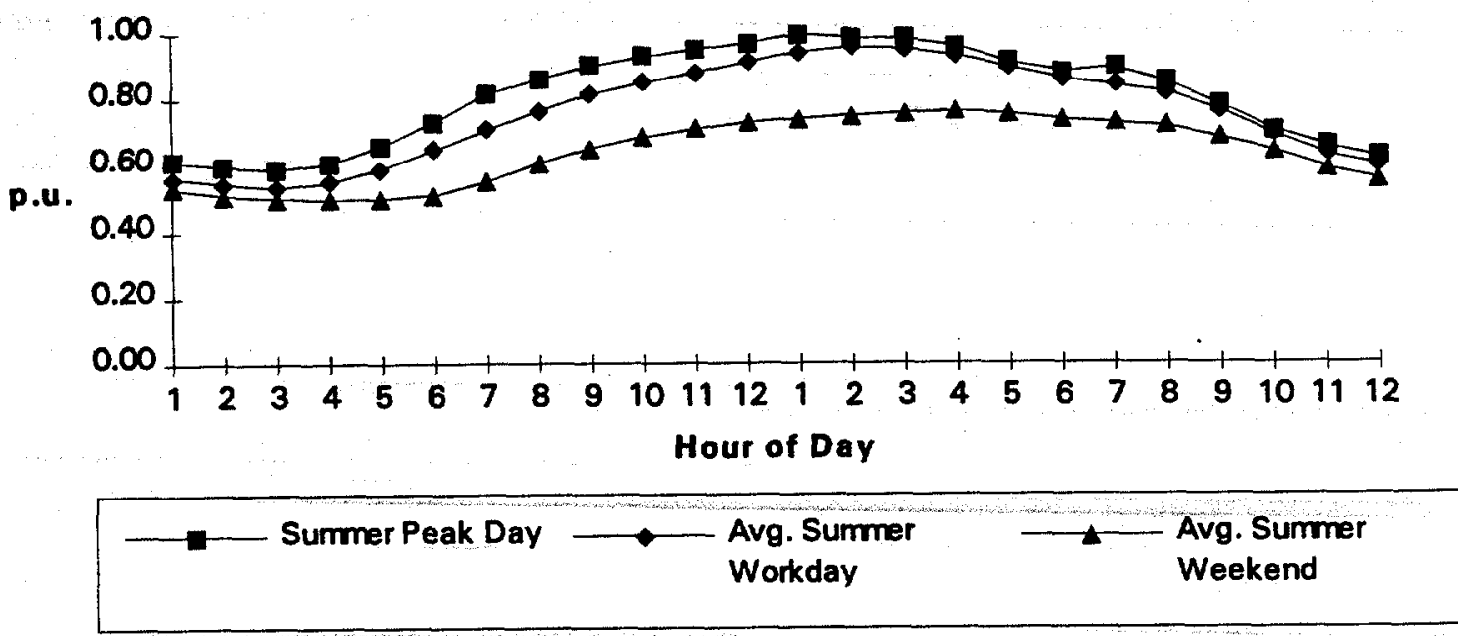

Fig. 7.4. GPC summer daily load shapes.

The magnitude of the annual capacity value was based on the projected annual cost of a GPC combustion turbine, which in 1998 dollars is assumed to be $\$ 42.75 / \mathrm{kW}$-year. This value was then escalated at $3.7 \%$ throughout the study period.

Transmission system benefits were derived from GPC-supplied general transmission system assumptions used in integrated resource planning studies, comparing demand side and supply-side resources in early 1993. The general transmission capital investment cost assumption was $\$ 120$ per $\mathrm{kW}$ in 1993 dollars. Transmission system losses were assumed to be $5.6 \%$ of the annual energy displacement value.

Distribution facility deferral benefits were not included. The PV performance data do not appear to correlate well with the time of annual feeder peaks, which may be just as likely to occur on cloudy days as on sunny days in the GPC service area.

Environmental externalities are not presently included in GPC planning studies. Hence, potential environmental externality benefits are not included in the GPC benefit calculations.

\subsection{BENEFIT-COST RESULTS}

Typically, the distribution secondary system would consist of a distribution transformer serving four to eight houses on quarter-acre lots. Each house would have its own service rather than using a common secondary system. Distribution secondary losses have been neglected for this study.

A representative 12-kV suburban primary system would consist of a 22.4-MVA transformer serving two or three 5-mile feeders. The feeders would consist of overhead construction using 397 kcmil or $750 \mathrm{kcmil}$ conductors and would contain several lateral taps serving residential and 
commercial customers. For this study, the representative suburban distribution system was assumed to contain two feeders loaded to $600 \mathrm{~A}$ or about $11 \mathrm{MW}$ each.

Table 7.4 presents the potential benefits and costs for the representative suburban distribution system with $397-\mathrm{kcmil}$ conductors assuming $10 \%$ fixed-orientation distributed PV penetration (2.2 MW). In this case, total combined PV benefits are $\$ 1033 / \mathrm{kW}$ and the benefit costratio is 0.14 . If the feeder conductor size is $750 \mathrm{kcmil}$, loss benefits are reduced from $\$ 62 / \mathrm{kW}$ to $\$ 37 / \mathrm{kW}$, resulting in a small reduction in benefits. If PV penetration is increased to $20 \%$, the resulting loss benefit is only reduced from $\$ 62 / \mathrm{kW}$ to $\$ 60 / \mathrm{kW}$. In this case, fixed-orientation PV is expected to be cost effective on the GPC system when the PV capital investment plus O\&M is less than the combined $\$ 1033 / \mathrm{kW}$ benefits.

Table 7.4 Benefit and cost results-suburban distribution system, $10 \%$ fixed-orientation PV penetration

\begin{tabular}{|c|c|c|}
\hline & PWRR \$ & $\$ / \mathrm{kW}$ \\
\hline \multicolumn{3}{|l|}{ Cost } \\
\hline Capital investment & $20,002,775$ & 7,070 \\
\hline Operating cost & 370,788 & 131 \\
\hline Total cost & $20,373,563$ & 7,201 \\
\hline \multicolumn{3}{|l|}{ Benefits } \\
\hline Distribution losses & 176,408 & 62 \\
\hline Voltage regulation & $-5,966$ & -2 \\
\hline Transmission capacity & 244,285 & 86 \\
\hline Transmission losses & 89,781 & 32 \\
\hline Generation capacity & 815,664 & 288 \\
\hline Energy displacement value & $1,603,224$ & 567 \\
\hline Total benefits & $2,923,395$ & 1,033 \\
\hline Benefit-to-cost ratio & 0.14 & \\
\hline
\end{tabular}

aresent worth of revenue requirements.

A representative long overhead $12-\mathrm{kV}$ rural feeder may be 11.5 miles long, with the first two miles containing $397 \mathrm{kcmil}$ ACSR, and the rest containing 1/0 ACSR. The peak demand on the feeder would be about 6.5 MW.

Table 7.5 presents the potential benefits and costs for the long rural feeder assuming a 1MW PV plant is installed near the end of the feeder. In this case, total combined PV benefits are $\$ 1124 / \mathrm{kW}$ and the benefit-cost ratio is 0.16 . The resulting loss benefit of $\$ 154 / \mathrm{kW}$ is significantly larger than the suburban feeder loss benefit. This larger benefit occurs because of the longer feeder length and smaller $1 / 0$ conductor size. In this case, fixed-orientation PV is expected to be costeffective on the GPC system when the PV capital investment plus O\&M is less than the combined $\$ 1124 / \mathrm{kW}$ benefits.

Two-axis tracking PV increases the GPC system benefits somewhat, but not nearly as much as the assumed $\$ 1200 / \mathrm{kW}$ PV cost increase. 
Table 7.5 Benefit and cost results-rural feeder, 1-MW fixed-orientation PV plant

\begin{tabular}{lcc}
\hline & PWRR $\$$ & \$/kW \\
\hline \multicolumn{1}{c}{ Cost } & $8,913,964$ & 7,070 \\
Capital investment & 165,235 & 131 \\
Operating cost & $\mathbf{9 , 0 7 9 , 1 9 9}$ & $\mathbf{7 , 2 0 1}$ \\
Total cost & & \\
$\quad$ Benefits & 194,632 & 154 \\
Distribution losses & $-4,489$ & -4 \\
Voltage regulation & 108,862 & 86 \\
Transmission capacity & 40,009 & 32 \\
Transmission losses & 363,490 & 288 \\
Generation capacity & 714,449 & 567 \\
Energy displacement & $1,416,923$ & 1,124 \\
Total benefits & & \\
& 0,16 & \\
Benefit-to-cost ratio & & \\
\hline Present worth of revenue requirements. &
\end{tabular}

\subsection{CASE STUDY CONCLUSIONS AND OBSERVATIONS}

Some conclusions and observations resulting from this case study are as follows:

- WT was not evaluated for GPC, as poor wind resources can be expected in the GPC service area.

- PV output has poor correlation with GPC summer peak day load shapes, as peak days are likely to occur on cloudy days as well as sunny days.

- Fixed-orientation PV installed in GPC suburban distribution systems can attain benefits of approximately $\$ 1033 / \mathrm{kW}$, resulting in a benefit-cost ratio of 0.14 .

- Fixed-orientation PV installed in GPC long rural distribution systems can attain benefits of approximately $\$ 1124 / \mathrm{kW}$, resulting in a benefit-cost ratio of 0.16 .

Two-axis and single-axis tracking increases both PV benefits and costs. For the assumptions in the GPC case study, incremental benefits are expected to be significantly less than the incremental PV capital investment for two-axis or single-axis tracking.

- If the $10 \%$ PV EPACT investment tax credit was available to GPC, the PV benefits would increase about $\$ 500 / \mathrm{kW}$ for the assumptions in this study.

- PV capital investment plus O\&M must be less than the above benefits before PV becomes an economically viable resource for the applications that were evaluated. 
- Battery storage is sure to be needed to back up PV to attain distribution deferral benefits, because of the poor correlation between solar insolation and load. Transportable battery storage, which is used in several applications and the battery costs allocated appropriately, may be a cost-effective option for distribution facility deferral. 


\section{FLORIDA POWER AND LIGHT}

This section presents the results of the Florida Power \& Light (FP\&L) case study. FP\&L distribution system and design practices are described. Representative PV performance characteristics in the FP\&L service area are described. Various FP\&L quantified benefits are described and pertinent assumptions are discussed. The case study results are then presented and summarized for the FP\&L system.

\subsection{DISTRIBUTION SYSTEM DESCRIPTION AND DESIGN PRACTICES}

FP\&L uses $138 \mathrm{kV}$ as its predominant transmission voltage. It does not operate any portions of their system as subtransmission.

Substation design generally consists of two three-phase transformers served by a looped incoming transmission line, each transformer then feeding up to three individually regulated distribution lines. Standard transformer sizes are 30, 45, and 56 MVA. Normal peak loading is $67 \%$ of nameplate. A faulted transformer can be isolated through the use of motor-operated high-side switches and distribution voltage disconnects. The FP\&L design standard is to limit contingency overloads on the remaining transformer to no more than $130 \%$ of nameplate rating. A recent innovation has been the utilization of a 20-MVA mobile transformer to replace a failed unit within approximately 2 hours, reducing the overload on the remaining substation unit and permitting higher substation loading under normal conditions.

FP\&L limits the available short circuit duty on its distribution system to $6700 \mathrm{~A}$ three-phase and $4000 \mathrm{~A}$ phase-to-ground. The limiting is done using of high-impedance transformers (typically $12-14 \%$ ) and adding reactors where necessary.

FP\&L considers its system to be summer peaking, although short-duration early morning winter peaks usually occur that technically exceed summer values. The system design accommodates the winter overloads within the tolerances established for summer loading. Most homes in the service territory are all-electric, since natural gas is not available to domestic customers. Most system load is residential, with refrigerated air conditioning. Homes are generally approximately $1000 \mathrm{ft}^{2}$ and $21 / 2$-ton air conditioners are the most commonly encountered size.

Two distribution voltages are in use, $7.62 / 13.2 \mathrm{kV}$ and $13.2 / 22.9 \mathrm{kV}$. The same general construction standards are used for both voltages. The $13.2 \mathrm{kV}$ system is by far the larger; while the 22.9-kV system is specifically applied in residential areas to defer construction of new substations. Feeders are typically constructed using $568 \mathrm{kcmil}$ AAAC conductor. Laterals are fused and underground branch lines are generally constructed of $1 / 0$ aluminum conductor with crosslinked polyethylene insulation. Insulation thickness is 175 mils for $13-\mathrm{kV}$ cable and 275 mils for $23-\mathrm{kV}$ usage.

Voltage regulation standards have been established by the Florida Public Service Commission which provide for utilization voltage to be $120 \mathrm{~V} \pm 5 \%$. FP\&L also has an internal standard requiring that voltage flicker be less than $5 \%$. This requirement has the effect of limiting overall voltage drop on the distribution system.

FP\&L's power factor correction goal is to achieve a power factor of $98.75 \%$ at the substation low-side bus. Most capacitors are radio-controlled switched units controlled by the system dispatcher, who coordinates the switching with field personnel. Very few substation capacitors are used.

New construction is $75 \%$ underground and $25 \%$ overhead. At present the overall system ratio is $48 \%$ underground and $52 \%$ overhead. 
Underground construction consists entirely of cables installed in polyvinyl duct (since 1985). Main line cables are $1000 \mathrm{kcmil}$, and laterals are $1 / 0$. Switching is generally accomplished with S\&C PMH-9 or -11 air-insulated switches.

Distribution transformers are installed for initial loading at $120 \%$ of nameplate, and replacements are made when loading reaches $200 \%$. Loading is monitored by a transformer load management system.

A summary of FP\&L's distribution design practices is presented in Table 8.1.

Table 8.1. FP\&L distribution design practices

\begin{tabular}{|c|c|}
\hline Substation: & \\
\hline $\begin{array}{l}\text { Subtransmission voltage } \\
\text { Minimum number of incoming lines } \\
\text { Standard transformer size } \\
\text { Normal operating limit } \\
\text { Emergency operating limit } \\
\text { Standard transformer bank size } \\
\text { Minimum number of transformers } \\
\text { Maximum substation size } \\
\text { Voltage regulation } \\
\text { Maximum short circuit duty } \\
\text { Substation capacitors? } \\
\text { Peak load characteristic }\end{array}$ & $\begin{array}{c}138 \mathrm{kV} \\
2 \\
30,45,56 \mathrm{MVA} \\
67 \% \\
130 \% \\
30,45,56 \mathrm{MVA} \\
2 \\
112 \mathrm{MVA} \\
1 \text { phase circuit regulators. } \\
6700 \mathrm{~A} \text { 3-phase , } 4000 \text { A to ground } \\
\text { no } \\
\text { summer }\end{array}$ \\
\hline \multicolumn{2}{|l|}{ Circuit design: } \\
\hline $\begin{array}{l}\text { Voltage } \\
\text { Power factor correction goal } \\
\text { Comply with NESC? } \\
\text { Peak design load } \\
\text { Ties with adjacent circuits }\end{array}$ & $\begin{array}{c}13.2 \mathrm{kV}, 22.9 \mathrm{kV} \\
88.75 \% \text { at } 13 \mathrm{kV} \text { bus } \\
\text { yes } \\
12 \mathrm{MVA} \\
\text { yes }\end{array}$ \\
\hline \multicolumn{2}{|l|}{ Field voltage regulation practices: } \\
\hline $\begin{array}{l}\text { Tapped transformers? } \\
\text { Design transformer loading } \\
\text { Average transformer loading } \\
\text { Design voltage criteria } \\
\text { Design voltage drop } \\
\text { Flicker voltage drop criteria }\end{array}$ & $\begin{array}{c}\text { not specified } \\
120 \% \text { initial } \\
\text { not specified } \\
114-126 \mathrm{~V} \\
5 \% \\
5 \%\end{array}$ \\
\hline \multicolumn{2}{|l|}{ Circuit protection practices: } \\
\hline $\begin{array}{l}\text { Extensive use of field reclosers? } \\
\text { Fused laterals? }\end{array}$ & $\begin{array}{l}\text { no } \\
\text { yes }\end{array}$ \\
\hline \multicolumn{2}{|l|}{ Overhead lines: } \\
\hline $\begin{array}{l}\text { Maximum number of circuits per pole line } \\
\text { Typical primary conductor sizes } \\
\text { Secondary \& service conductor sizes }\end{array}$ & $\begin{array}{l}\text { not specified } \\
586 \mathrm{kcmil} \text { AAAC } \\
\text { not specified }\end{array}$ \\
\hline \multicolumn{2}{|l|}{ Underground lines: } \\
\hline $\begin{array}{l}\text { Installation method, residential } \\
\text { Installation method, feeders } \\
\text { Typical primary conductor sizes } \\
\text { Secondary \& service conductor sizes } \\
\text { Primary cable insulation } \\
\text { Switching equipment }\end{array}$ & $\begin{array}{c}\text { duct } \\
\text { duct } \\
1 / 0,1000 \mathrm{kcmil} A L \\
\text { not specified } \\
\text { clp } \\
\text { air }\end{array}$ \\
\hline Unique concerns: & \\
\hline
\end{tabular}




\subsection{PV PERFORMANCE CHARACTERISTICS}

Per-kW PV performance assumptions for the FP\&L case study were based on SOLMET data for Miami. This site is representative of expected solar insolation in the FP\&L service area. Table 8.2 presents a summary of expected annual performance for a $10 \mathrm{~m}^{2}$ PV system rated at $1 \mathrm{~kW}$, assuming fixed-orientation at the site latitude of $25.8^{\circ}$, and assuming two-axis tracking. The fixedorientation PV system capacity factor is about $18.8 \%$, and the capacity factor of the two-axis tracking PV system is about $23.9 \%$. Monthly performance for the two PV system configurations is presented in Fig. 8.1.

Table 8.2. Ten square meter, 1-kW PV at Miami,

\begin{tabular}{lc}
\hline Configuration & $\begin{array}{c}\text { Annual capacity } \\
\text { factors (\%) }\end{array}$ \\
\hline Fixed tilt $25.8^{\circ}$ & 18.8 \\
Two-axis tracking & 23.9 \\
\hline
\end{tabular}

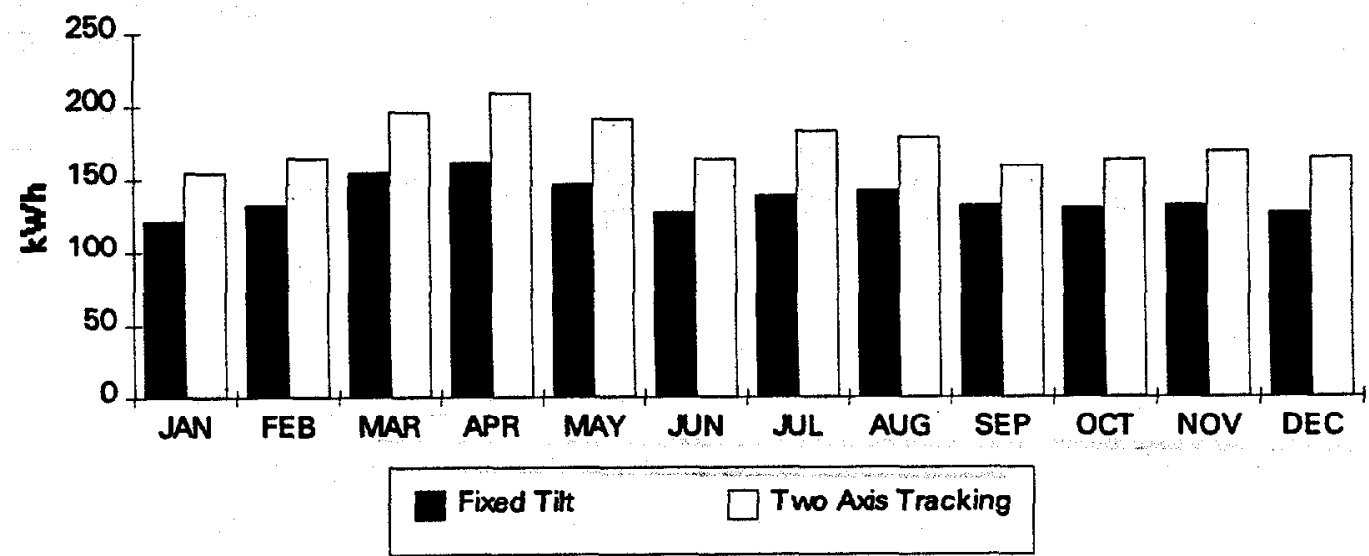

Fig. 8.1. PV system monthly performance per $\mathrm{kW}$.

Figure 8.2 shows the hourly performance for the fixed-orientation $1-\mathrm{kW}$ PV system for the peak solar insolation day and average solar insolation day in April and June. In April and June, during high solar insolation periods, the PV can provide fairly high levels of $\mathrm{kW}$ output. As at GPC, the average monthly output in both June and April is relatively low compared with SCE and PNM. It seems clear from this information that for many days, PV output will not correlate with system daily peak loads during the summer peak season. 

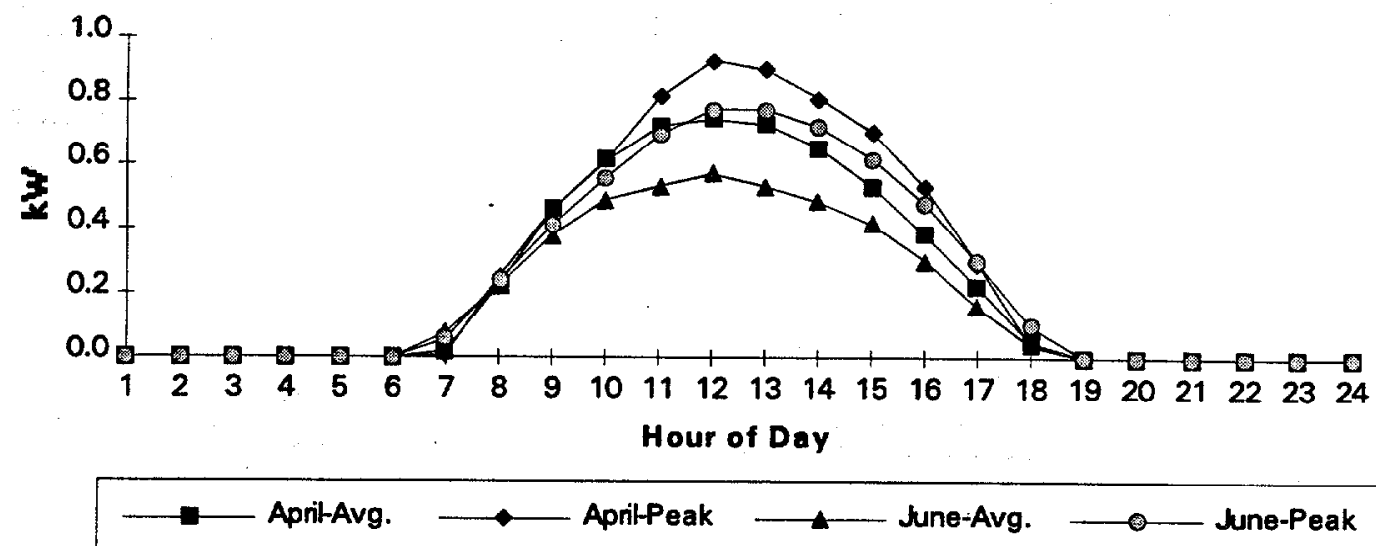

Fig. 8-2. Fixed-orientation PV daily output per $\mathrm{kW}$.

Figure 8.3 shows the corresponding hourly performance for the two-axis tracking $1 \mathrm{~kW} \mathrm{PV}$ system for April and June. This figure shows that two-axis tracking provides somewhat better PV performance. However, the average monthly performance of the two-axis tracking PV system is still low compared with SCE and PNM. As at GPC, even with two-axis tracking, it is likely that on many days PV performance will not correlate with daily peak loads during the summer peak season.

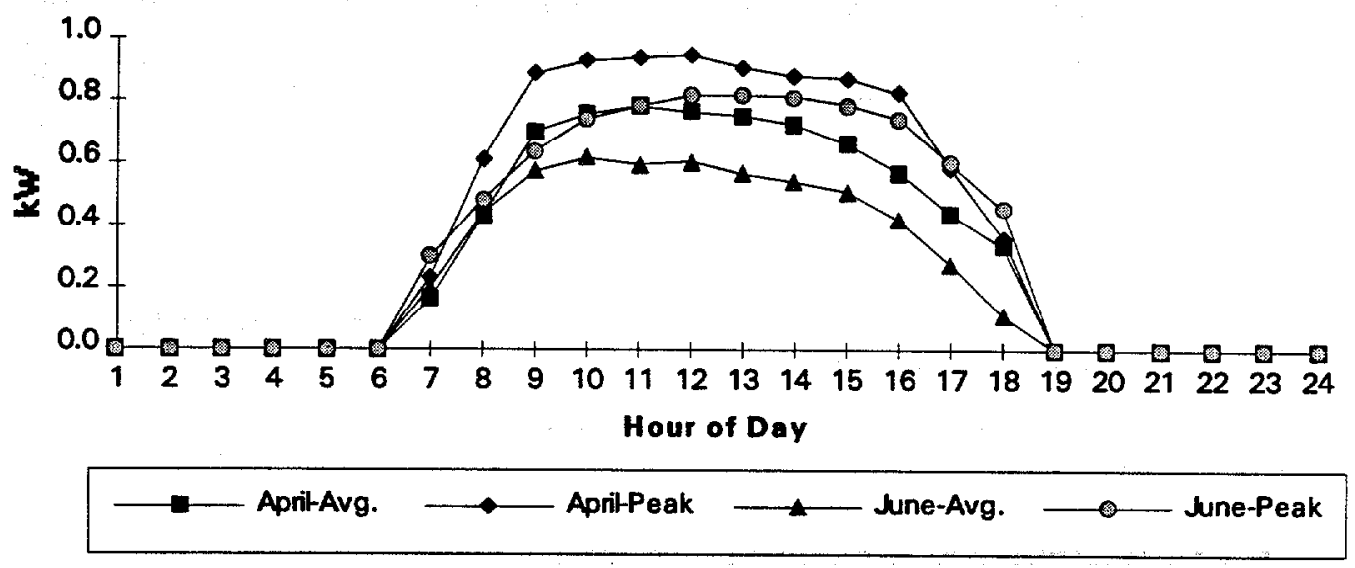

Fig. 8.3. Two-axis tracking PV daily output per $\mathrm{kW}$. 
Discussions with FP\&L personnel and review of the wind atlas indicated that poor wind resources can be expected in the FP\&L service area, and no wind data were available. Thus WT was not evaluated for FP\&L in this study.

\subsection{ASSUMPTIONS AND BENEFITS QUANTIFIED}

The following assumptions were obtained from interaction with FP\&L distribution engineers and planning personnel. They are compatible with financial assumptions and cost estimates used by FP\&L in early 1993 . General financial assumptions used for the FP\&L case study are listed in Table 8.3.

Table 8.3. Florida Power \& Light financial assumptions

\begin{tabular}{lc}
\hline Parameter & Assumption \\
\hline Discount rate & $10 \%$ \\
Levelized fixed charge rate-all CI & $16.38 \%$ \\
Escalation rate-everything but fuel & $3.8 \%$ \\
Escalation rate-fuel & $4.5 \%$ \\
\hline
\end{tabular}

The following benefits were quantified in the FP\&L case study:

- distribution losses,

- voltage regulation and power factor correction,

- generation capacity, and

- energy displacement value.

Relative distribution losses with and without renewable energy sources were calculated hourly for work days and weekend days in each month of the year. The annual cost of losses was then determined using appropriate marginal energy costs and annual demand charges, which were also used to calculate annual energy displacement value and generation capacity value.

FP\&L maintains a $98.75 \%$ power factor correction policy at the distribution substation. PV with line commutated inverters that require vars would incur a penalty. Line-commutated PV was assumed to be designed for 0.9 power factor. Self-commutated PV would not incur this penalty, and possibly would obtain a benefit if appropriate utility var control were incorporated in its design. The cost of fixed or switched shunt capacitors for power factor correction for FP\&L was assumed to be $\$ 12 /$ kvar.

The study considers small PV penetration levels compared with the total FP\&L system load. Thus, for this study, FP\&L supplied estimated future hourly marginal energy values, which were used to calculate energy displacement value for PV One marginal energy cost was used for summer and winter season on-peak and off-peak and time periods throughout the year. In 1998 the marginal cost was $31.2 \mathrm{mills} / \mathrm{kWh}$.

The generation capacity rating for PV was assumed to be $60 \%$ of nameplate PV kW. This factor was determined by observing average PV performance during the daily FP\&L system summer 
peak periods. FP\&L summer daily load shapes are shown in Fig. 8.4. Note that FP\&L's daily summer peak occurs relatively late in the day, tending to reduce PV capacity value.

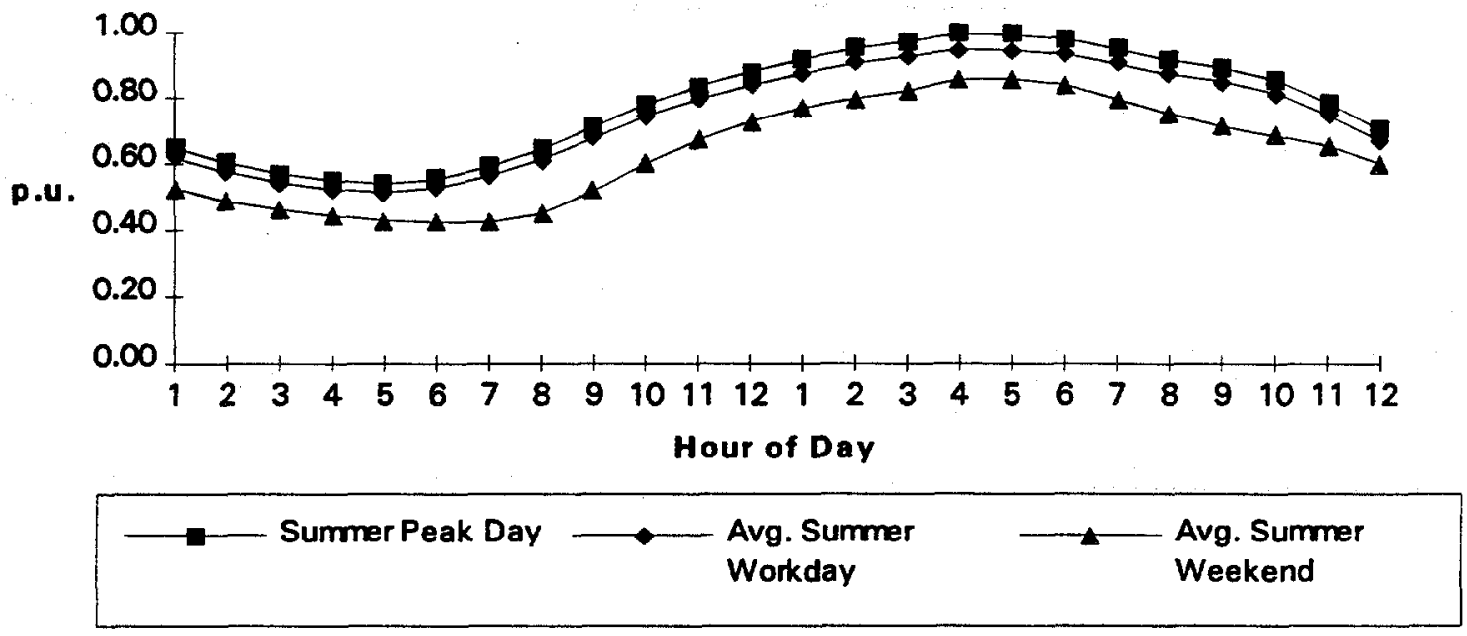

Fig. 8.4. FP\&L summer daily load shapes.

The magnitude of the annual $\$ / \mathrm{kW}$-year capacity value was based on the projected annual cost of a future FP\&L combined cycle unit, which in 1998 dollars is assumed to cost $\$ 141.85 / \mathrm{kW}$ year. This value was then escalated at $3.8 \%$ throughout the study period.

Distribution facility deferral benefits were not included. The PV performance data do not appear to correlate well with the time of annual feeder peaks, which may be just as likely to occur on cloudy days as on sunny days in the FP\&L service area.

No transmission benefits were available. Hence, no transmission benefits were included for FP\&L.

Environmental externalities are not presently included in FP\&L planning studies. Hence, potential environmental externality benefits are not included in the FP\&L benefit calculations.

\subsection{BENEFTT-COST RESULTS}

A representative FP\&L 120/240-V residential secondary system consists of a $75-\mathrm{kVA}$ distribution transformer serving 20 houses with air conditioning. The coincident secondary system load is assumed to be approximately $4 \mathrm{kVA}$ per house or about $80 \mathrm{kVA}$ at a power factor of approximately $85 \%$. This representative secondary system was used to calculate secondary system losses for incorporation in the suburban distribution system assessment.

A representative $13.2-\mathrm{kV}$ suburban primary system serving primarily residential loads may consist of two 45-MVA transformers serving six feeders. The feeders, each assumed to be 1.75 miles long, consist of overhead construction, using 568-kcmil conductors, and would contain several lateral taps serving residential and commercial customers. For this study, the representative suburban distribution system was assumed to be loaded to about $52 \mathrm{MW}$ with power factor correction of $98.75 \%$. 
Table 8.4 presents the potential benefits and costs for the representative suburban distribution system, assuming $10 \%$ fixed-orientation distributed PV penetration (5.2 MW). In this case, total combined PV benefits are $\$ 1203 / \mathrm{kW}$ and the benefit cost ratio is 0.17 . If PV penetration is increased to $20 \%$, the resulting loss benefit is only reduced from $\$ 45 / \mathrm{kW}$ to $\$ 43 / \mathrm{kW}$. In this case, fixed-orientation PV is expected to be cost effective on the FP\&L system when the PV capital investment plus O\&M is less than the combined $\$ 1203 / \mathrm{kW}$ benefits.

Table 8.4 Benefit and cost results-suburban distribution system, 5.2-MW distributed fixed-orientation $P V$

\begin{tabular}{lcc}
\hline & PWRR $\mathbf{S}^{\mathbf{a}}$ & \$/kW \\
\hline \multicolumn{1}{c}{ Cost } & $56,511,794$ & 7,070 \\
Capital investment & 832,294 & 104 \\
Operating cost & $\mathbf{5 7 , 3 4 4 , 0 8 8}$ & $\mathbf{7 , 1 7 4}$ \\
Total cost & & \\
$\quad$ Benefits & 363,099 & 45 \\
Distribution losses & $-27,350$ & -3 \\
Voltage regulation & $5,859,289$ & 733 \\
Generation capacity & $3,420,085$ & 428 \\
Energy displacement value & $\mathbf{9 , 6 1 5 , 1 2 3}$ & $\mathbf{1 , 2 0 3}$ \\
Total benefits & & \\
& $\mathbf{0 . 1 7}$ & \\
Benefit-to-cost ratio &
\end{tabular}

FP\&L has some long 10- to 12-mile rural 13.2-kV feeders. Installing PV on these feeders may result in increased distribution loss benefits compared with the representative suburban case. However, most FP\&L rural feeders are lightly loaded to around $150 \mathrm{~A}$ or less. For these lightly loaded rural feeders, loss benefits in $\$ / \mathrm{kW}$ were about the same as for the suburban distribution system. Hence, the resulting total benefits were similar.

Two-axis tracking PV increases the FP\&L system benefits somewhat, but not nearly as much as the assumed $\$ 1200 / \mathrm{kW}$ PV cost increase.

\subsection{CASE STUDY CONCLUSIONS AND OBSERVATIONS}

Some conclusions and observations resulting from this case study are as follows:

- WT was not evaluated for FP\&L, as poor wind resources can be expected in the FP\&L service area.

- PV output has poor correlation with FP\&L summer peak day load shapes, as peak days are likely to occur on cloudy days as well as sunny days.

- Fixed-orientation PV installed in FP\&L suburban or rural distribution systems can produce benefits of approximately $\$ 1203 / \mathrm{kW}$, resulting in a benefit-cost ratio of 0.17 . These benefits do not include potential transmission benefits, which were not available for this 
study. If transmission benefits were included, it is expected that the total combined benefits would be at least $\$ 100 / \mathrm{kW}$ larger, based on GPC case study transmission benefits.

- Two-axis and single-axis tracking increases both PV benefits and costs. For the assumptions in the FP\&L case study, incremental benefits are expected to be significantly less than the incremental PV capital investment for two-axis or single-axis tracking.

- If the $10 \%$ EPACT investment tax credit was available to FP\&L, the PV benefits would increase about $\$ 500 / \mathrm{kW}$ for the assumptions in this study.

- PV capital investment plus O\&M must be less than the above benefits before PV becomes an economically viable resource for the applications that were evaluated.

- Battery storage is sure to be needed to back up PV to obtain distribution deferral benefits, because of the poor correlation between solar insolation and load. Transportable battery storage, which is used in several applications and the battery costs allocated appropriately, may be a cost-effective option for distribution facility deferral. 


\section{LENOIR CITY UTHLTIES BOARD}

This section presents the results of the Lenoir City Utilities Board (LCUB) case study. LCUB distribution system and design practices are described. Representative PV performance characteristics in the LCUB service area are described. Various LCUB quantified benefits are described and pertinent assumptions are discussed. The case study results are then presented and summarized for the LCUB system.

\subsection{DISTRIBUTION SYSTEM DESCRIPTION AND DESIGN PRACTICES}

LCUB is a power distribution company located near Knoxville, Tennessee. Presently all of LCUB's power is supplied by the Tennessee Valley Authority (TVA). TVA rules allow distributors like LCUB to self-generate if at least $20 \%$ of the generation is supplied by renewable resources. LCUB system peak loads occur during the coldest winter periods.

LCUB distribution design standards are based on Rural Electrification Administration overhead construction specifications. Underground facilities are installed only when requested by a customer. The customer is then required to pay the cost differential.

Most LCUB distribution substation transformers are either $161 \mathrm{kV}$ or $69 \mathrm{kV}$ to $12.5 \mathrm{kV}$, rated at 20 MVA. LCUB has $12.5 / 7.2 \mathrm{kV}$, three-phase, four wire grounded wye distribution feeders. Most main feeders are $556 \mathrm{kcmil}$ AAC for their entire length, which averages approximately 4.1 miles. LCUB has many old feeder taps of $\# 6, \# 4, \# 2$ and $2 / 0$ copper. All new feeder taps are at least \#2 aluminum.

\subsection{PV PERFORMANCE CHARACTERISTICS}

Per-kW PV performance assumptions for the LCUB case study were based on SOLMET data for Knoxville. This site is representative of expected solar insolation in the LCUB service area. Expected annual capacity factor for a $10 \mathrm{~m}^{2} \mathrm{PV}$ system rated at $1 \mathrm{~kW}$, assuming fixed-orientation at the site latitude of $35.8^{\circ}$, is about $17.2 \%$. Monthly performance for the PV system is presented in Fig. 9.1.

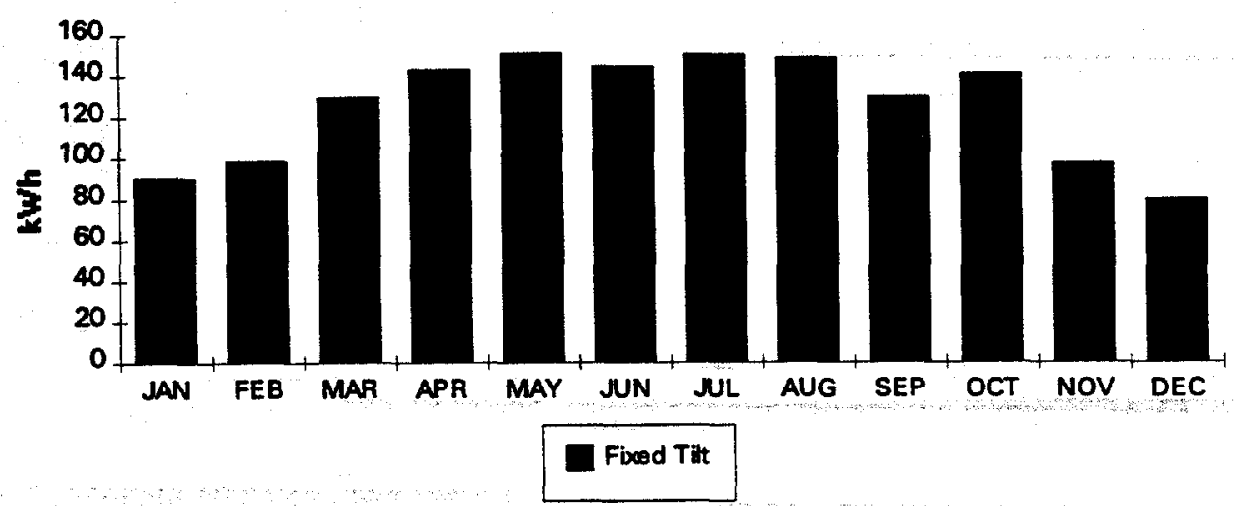

Fig. 9.1. PV system monthly performance per $\mathbf{k W}$. 
Figure 9.2 shows the hourly performance for the fixed-orientation 1-kW PV system for the peak solar insolation day and average solar insolation day in December. During high solar insolation periods, the PV system can provide fairly high levels of $\mathrm{kW}$ output. However, the average monthly output in December is relatively low. It seems clear from this information that, for many days, PV output will not correlate with system daily peak loads during the winter peak season. Figure 9.3 shows the daily LCUB winter load shape with and without $10 \%$ PV penetration. There is essentially no peak reduction, as the daily winter peak load occurs at 8:00 a.m.

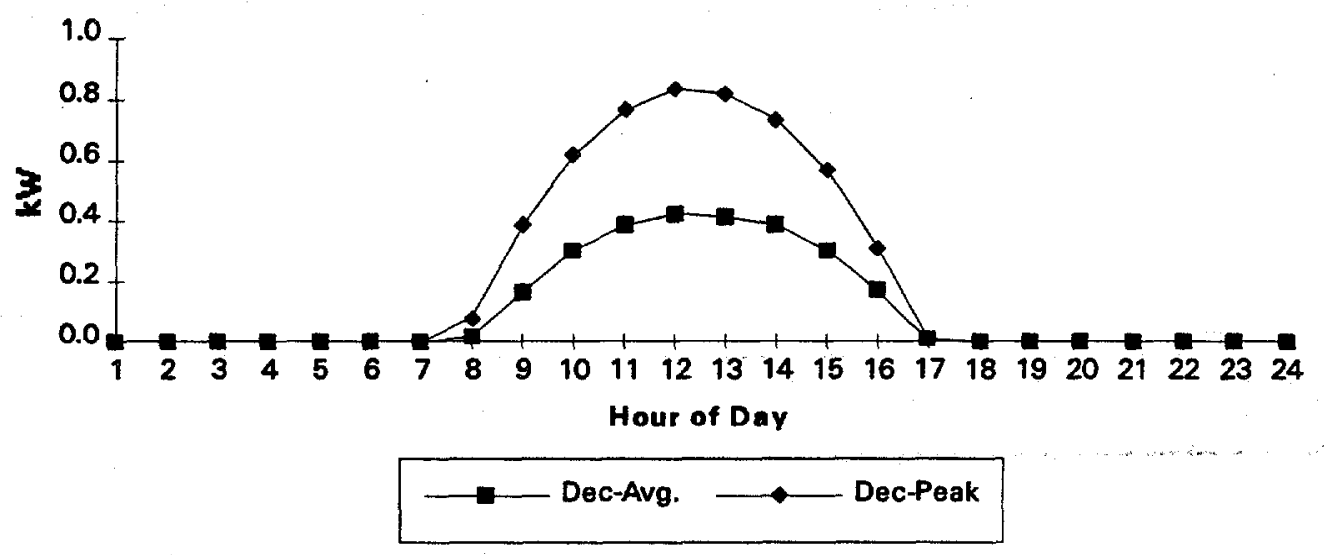

Fig. 9.2. Representative winter fixed-orientation PV daily output per $k W$.

Discussions with local residents and review of the wind atlas indicated that poor wind resources can be expected in the LCUB service area, and no wind data were available. Thus WT was not evaluated for LCUB in this study.

\subsection{ASSUMPTIONS AND BENEFTTS QUANTIFIED}

The following assumptions were obtained from LCUB personnel. They are compatible with financial assumptions and cost estimates used by LCUB in early 1993. LCUB uses a simple payback methodology for economic calculations. Currently. any capital investment project must achieve a payback in less than 5 years.

TVA changed LCUB's billing system to an "end use wholesale" system in the spring of 1992. LCUB currently pays no "demand charge" for peak power consumption. LCUB is charged only by the $\mathrm{kWh}$ billed to LCUB's customers. LCUB current combined demand and energy cost is $4.2 \mathrm{c} / \mathrm{kWh}$.

Distribution system loss benefits were assumed to be $7.5 \%$ of the resulting energy displacement benefits.

EPACT benefits were assumed to apply. Since LCUB is publicly owned, a $1.5 \notin$ per $\mathrm{kWh}$ production credit was assumed.

Environmental externalities are not presently included in LCUB planning studies. Hence, potential environmental externality benefits are not included in the LCUB benefit calculations. 


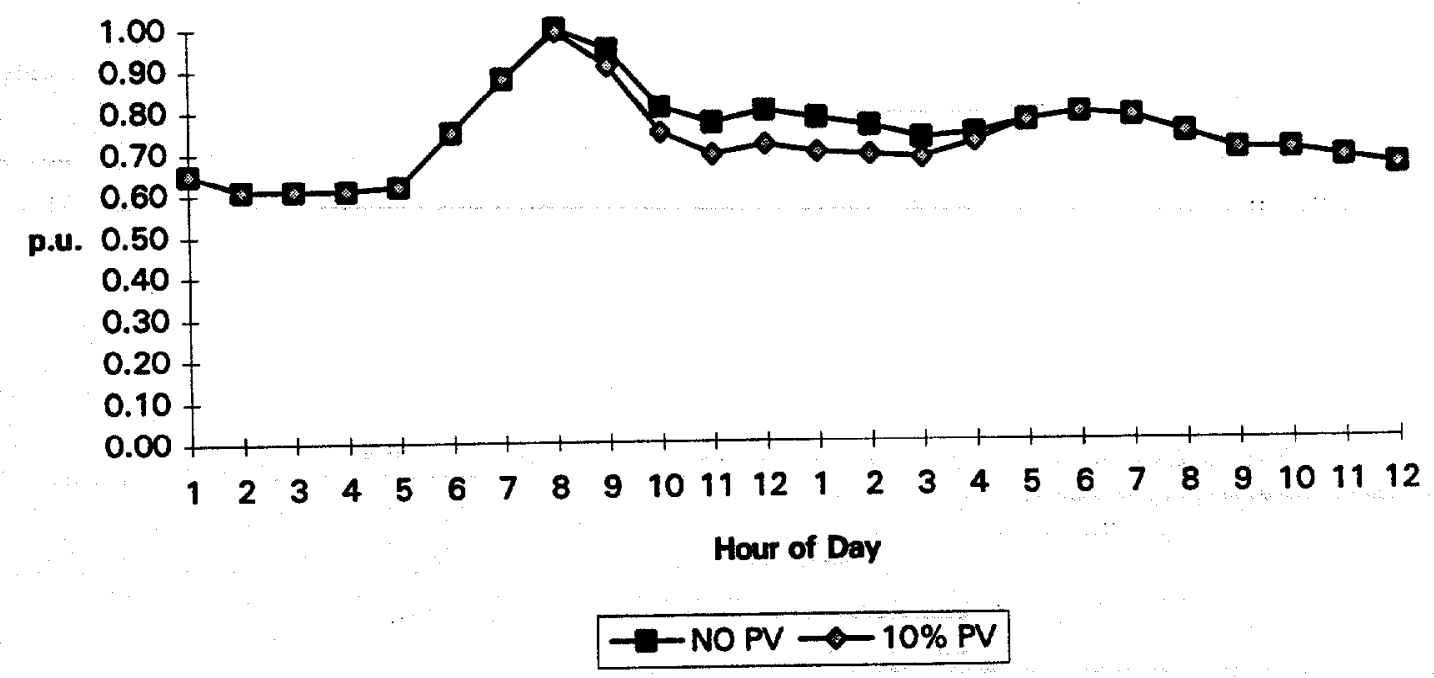

Fig. 9.3 Representative LCUB winter peak day load shape with and without PV.

\subsection{BENEFIT-COST RESULTS}

Potential annual benefits associated with installing PV on the LCUB system are presented in Table 9.1. Projected annual benefits total about $\$ 90$ per $\mathrm{kW}$ per year. For a 5-year payback. PV capital investment would have to be less than $\$ 450 / \mathrm{kW}$.

Table 9.1. PV annual benefit cost summary-Lenoir City Utilities Board

\begin{tabular}{lc}
\hline Benefit description & $\begin{array}{c}\text { Annual benefit } \\
(\$ / \mathrm{kW}-\text { year })\end{array}$ \\
\hline Energy displacement & 63.2 \\
Distribution losses & 4.7 \\
Energy Policy Act production incentive & 22.6 \\
Total combined benefit & 90.5 \\
\hline
\end{tabular}

\subsection{CASE STUDY CONCLUSIONS AND OBSERVATIONS}

Some conclusions and observations resulting from this case study are as follows:

- WT was not evaluated for LCUB, as poor wind resources can be expected in the LCUB service area. 
- PV output has poor correlation with LCUB winter peak day load shapes.

- Fixed-orientation PV installed in LCUB suburban or rural distribution systems can produce benefits of approximately $\$ 90 / \mathrm{kW}$-year. For 5-year payback used by LCUB in their resource decisions, PV capital investment must be less than $\$ 450 / \mathrm{kW}$. The 5-year simple payback criterion vs life-cycle costing is a significant impediment to PV usage by LCUB.

- Two-axis and single-axis tracking increases both PV benefits and costs. For the assumptions in the LCUB case study, incremental benefits are expected to be significantly less than the incremental PV capital investment for two-axis or single-axis tracking.

- Battery storage is sure to be needed to back up PV to obtain distribution deferral benefits, because of the poor correlation between solar insolation and load. Transportable battery storage, which is used in several applications and the battery costs allocated appropriately, may be a cost-effective option for distribution facility deferral. However, the 5-year simple payback criterion is a significant impediment. 


\section{ORCAS POWER AND LIGHT COMPANY}

This section presents a preliminary benefit-cost assessment of potential PV and WT applications on an Orcas Power and Light Company (OPALCO) $25-\mathrm{kV}$ distribution circuit. The present distribution expansion plan is discussed. Potential PV and WT performance characteristics in the OPALCO service area are described. Potential benefits and pertinent assumptions are discussed. Preliminary study results are then presented and summarized.

\subsection{DISTRIBUTION CIRCUIT EXPANSION PLAN DESCRIPTION}

OPALCO serves the San Juan Islands in Puget Sound, north of Seattle, Washington. OPALCO power is supplied by Bonneville Power Administration (BPA). The interconnection point is on Lopez Island. The $25-\mathrm{kV}$ circuit in question extends from the BPA interconnection point to Shaw Island and then on to Orcas Island, using both overhead construction and underwater cables. The far end of the line is located at Eastsound, where OPALCO has a 1-MW diesel plant.

In 1995-1996, OPALCO plans to uprate this $25-\mathrm{kV}$ circuit to $69 \mathrm{kV}$, because of projected future winter peak load growth at Eastsound on Orcas Island. The purpose of this preliminary assessment is to determine whether adding $1 \mathrm{MW}$ of PV or WT at Eastsound can defer converting this $25-\mathrm{kV}$ line to $69 \mathrm{kV}$, and to determine the economic benefits and costs of the addition.

\subsection{PV AND WT PERFORMANCE CHARACTERISTICS}

Per-kW PV performance assumptions for the OPALCO case study were based on SOLMET data for Whidbey Island, Washington. Expected annual capacity factor for a $10-\mathrm{m}^{2}$ PV system rated at $1 \mathrm{~kW}$, assuming fixed orientation at the site latitude of $48.8^{\circ}$, is about $14.4 \%$. Monthly performance for the fixed-orientation PV system is presented in Fig. 10.1. Discussions with Local OPALCO personnel indicated that Orcas Island is expected to have significantly higher solar insolation than Whidbey Island. Therefore, for this preliminary study, the PV capacity factor was increased by $20 \%$ to $17.3 \%$, as shown in Fig. 10.1 .

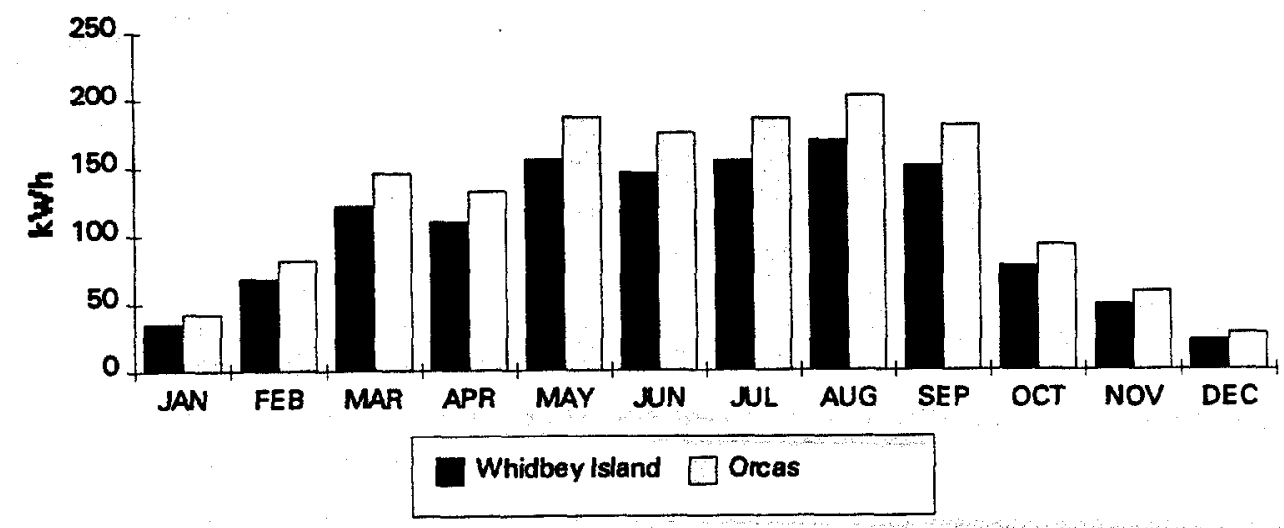

Fig. 10.1. PV system monthly performance per $\mathbf{k W}$. 
Figure 10.2 shows the hourly performance for the fixed orientation 1-kW PV system for the peak solar insolation day and average solar insolation day in June and December. During high solar insolation periods in the summer, the PV can provide fairly high levels of $\mathrm{kW}$ output. However, the average monthly output in the winter during peak periods is expected to be relatively low. It seems clear from this information that, for many days, PV output will not correlate with system daily peak loads during the winter peak season.

Figure 10.3 shows the 1990 OPALCO winter peak day load shape. The data in Fig. 10.2 and 10.3 indicate that there will be essentially no peak reduction, as the daily winter peak load occurs at 9 a.m.

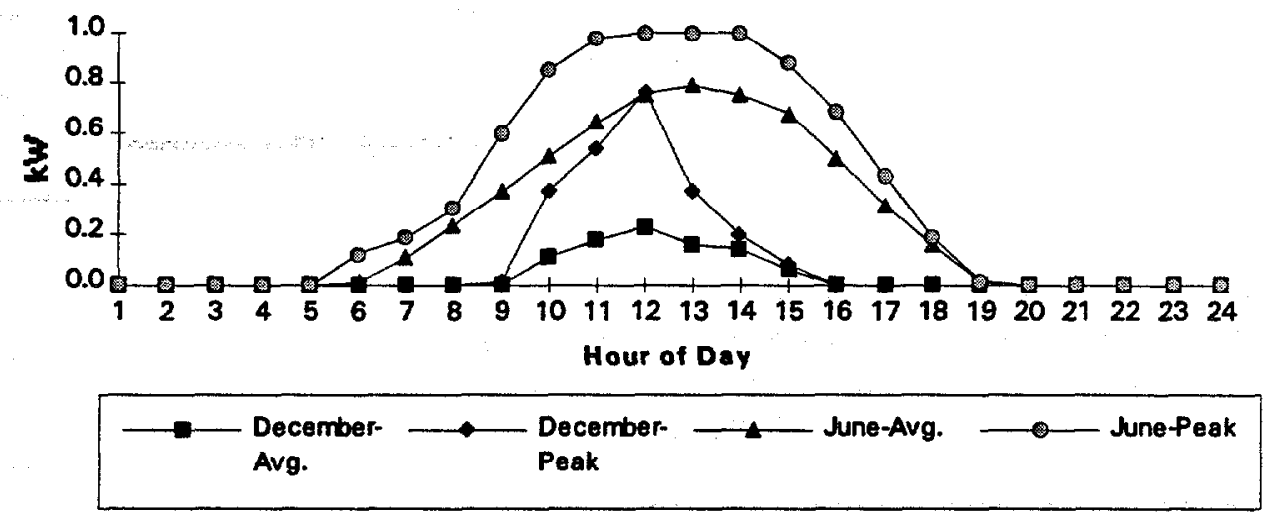

Fig. 10.2. Fixed-orientation $P V$ daily output per $k W$.

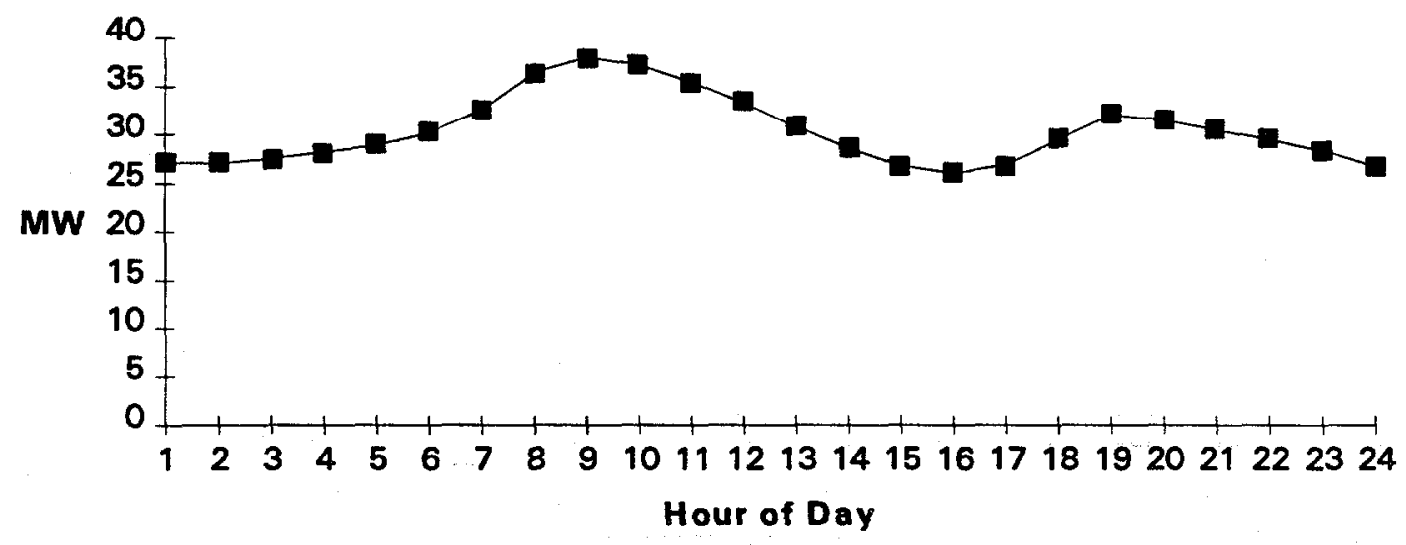

Fig. 10.3. Orcas Power \& Light Company February peak daily load shape. 
Discussions with OPALCO personnel indicated that high wind can be expected near Eastsound on Orcas Island during cold windy weather conditions that cause the annual system peak. Hence, good correlation between high wind conditions and Orcas Island peak load conditions are expected. Hence, for this preliminary study, a good, $30 \%$ capacity factor wind site was assumed.

\subsection{ASSUMPTIONS AND BENEFITS QUANTIFIED}

The following assumptions were obtained from OPALCO distribution engineers and planning personnel. These assumptions are compatible with financial assumptions and cost estimates used by OPALCO in summer 1993. General financial assumptions used for the preliminary OPALCO assessment are listed in Table 10.1.

Table 10.1. OPALCO financial assumptions

\begin{tabular}{lc}
\hline Parameter & Assumption \\
\hline Discount rate & $8.37 \%$ \\
Levelized fixed charge rate - all CI & $16.2 \%$ \\
Escalation rate & $4 \%$ \\
\hline
\end{tabular}

The following benefits were evaluated in the OPALCO study:

- distribution losses,

- deferral of Lopez-Eastsound line upgrade,

- demand charge reduction,

- energy displacement value, and

- EPACT production incentive for both PV and WT.

Relative distribution loss benefits with renewable energy sources were conservatively estimated to be $\$ 50$ per $\mathrm{kW}$ for this preliminary assessment. This value is compatible with the values calculated in the more detailed utility case studies in Sect. 3 through 9.

Distribution facility deferral benefits are based on deferring the Lopez-Eastsound $25-\mathrm{kV}$ circuit upgrade to $69 \mathrm{kV}$. Table 10.2 presents a breakdown of the costs associated with OPALCO's current plan to upgrade the Lopez-Eastsound $25-\mathrm{kV}$ line to $69 \mathrm{kV}$ in $1995-1996$. Also presented are additional costs presently planned for the year 2000 or beyond. The distribution deferral benefits in the preliminary study are based on deferring these costs. For this study, all costs are assumed to be escalated at $4 \%$ to the appropriate installation year.

OPALCO supplied its demand charge and energy cost data for 1994-1995, as shown in Table 10.3. These data were escalated $4 \%$, and used for this preliminary assessment.

EPACT solar and wind benefits were assumed to apply as discussed in Sect. 2 . Since OPALCO is publicly owned, a $1.5 \notin$ per-kWh EPACT production incentive benefit in 1993 dollars was assumed for both solar and wind for the first 10 years of operation. The EPACT production incentive benefit was escalated each year, assuming a $4 \%$ inflation rate adjustment. 
Table 10.2. Planned Lopez-Eastsound circuit upgrade costs

Project

Projected Cost

(1992\$)

Presently planned for 1995-1996

Build 69-kV terminal on Shaw

250,000

Build $69-\mathrm{kV}$ terminal on Orcas

250,000

Terminate cable installed in 1993-1994

185,000

Upgrade transmission breaker to $69 \mathrm{kV}$

65,000

Upgrade Shaw substation to $69 \mathrm{kV}$

600,000

Upgrade Orcas Substation to $69 \mathrm{kV}$

665,000

Total

$\$ 2,015,000$

Presently planned for year $\mathbf{2 0 0 0}$ or later

Purchase cable Lopez/Shaw and Shaw/Orcas

960,000

Install and terminate 69-kV cable between Lopez and

400,000

Shaw

Install and terminate 69-kV cable between Shaw and

400,000

Orcas

Total

$\$ 1,760, \$ 00$

Table 10.3. OPALCO 1994-1995 demand and energy cost

\begin{tabular}{lc}
\hline Demand charge & $\$ 4.14 / \mathrm{kW}-$ month \\
Energy charge-winter & $22.2 \mathrm{mills} / \mathrm{kWh}$ \\
Energy charge-summer & $16.3 \mathrm{mills} / \mathrm{kWh}$ \\
\hline
\end{tabular}

As discussed with OPALCO personnel, the projected peak load growth at Eastsound drives the need for upgrading the $25-\mathrm{kV}$ line to $69 \mathrm{kV}$ in 1995-1996. The projected peak load at Eastsound for the next several years is shown in Table 10.4. In 1994-1995, the projected peak load is $7202 \mathrm{~kW}$. When the peak load reaches $7519 \mathrm{~kW}$ in $1995-1996$, the $25-\mathrm{kV}$ line must be uprated. The annual peak load is projected to grow at slightly over $300 \mathrm{~kW}$ per year. For this preliminary assessment, distribution deferral benefits result from maintaining the Eastsound peak load at or near the projected 1994-1995 level. 
Table 10.4. Projected annual peak load at Eastsound

\begin{tabular}{lc}
\hline Year & $\begin{array}{c}\text { Projected peak } \\
\text { load (kW) }\end{array}$ \\
\hline $1994-1995$ & 7202 \\
$1995-1996$ & 7519 \\
$1996-1997$ & 7839 \\
$1997-1998$ & 8174 \\
$1998-1999$ & 8497 \\
$1999-2000$ & 8823 \\
$2000-2001$ & 9151 \\
\hline
\end{tabular}

Environmental externalities are not presently included in OPALCO planning studies. Hence, potential environmental externality benefits are not included in the OPALCO benefit calculations.

\subsection{BENEFTT-COST RESULTS}

Table 10.5 presents the resulting benefits and costs assuming a 1-MW fixed-orientation PV plant is installed at Eastsound. Total combined benefits are less than $\$ 600 / \mathrm{kW}$ and the resulting benefit-to-cost ratio is less than 0.1 . No distribution deferral benefits are available to $P V$. Energy displacement benefits of $\$ 344 / \mathrm{kW}$ are significantly lower than in the other case studies because of the relatively low OPALCO energy costs. In summary, this site looks like a poor application for PV compared with the other utilities in this study.

Table 10.5. Benefit and cost results-1-MW PV fixed-orientation

\begin{tabular}{|c|c|c|}
\hline & PWRR \$ & $\$ \pi \mathbf{k W}$ \\
\hline $\begin{array}{l}\quad \text { Cost } \\
\text { Capital investment } \\
\text { Operating cost } \\
\text { Total cost }\end{array}$ & $\begin{array}{c}12,456,610 \\
180,975 \\
12,637,585\end{array}$ & $\begin{array}{c}7,070 \\
103 \\
7,173\end{array}$ \\
\hline $\begin{array}{l}\quad \text { Benefits } \\
\text { Distribution facility deferral } \\
\text { Distribution losses } \\
\text { Demand charge reduction } \\
\text { Energy displacement value } \\
\text { Energy Policy Act } \\
\text { Total benefits }\end{array}$ & $\begin{array}{c}0 \\
87,625 \\
144,975 \\
603,254 \\
184,024 \\
1,019,877\end{array}$ & $\begin{array}{c}0 \\
50 \\
82 \\
342 \\
104 \\
579\end{array}$ \\
\hline Benefit-to-cost ratio & 0.08 & \\
\hline
\end{tabular}

Present worth of revenue requirements. 
Table 10.6 presents the resulting benefits and costs assuming that a 1-MW windfarm containing three 300 - to $350-\mathrm{kW}$ wind turbines with a $30 \%$ capacity factor is installed at Eastsound, and assuming that there is good correlation between high winds and the annual winter peak. In this case, the total combined benefits are $\$ 1429 / \mathrm{kW}$, and the benefit-to-cost ratio is 1.20 , which shows that WT is a cost-effective alternative for OPALCO. In this case, adding the 1-MW windfarm can defer the planned Lopez-Eastsound circuit upgrade for 3 years, resulting in a large $\$ 552 / \mathrm{kW}$ benefit, in addition to the nonsite-specific energy displacement and demand charge reduction benefits.

Table 10.6. Benefit and cost results-1-MW windfarm

\begin{tabular}{lcc}
\hline & PWRR \$a & $\$ / \mathrm{kW}$ \\
\hline \multicolumn{1}{c}{ Cost } & & \\
Capital investment & $1,761,897$ & 1,000 \\
Operating cost & 335,781 & 191 \\
Total cost & $\mathbf{2 , 0 9 7 , 6 7 8}$ & $\mathbf{1 , 1 9 1}$ \\
$\quad$ Benefits & & \\
Distribution facility deferral & $\mathbf{9 7 3 , 2 4 9}$ & 552 \\
Distribution losses & $\mathbf{8 7 , 6 2 5}$ & 50 \\
Demand charge reduction & 251,518 & 143 \\
Energy displacement & $\mathbf{8 7 6 , 8 1 1}$ & 498 \\
Energy Policy Act & 329,203 & 187 \\
Total benefits & $\mathbf{2 , 5 1 8 , 4 0 6}$ & $\mathbf{1 , 4 2 9}$ \\
& & \\
Benefit-to-cost ratio & $\mathbf{1 . 2 0}$ & \\
\hline aresent worth of revenue requirements. & &
\end{tabular}

The demand charge reduction benefit was calculated using a capacity rating equal to $30 \%$ of the total installed WT nameplate $\mathrm{kW}$. Although no wind data were available, this assumption is comparable with capacity ratings assigned to WTs by other utilities.

Assuming that adding the 1-MW windfarm can only reduce the Eastsound peak winter load 600 to $700 \mathrm{~kW}$ rather than the full 1-MW, the Lopez-Eastsound line upgrade be deferred only for 2 years rather than the full 3 years. The resulting distribution facility deferral benefit drops from $\$ 552 / \mathrm{kW}$ to $\$ 374 / \mathrm{kW}$. In this case, the total combined benefits are $\$ 1251 / \mathrm{kW}$, and the benefit-tocost ratio is 1.05 . In this case, the $1-\mathrm{MW}$ windfarm is still a cost-effective alternative for OPALCO.

The total $1 \mathrm{MW}$ of WT does not have to be installed in the first year to defer the LopezEastsound line upgrade. Table 10.7 presents the benefits and costs associated with adding one third of the WT capacity modularly in each of the 3 years. In this case, the resulting WT costs are reduced $\$ 12$ per $\mathrm{kW}$ from $\$ 1179 / \mathrm{kW}$ to $\$ 1058 / \mathrm{kW}$. OPALCO benefits are also reduced slightly, about $\$ 5 / \mathrm{kW}$. In this case, the benefit-to-cost ratio is 1.21 . This case shows that adding the WT modularly over the 3 years is an even more cost effective alternative.

Figure 10.4 presents a plot of the projected 1997-1998 winter January, February and March peak load days, assuming the 1990 load shape data supplied by OPALCO. In this third year of the Lopez-Eastsound line deferral, only in February does the daily load exceed $7202 \mathrm{~kW}$. In fact, it appears to be a very rare occurrence for the projected winter load to exceed $6000 \mathrm{~kW}$. Hence, it appears very unlikely that the Eastsound load will exceed $7200 \mathrm{~kW}$ when it is not cold and windy. 
Table 10.7. Benefit and cost results-modular addition of 1-MW windfarm

\begin{tabular}{lcc}
\hline & & \\
\hline \multicolumn{1}{c}{ Cost } & $1,677,862$ & 992 \\
Capitalinvestment & 316,943 & 187 \\
Operating cost & $1,994,805$ & 1,179 \\
Total cost & & \\
$\quad$ Benefits & 973,249 & 575 \\
Distribution facility deferral & 82,709 & 49 \\
Distribution losses & 237,407 & 140 \\
Demand charge reduction & 827,620 & 489 \\
Energy displacement & 290,389 & 172 \\
Energy Policy Act & $2,411,374$ & 1,425 \\
Total benefits & & \\
& 1.21 & \\
Benefit-to-cost ratio & & \\
\hline
\end{tabular}

- Present worth of revenue requirements.

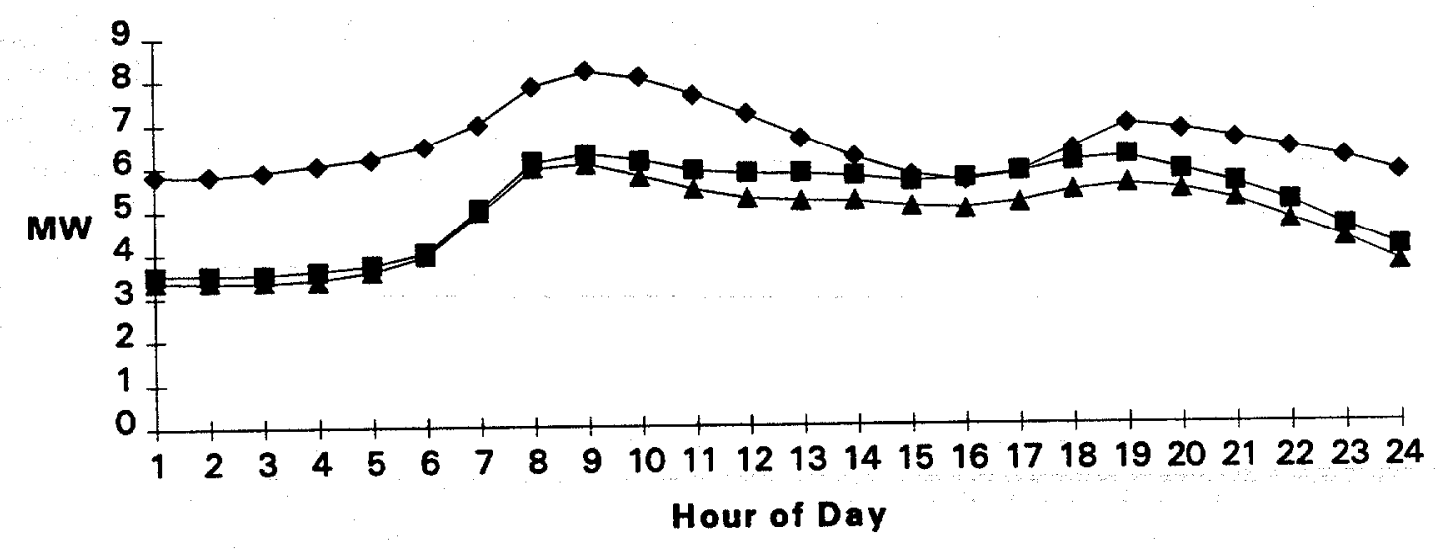

$\longrightarrow$ January $\longrightarrow$ February March

\section{Fig. 10.4. Projected 1997-1998 winter peak load days for January, February, and March.}

When the wind data are collected over the next winter, they may show that there is not perfect correlation between high wind speed and Eastsound annual peak load exceeding $7200 \mathrm{~kW}$. For these few hours per year, the 1-MW diesel plant located at Eastsound can be run to reduce the Lopez-Eastsound line flows.

An appropriately sized battery storage plant installed at Eastsound could be an alternative to using the Eastsound diesel plant to back up the WT. This alternative would obviously be more costly than using the diesels, because they are a sunk cost. However, the battery plant may be much 
easier to start and operate during the cold, windy weather, and the battery plant output could be controlled automatically by an appropriate control algorithm.

Appropriate battery plant $\mathrm{kW}$ size and storage requirements would be determined after WT performance is determined from the wind data to be collected. In the worst case shown in Fig. 10.5, a 1-MW, 3-hour battery plant could be employed to reduce the daily Eastsound peak load below $7200 \mathrm{~kW}$ on the projected 1997-1998 winter annual peak day in February. The 1-MW, 3-hour battery could also be used to reduce other monthly peaks throughout the year. However, due to the difference in daily load shape, 1-MW peak reduction will not be obtained in every month because of the battery energy storage limitation, assuming only one daily battery charge/discharge cycle. For example, in August the monthly peak demand can be reduced only by about $500 \mathrm{~kW}$ (Fig. 10.6).

A 1-MW 3-hour battery may cost as much as $\$ 1000 / \mathrm{kW}$, as presented in the EPRI Technical Assessment Guide. Buying this battery plant in addition to the 1-MW WT is clearly not a costeffective alternative. However, use of a transportable battery plant for only 3 years may be financially feasible and should be investigated as part of further more detailed study.

For example, assume that a "worst case" 1-MW battery could be obtained for 3 years at an annual cost of $\$ 162,000$ per year, and the levelized fixed charge rate is $16.2 \%$. This battery plant could back up the WT and increase average monthly peak reduction by 300 to $750 \mathrm{~kW}$, increasing the annual demand reduction benefit.

Table 10.8 presents the benefits and costs with the 1-MW battery added. In this "worst case," the WT with the battery plant is still a cost-effective alternative. However, this is not nearly as cost-effective as adding the WT and using the existing diesels occasionally. If the detailed study indicates that the WT needs to be backed up by battery storage in addition to the existing diesels, a much smaller (and less expensive) battery than a 1-MW 3-hour battery probably will be adequate.

Table 10.8. Benefit and cost results-1-MW windfarm plus transportable battery for 3 years

\begin{tabular}{lcc}
\hline \multicolumn{1}{c}{ Cost } & PWRR $\$$ & $\$ / \mathrm{kW}$ \\
\hline Capital investment & & \\
Operating cost & $2,176,615$ & 1,235 \\
Total cost & 335,781 & 191 \\
$\quad$ Benefits & $2,512,396$ & 1,426 \\
Distribution facility deferral & & \\
Distribution losses & 973,249 & 552 \\
Demand charge reduction & $\mathbf{8 7 , 6 2 5}$ & 50 \\
Energy displacement & 313,321 & 178 \\
Energy Policy Act & $\mathbf{8 7 6 , 8 1 1}$ & 498 \\
Total benefits & 329,203 & 187 \\
& $\mathbf{2 , 5 8 0 , 2 0 9}$ & $\mathbf{1 , 4 6 4}$ \\
Benefit-to-cost ratio & & \\
\hline
\end{tabular}

\footnotetext{
Present worth of revenue requirements.
} 


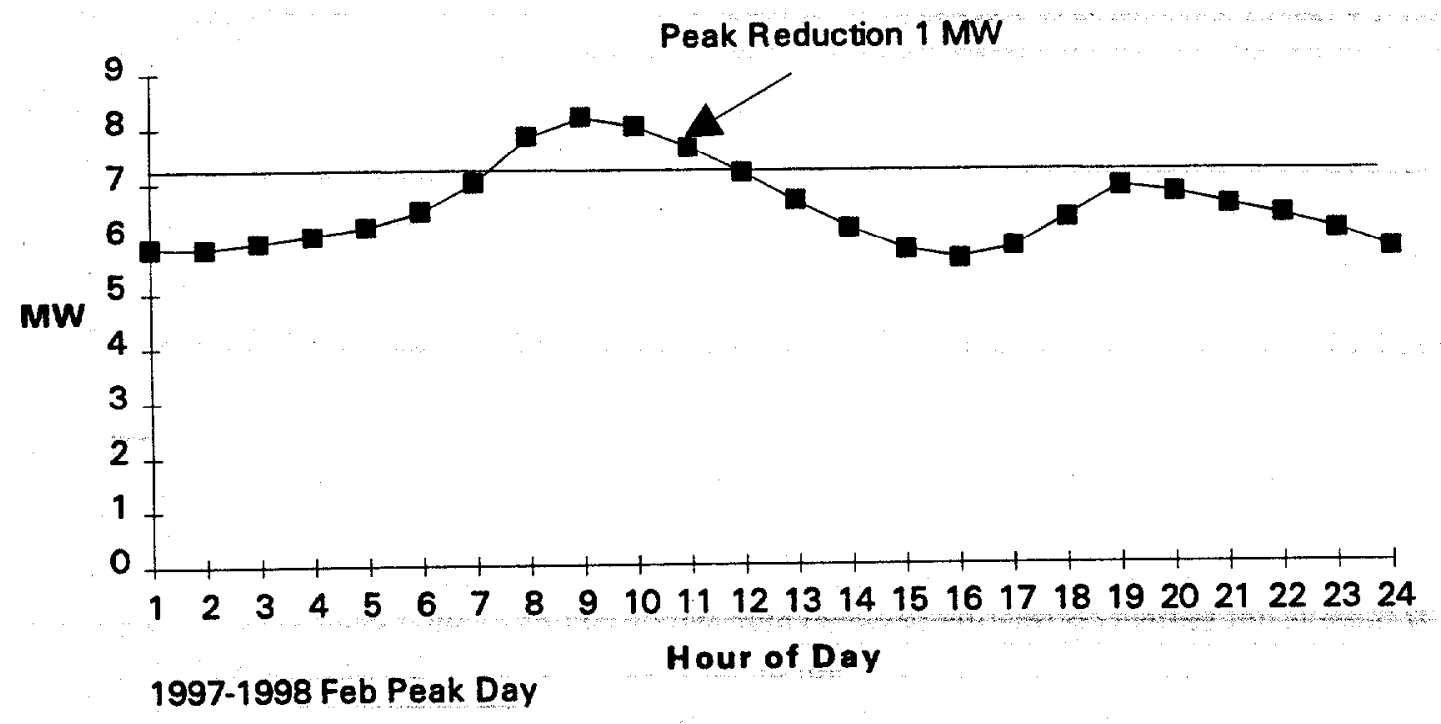

Fig. 10.5. Use of a 1-MW, 3-hour battery plant to reduce February 1997-1998 peak load.

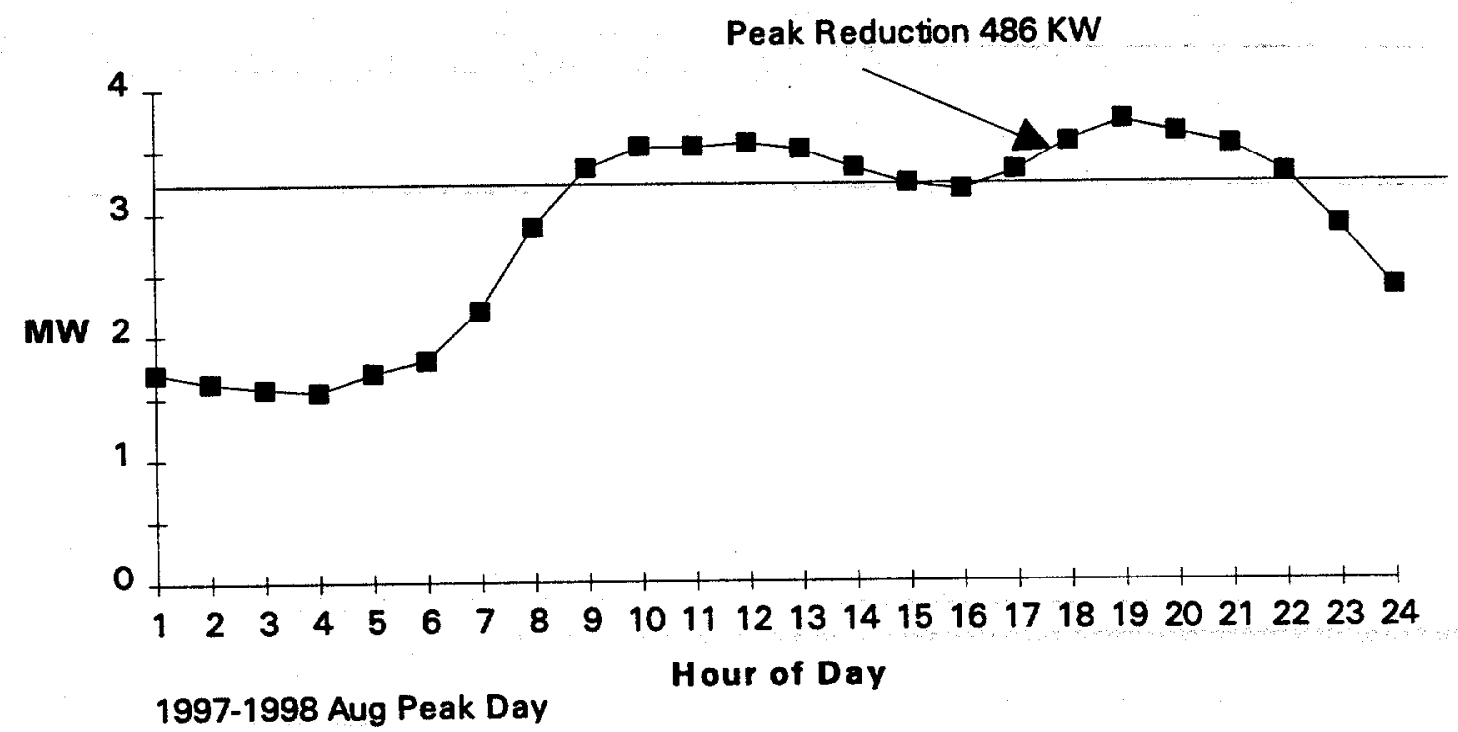

Fig. 10.6. Use of a 1-MW, 3-hour battery plant to reduce August 1998 peak load. 


\subsection{PRELIMINARY STUDY OBSERVATIONS}

Some observations resulting from this preliminary benefit-cost assessment are as follows:

- If there turns out to be a good wind site on Orcas Island, wind turbines located at Eastsound are expected to be a cost-effective resource for OPALCO. Preliminary study benefits for three $300-$ to $350-\mathrm{kW}$ WTs added modularly are about $\$ 1425 / \mathrm{kW}$, and the benefit-cost ratio is 1.21 .

- For excellent high wind and Eastsound peak load conditions, 1 MW of WT located at Eastsound can defer upgrading the Lopez-Eastsound 25-kV distribution line to $69 \mathrm{kV}$ for 3 years from 1995-1996 to 1998-1999.

- If there is not perfect correlation between high winds and Eastsound peak loads, the existing 1-MW diesel plant at Eastsound can be started to reduce Lopez-Eastsound 25-kV distribution line loading during the 3-year deferral period.

- Use of a transportable battery plant for 3 years during the Lopez-Eastsound 25-kV distribution line deferral period may be an alternative method of backing up the windfarm.

- Wind data collection over the upcoming winter and further detailed analysis are required to determine WT economic viability and the potential need for battery storage backup.

- PV output has poor correlation with OPALCO winter peak day load shapes.

- One MW of fixed-orientation PV installed at Eastsound can produce benefits of approximately $\$ 579 / \mathrm{kW}$, resulting in a benefit-cost ratio of less than 0.1 .

- PV capital investment plus O\&M must be less than the above benefits before PV becomes an economically viable resource for the PV application that was evaluated. 


\section{REFERENCES}

1. E.L. Grant, and G.W. Ireson,. Principles of Engineering Economy, Ronald Press Company, New York, 1964.

2. P.H. Jakes Profitability and Economic Choice, The Iowa State University Press, Ames, Iowa, 1968.

3. Electric Power Research Institute, TAG ${ }^{M}$ Technical Assessment Guide Volume 1, Palo Alto, Calif., 1989.

4. Califomia Public Utilities Commision, General Order No. 128:Rules for Overhead Electric Line Construction, November 1990.

5. California Public Utilities Commision, General Order No. 95: Rules for Construction of Underground Electric Supply and Communication Systems, March 9, 1988.

6. Institute of Electrical and Electronic Engineers, 1993 National Electric Safety Code, August 3, 1992.

7. United States Department of Energy, Transmission and Distribution Loss Analysis, prepared by Westinghouse Electric Corporation and Niagara Mohawk Power Corporation, May 1982.

8. IEEE Industry Application Society/Power Engineering Society, IEEE Std 519-1992, IEEE Recommended Practices and Requirements for Harmonic Control in Electrical Power Systems, April 12, 1993.

9. Pacific Gas \& Electric Company, A Case Study of Photovoltaics Serving Kerman Substation, November 4, 1992.

10. Arizona Public Service Company, Distributed Photovoltaic Generation: A Comparison of System Costs vs Benefits for Cocopah Substation, October 1992.

11. U.S. House of Representatives, Conference Report:Energy Policy Act of 1992 to Accompany H.R. 776, U. S. Government Printing Office, Washington D.C., October 5, 1992.

12. U.S. House of Representatives, Conference Report:Clean Air Act Amendments of 1990 to Accompany S. 1630, U.S. Government Printing Office, Washington D.C., October 26, 1990.

13. C.L. Knapp, Isolation Data Manual, Solar Energy Research Institute, Golden, Colo., 1980.

14. C.L. Knapp and T.L. Stoffel, Direct Normal Solar Radiation Data Manual, Solar Energy Research Institute, Golden, Colo., 1982.

15. Solar Energy Research Institute, Solar Radiation Directory, Golden, Colo., 1983. 
16. W. Marion and D. Myers, A Comparison of Data from SOLMET/ERZATZ and the National Solar Radiation Data Base, National Renewable Energy Laboratory, Golden, Colo., 1992.

17. F.T. Quinlan, Typical Metereological Year User's Manual, National Climatic Data Center, Asheville, N.C., 1981.

18. D.F. Menicucci and J.P. Fernandez, User's Manual for PVFORM: A Photovoltaic System Simulation Program For Stand-Alone and Grid-Interactive Applications, Sandia National Laboratories, Albuquerque, N.M., 1988.

19. Bechtel Group, Inc., Engineering and Economic Evaluation of Central-Station PhotovoltaicPower Plants, Electric Power Research Institute, EPRI TR-101255, Palo Alto, Calif., 1992.

20. Personal conversation with David Collier, SMUD, January 14, 1994.

21. W Stolte, R. Wisnant and C. McGowin, Design, Performance and Cost from High Concentration and Flat-Plate Utility-Scale PV Systems, Conference Record of the IEEE 23rd Photovoltaic Specialist Conference, Louisville, KY, 5/93

22. C. Jennings, et al., PVUSA Kerman Costs, Conference Record of the IEEE 23rd Photovoltaic Specialist Conference, Louisville, KY, 5/93.

23. R. Lynette and K.Conover, Photovoltaic Operation and Maintenance Evaluation, Electric Power Research Institute, EPRI GS-6625, Palo Alto, Calif., 1989, p. 4-21.

24 D.L. Elliott, Wind Energy Resource Atlas of the United States, Pacific Northwest Laboratory, Richland, WA, 1987.

25. R. Lynette, Assessment of Wind Power Station Performance and Reliability, Electric Power Research Institute, EPRI GS-6256, Palo Alto, Calif., 1989.

26. State of California Energy Commision, Committee Report:1992 Draft Final Electricity Report, November 1992. 


\section{APPENDIX A. COMPARISON WTTH PG\&E AND APS BENEFITS}

Appendix A compares calculated benefits for a comparable SCE case in this study with the benefits obtained in the PG\&E Kerman study and the APS Cocopah study. ${ }^{9,10}$ A $500 \mathrm{~kW}$ and one MW single axis tracking PV were evaluated in the PG\&E and APS studies respectively. The PV in the PG\&E study had a capacity factor of about $32 \%$, and the PV in the APS study had a capacity factor of about $39 \%$.

In this study, both distributed fixed orientation and MW scale two-axis tracking PV were evaluated. In the SCE case study, a two axis tracking PV had a capacity factor of about $34 \%$, and a fixed orientation PV had a capacity factor of about $25 \%$. Thus, for this comparison, two-axis tracking PV benefits in Table 4.7 are compared with the PG\&E and APS study results, as this twoaxis tracking PV had similar annual output.

The SCE PWRR results have been converted to levelized annual $\$ / \mathrm{kW}$-year values using the equations described in Sect. 2 to put these values in similar units. In addition, a potential EPACT PV investment tax credit of $\$ 523 / \mathrm{kW}$ has been assumed for this comparison. Note that this potential benefit is not directly available to utilities as discussed in Sect. 2 . Hence, it was not included in Table 4.7.

Figure A-1 presents a stacked bar graph comparing the total benefits calculated in the three studies. The resulting total benefits are comparable for the three utilities.

Figure A-2 compares the benefits calculated in this study case with corresponding benefits calculated in the other two studies. Eight categories of benefits are compared as described below:

- The energy displacement values are compatible. The SCE case has the largest value and PG\&E has the smallest. The difference is due to differences in marginal energy costs assumed for the different utility systems.

- Generation capacity value is similar for SCE and APS. PG\&E's value is lower.

- Transmission and distribution losses are slightly larger for SCE because a longer feeder was used.

- Distribution deferral benefits are higher for APS and PG\&E because a higher load growth was assumed for the SCE case. In other cases in this study, larger distribution deferral benefits were obtained when the load growth rate was reduced.

- Transmission deferral benefits were similar for all three utilities.

- The enhanced reliability benefit is much larger for PG\&E, than for APS. Enhanced reliability benefits were not justified for any of the utilities in this study as discussed in Sect. 2.

- Environmental externality benefits were similar for SCE and PG\&E. APS benefits were calculated using the Pace study. 
- Potential EPACT benefits were calculated for SCE in this comparison. This potential benefit was not included in the other two studies. APS added some miscellaneous benefits, which were not included in the other two studies. 


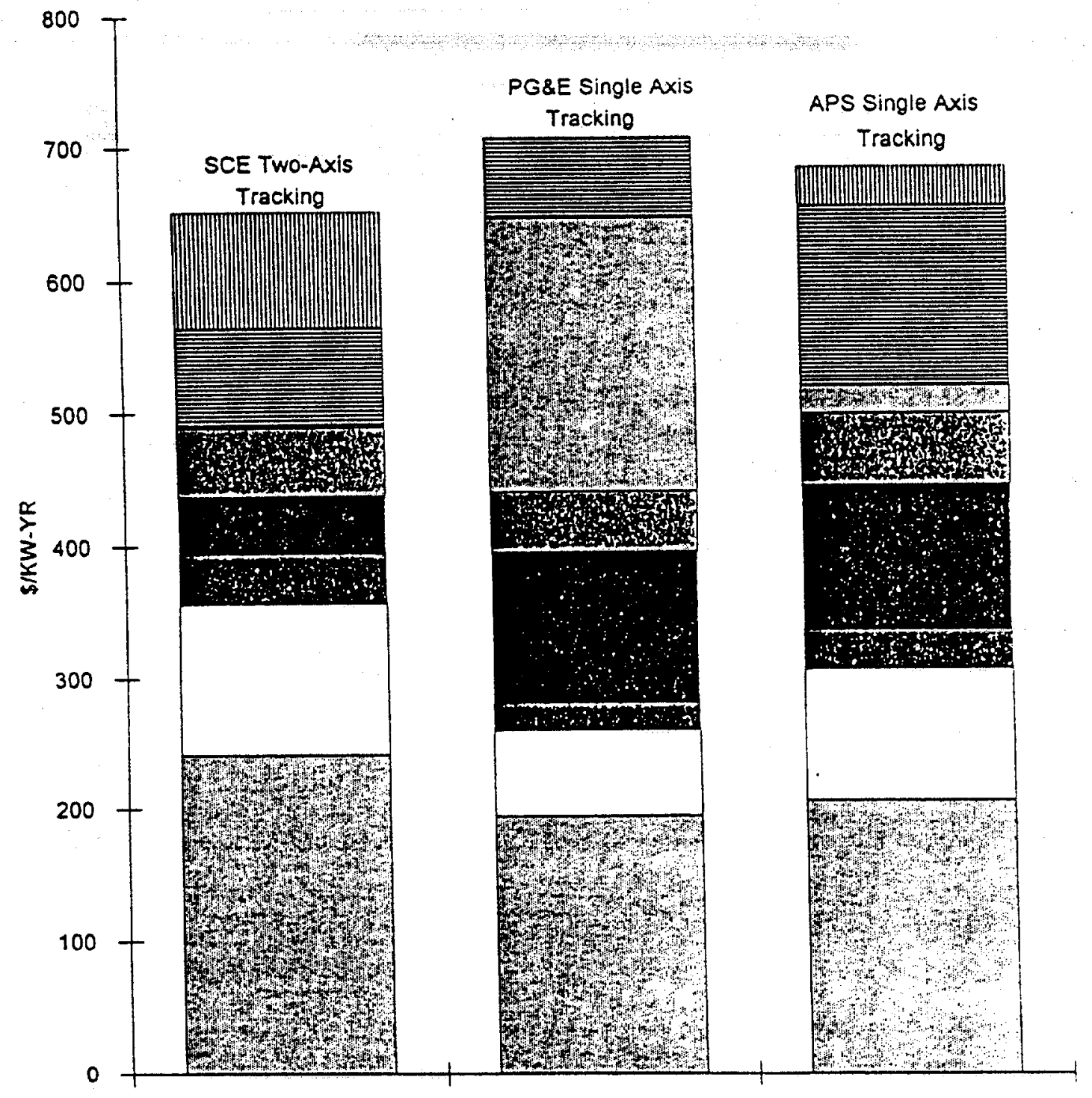

\begin{tabular}{|c|c|c|c|}
\hline Energy Value & $\square$ Gen Capacity & $\begin{array}{l}\text { Tran \& Dist } \\
\text { Losses }\end{array}$ & Disı Deferral \\
\hline & $\begin{array}{l}\text { Enhanced } \\
\text { Reliability }\end{array}$ & $\begin{array}{l}\text { E Environmental } \\
\text { Extern }\end{array}$ & $\begin{array}{l}\text { III] NEPA } 92 \& \\
\text { Other Benefits }\end{array}$ \\
\hline
\end{tabular}

Fig. A.1. Comparison of SCE, APS, and PG\&E benefits. 


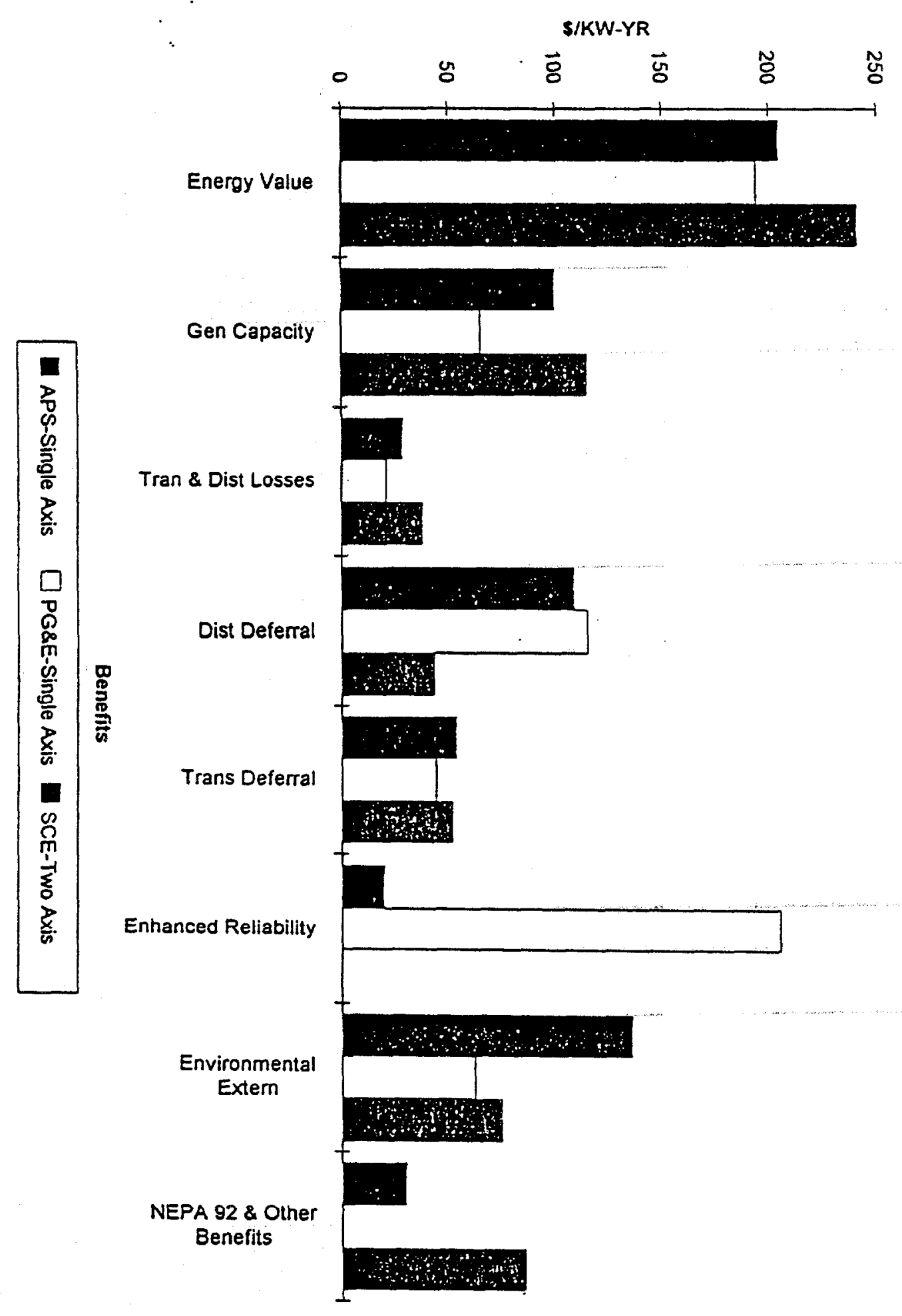

Fig. A.2. Breakdown in values by benefit classification. 
ORNL-6775/N2

Dist. Categories UC-1210, UC-1250, UC-1300

\section{INTERNAL DISTRIBUTION}

1-10. P. R. Barnes

11. J. Christian

12. S. M. Cohn

13. G. E. Courville

14. T. R. Curlee

15. S. S. Das

16. W. M. Dykas, Jr.

17. B. J. Kirby

18. M. A. Kuliasha

19-28. B. W. McComnell

29. R. D. Perlack

30. D. T. Rizy
31. R. B. Shelton

32. J. P. Stovall

33. J. W. Van Dyke

34. J. VanCoevering

35. P. P. Wolff

36. ORNL Patent Office

37. Central Research Library

38. Document Reference Section

39. Y-12 Technical Library

40-41. Laboratory Records

42. Laboratory Records-RC

\section{EXTERNAL DISTRIBUTION}

43. Abbas A. Akhil, P.E., Senior Technical Staff Member, Sandia National Laboratories, Division 2525, Storage Batteries, P.O. Box 5800, Albuquerque, NM 87185.

44. Bob Allan, Florida Power \& Light, P.O. Box 14000-PDL, Juno Beach, FL 33408-0420.

45. American Public Power Assoc., 2301 M Street, NW, Washington, D.C. 20037-1484.

46-55. Dan Ancona, Department of Energy, 1000 Independence Avenue, SW, Washington, D.C. 20585.

56. Tom Bath, Office of Energy Management, National Renewable Energy Laboratory, 1617 Cole Boulevard, Golden, CO 80401-3393.

57. Doug Bechtel, Orcas Power \& Light, P.O. Box 187, Eastsound, WA 98245-0187.

58. Ralph H. Berry, Manager Transmission Planning, System Planning Dept., Arizona Public Service Company, P.O. Box 53999, Phoenix, AZ 85072-3999.

59. John Bigger, Project Manager, Solar Power, Electric Power Research Institute, P.O. Box 10412, Palo Alto, CA 94303.

60. Douglas R. Bohi, Director, Energy and Natural Resources Division, Resources for the Future, $1616 \mathrm{P}$ Street NW, Washington, D.C. 20036.

61. Ben Bonfoey, Lenoir City Utilities Board, P.O,. Box 449, Lenoir City, TN 37771.

62. Larry Bryant, Public Service Company of New Mexico, Alvardo Square, Albuquerque, NM 87158.

63-72. Robert Brewer, DOE Office of Energy Management, CE-14, 1000 Independence Avenue, SW, Washington D.C. 20585.

73-82. Jack Cadogan, Department of Energy, 1000 Independence Avenue SW, Washington, D.C. 20585.

83. Judith Carroll, Sustainable Energy Development Council, P.O. Box 12428, Austin, TX 78711.

84. Margaret Cheng, Southern California Edison, P.O. Box 800, Rosemead, CA 91770.

85. Lynn R. Coles, National Renewable Energy Laboratory, Analytic Studies Division, 1617 Cole Boulevard, Golden, CO 80401.

86. Thomas E. Drabek, Department of Sociology, University of Denver, Denver, CO 80208-0209.

87. P. R. Ellis, Consulting Electrical Engineer, Ellis Power Engineering, 4695 David Way, San Bernardino, CA 92404.

88. Dieter Franz, Southern California Edison, P.O. Box 800, Rosemead, CA 91770. 
89. Steve Hill, Southern California Edison, P.O. Box 800, Rosemead, CA 91770.

90. Walter Hipp, Green Mountain Power Corporation, 25 Green Mountain Drive, Box 850, South Burlington, VT 05402.

91. Allan Hoffman, DOE Office of Utility Technologies, CE-10, Forrestal Building, Room 6C-036, 1000 Independence Avenue, SW, Washington, D.C. 20585.

92. John Hoffner, Program Manager, Alternative Energy, Austin Electric Utility, 721 Barton Springs Road, Austin, TX 78704.

93. Joe Iannucci, Distributed Utility Associates, 3170 Crow Canyon Road, Suite 140, San Ramon, CA 94583.

94. C. Travis Johnson, Georgia Power Company, 270 Peachtree Street, Atlanta, GA 30303.

95. Stephen Jones, Southwestern Public Service Company, P.O. Box 1261, Amarillo, TX 79170.

96. Sia Kanellopoulos, Full Circle, Inc., 30 Sandwich Road, E. Falmouth, MA 02536.

97. Landis Kannberg, PG\&E Research \& Development, 3401 Crow Canyon Road, Suite 100, San Ramon, CA 94583.

98. J. Kappenman, Minnesota Power, 30 W. Superior Street, Duluth, MN 55802.

99. Hamid Kazerooni, Southern California Edison, P.O. Box 800, Rosemead, CA 91770.

100. Abdul Khan, Southern California Edison, P.O. Box 800, Rosemead, CA 91770.

101. Ron Kincaid, Southern California Edison, P.O. Box 800, Rosemead, CA 91770.

102. Joseph L. Koepfinger, Director, Systems Studies and Research, Duquesne Light Company, One Oxford Center, 301 Grant Street (19-5), Pittsburgh, PA 15279.

103. Steve Larson, Public Service Company of New Mexico, 4201 Edith Boulevard, Albuquerque, NM 87158.

104. Deborah Lewis, Senior System Planner, Electric Resource Planning, Lower Colorado River Authority, P.O. Box 220, Austin, TX 78767-0220.

105-114. Ron Loose, Department of Energy, 1000 Independence Avenue, SW, Washington, D.C. 20585.

115. Calvin D. MacCracken, President, Calmac Manufacturing Corporation, P.O. Box 710, Englewood, NJ 07631.

116. Paul Maycock, PV Energy Systems, Inc., P.O. Box 290, Casanova, VA 22017.

117. Joe McGuirk, Arizona Public Service Company, P.O. Box 53999, M/S 9100, Phoenix, AZ 85072.

118. David Meakin, Solar Energy Industries Association, 777 N. Capitol Street, NE, Suite 805, Washington, D.C. $20002-4226$.

119. Stuart Nelson, Transmission Planning, Transmission Analysis Department, Lower Colorado River Authority, P.O. Box 220, Austin, TX 78767.

120. S. Nilsson, Program Manager, Electric Power Research Institute, Electrical Systems Division, 3412 Hillview Avenue, P.O. Box 14012, Palo Alto, CA 94303.

121-130. Phil Overholt, DOE Office of Energy Management, CE-14, 1000 Independence Avenue, SW, Washington, D.C. 20585.

131. Roger Pupp, Ph.D., Quantitative Solutions, 160 Sansome Street, Suite 400, San Francisco, CA 94104.

132. Kenneth Ragsdale, Alternative Energy Engineer, Austin Electric Utility, 721 Barton Springs Road, Austin, TX 78704.

133. Bill Ralph, Green Mountain Power Corporation, 25 Green Mountain, Box 850, South Burlington, VT 05402.

134. James E. Rannels, Director, Photovoltaic Technology Division, U.S. Department of Energy, 1000 Independence Avenue, S.W., Washington, D.C. 20585.

135. James. J. Ray, R\&D Coordinator, Division of System Planning, BPA, P.O. Box 3621-EO, Portland, OR 97208.

136. T. W. Reddock, Electrotek Concepts, Inc., 10305 Dutchtown Road, Suite 103, Knoxville, TN 37932.

137-146. V. N. Rice, DOE Office of Energy Management, CE-14, 1000 Independence Avenue, SW, Washington, D.C. 20585. 
147-156. Susan Rogers, DOE Office of Energy Management, CE-14, 1000 Independence Avenue, SW, Washington, D.C. 20585.

157. J. E. Scalf, Florida Power \& Light Company, P.O. Box 14000, 700 Universe Boulevard, Juno Beach, FL 33408.

158. John C. Schaefer, Consultant, P. O. Box 60785, Palo Alto, CO 94306.

159. Rick Sellers, Solar Energy Industries Association, 777 N. Capitol Street, N.E., Suite 805, Washington, D.C. $20002-4226$.

160. Jacqueline B. Shrago, Director, Office of Technology Transfer, 405 Kirkland Hall, Vanderbilt University, Nashville, TN 37240.

161. Scott Sklar, Solar Energy Industries Association, 777 N. Capitol Street, NE, Suite 805, Washington, D.C. 20002-4226.

162. Paul Skvarna, Southern California Edison, P.O. Box 800, Rosemead, CA 91770.

163. George F. Sowers, P.E., Senior Vice-President, Law Companies Group, Inc., 114 Townpark Drive, Suite 250, Kennesaw, GA 30144-5599.

164. John W. Stevens, P.E., Sandia National Laboratories, Photovoltaic Systems, Division 6218, P.O. Box 5800, MS 6218, Albuquerque, NM 87185-5800.

165. Randall Swisher, Executive Director, American Wind Energy Association, 777 N. Capitol Street, NE, Suite 805, Washington, D.C. 20002.

166. L. L. Taylor, Northern States Power Company, 414 Nicollet Mall, Minneapolis, MN 55401.

167. Roger W. Taylor, Senior Utilities Engineer, National Renewable Energy Laboratory, 1617 Cole Boulevard, Golden, CO 80401-3393.

168. F. M. Tesche, Consulting Scientist, 6714 Norway Road, Dallas, TX 75230.

169. D. R. Volzka, Senior Project Engineer, Wisconsin Electric Power Company, 333 West Everett Street, Milwaukee, WI 53201.

170. Rebecca Vories, Infinite Energy, P.O. Box 481905, Denver, CO 80248

171. Yih-huei Wan, P.E., Senior Utility Systems Analyst, National Renewable Energy Laboratory, 1617 Cole Boulevard, Golden, CO 80401-3393.

172. C. Michael Walton, Ernest H. Cockrell Centennial Chair in Engineering and Chairman, Department of Civil Engineering, University of Texas at Austin, Austin, TX 78712-1076.

173. Lee E. Westbrook, Manager, Transmission Planning, TUElectric, 400 N. Olive Street, L.B. 81 , Dallas, TX 75201.

174-183. H. W. Zaininger, ZECO, 1590 Oakland Road, Suite B211, San Jose, CA 95131.

184. Office of Assistant Manager for Energy, Research and Development, DOE-ORO, P.O. Box 2001, Oak Ridge, TN 37831.

185. OSTI, U.S. Department of Energy, P.O. Box 62, Oak Ridge, TN 37831.

For distribution by microfiche as shown in DOE/OSTI-4500, Distribution Categories UC-1250 (Photovoltaics), UC-1300 (Solar Thermal Electric), and UC-1210 (Wind Energy). 
